\title{
A conserved ubiquitin- and ESCRT-dependent pathway to regulate human \\ lysosomal membrane proteins
}

\section{Author list:}

Weichao Zhang ${ }^{1}$, Xi Yang ${ }^{1}$, Liang Chen ${ }^{1}$, Yun-Yu Liu1, Varsha Venkatarangan ${ }^{1}$, Lucas

Reist ${ }^{1}$, Phyllis Hanson ${ }^{2}$, Haoxing $\mathrm{Xu}^{1}$, Yanzhuang Wang ${ }^{1}$, and Ming $\mathrm{Li}^{1,3^{*}}$

\section{Affiliations:}

1: Department of Molecular, Cellular, and Developmental Biology, University of

Michigan, Ann Arbor, MI 48109, USA

2: Department of Biological Chemistry, University of Michigan, Ann Arbor, MI 48109, USA

3: Lead Contact

${ }^{*}$ Corresponding Author: Ming Li

Email: mlium@umich.edu

Phone: (734)647-7264

\section{Keywords:}

Lysosome, Ubiquitin, ESCRT, membrane protein, 


\section{Abstract}

The lysosome is an essential organelle to recycle cellular materials and maintain nutrient homeostasis, but the mechanism to down-regulate lysosomal membrane proteins is poorly understood. In this study, we developed a cycloheximide chase assay to measure the half-lives of $\sim 30$ human lysosomal membrane proteins, and identified RNF152 as a short-lived protein. The degradation of RNF152 depends on ubiquitin and the endosomal sorting complexes required for transport (ESCRT) machinery. Ubiquitinated RNF152 is sorted and internalized by the ESCRT machinery into the lysosomal lumen for degradation. Strikingly, when expressed in budding yeast, human RNF152 is also degraded by the vacuole (yeast lysosome) in an ESCRT-dependent manner. Thus, our study uncovered a conserved mechanism to down-regulate lysosome membrane proteins. 


\section{Introduction}

As an essential organelle, the lysosome is responsible for various cellular processes, including protein turnover and recycling, energy metabolism, intracellular signaling, and nutrient storage (Lawrence and Zoncu, 2019). The lysosome membrane contains hundreds of transmembrane proteins, many of which are transporters and channels that shuttle cargoes (ions, amino acids, cholesterol, etc.) across the lysosomal membrane (Schröder et al., 2007; Chapel et al., 2013; Bissa et al., 2016; Wyant et al., 2018). Malfunction of these lysosomal membrane proteins (LMPs) can give rise to inherited genetic disorders called lysosomal storage diseases (LSDs). Without treatment, almost all types of LSD patients will develop severe neurodegeneration in the central nervous system. Furthermore, growing evidence suggests that mutations in LMPs and lysosome dysfunction are associated with age-related neurodegeneration diseases such as Alzheimer's disease, frontotemporal dementia, and Parkinson's disease (Nixon et al., 2006; Amick and Ferguson et al., 2017; Cook et al., 2012). As we age, the lysosome membrane gradually accumulates damaged proteins and loses its activity, which dampens the cell's ability to remove pathogenic protein aggregates and damaged organelles, eventually leading to cell death and inflammation (Carmona-Gutierrez et al., 2016; Cheon et al., 2019; Yambire et al., 2019). Strategies to maintain the lysosome membrane integrity during aging will likely delay the onset of neurodegenerative symptoms.

Given the physiological importance and clinical implications of LMPs, we wonder how LMPs are regulated and quality controlled. At the organelle level, if the lysosomal 
membrane is mildly damaged by insults like lysosomotropic compounds or irondependent oxidative stress, the endosomal sorting complexes required for transport (ESCRT) machinery can be recruited to the lysosome surface to repair the membrane (Mittal et al., 2018; Radulovic et al., 2018; Skowyra et al., 2018). If the lysosome damage is too severe to be repaired, ruptured lysosomes will be sequestered and degraded by selective autophagy, a process termed as lysophagy (Hung et al., 2013; Maejima et al., 2013).

At the protein level, removal of specific membrane proteins from the lysosome surface is essential for adjusting its membrane protein composition in response to environmental cues. However, very little is known about the mechanism underlying this process. A process like lysophagy, which engulfs whole lysosomes, could not possibly turn over a few proteins selectively. This leads us to ask important questions as to how the human lysosome selectively downregulates its membrane proteins and what machinery might be involved in the process.

In this study, we screened $\sim 30$ human LMPs using a cycloheximide chase assay and identified a few candidates with short half-lives. Among those candidates, we focused on RNF152 (a lysosome membrane-anchored E3 ligase) as cargo to examine the possible mechanisms of LMP turnover in human cells. We uncovered that the degradation of RNF152 is both ubiquitination- and lysosome-dependent. Further, we provided evidence that the conserved ESCRT machinery plays an important role in the internalization of RNF152. Collectively, our work suggests that the ubiquitin- and ESCRTdependent degradation pathway is a conserved mechanism to downregulate LMPs in both yeast and human cells. 


\section{RESULTS}

\section{Cycloheximide (CHX) Chase Screen to Determine the Half-lives of LMPs}

To study the regulation and quality control of lysosomal membrane proteins (LMPs) in human cells, we urgently needed a substrate with fast turnover. To this end, we collected more than 30 GFP- or mCherry-tagged human lysosome membrane proteins. These proteins were identified as lysosomal by either microscopy or Mass Spectrometry studies (Schröder et al., 2007; Chapel et al., 2013; Schwake et al., 2013; Bissa et al., 2016; Wyant et al., 2018). We transiently transfected HEK293 cells with plasmids encoding these membrane proteins and determined their half-lives using the cycloheximide chase assay. Cycloheximide is a protein synthesis inhibitor that allows us to measure the half-lives of the pre-existing protein population (Kao et al., 2015). Here, we present some examples of the cycloheximide chase screen (Figure 1A-B, Figure S1, and Table 1). While most LMPs are relatively stable (examples: TMEM175, PQLC2, CTNS, CLCN7, LAMP2, and TMEM192), a few LMPs have half-lives less than 9 hours (e.g., LAPTM4A, RNF152, and OCA2) (Figure 1A-B). For LAPTM4A, RNF152, and OCA2, we confirmed their lysosome localizations by co-staining with the lysosome-associated membrane protein 2 (LAMP2) (Figure 1C). Of note, a small fraction of GFP-RNF152 puncta do not colocalize with LAMP2 (white arrows in Figure 1C). This observation is consistent with a recent study indicating that RNF152 could also localize to endosomes (Xiong et al., 2020).

Although OCA2 shows the fastest degradation kinetics, it is a melanosome protein that does not exist in normal lysosomes (Sitaram et al., 2009). Studying the degradation 
of OCA2 in cells other than melanocytes may be physiologically irrelevant. Therefore, we focused on the other fast turnover protein RNF152 to investigate the degradation pathway for lysosome membrane proteins.

\section{RNF152 is a protein of short half-life}

RNF152 is a single pass, Type-II transmembrane protein with 203 amino acids (Figure 2A). It was recently characterized as a lysosome E3 ligase that negatively regulates mTORC1 activity by ubiquitinating RagA (Deng et al., 2015). We tagged RNF152 with GFP at its N-terminus so that GFP is facing the cytosol. The molecular weight of RNF152 is 23 kDa. After fusing with GFP, the calculated size is around 50kDa.

Our original screen was conducted with transient transfection. To avoid variations of GFP-RNF152 expression in cells, we generated cell lines (HEK293 and HeLa) that stably express GFP-RNF152 by lentivirus infection. We treated these stable cell lines with cycloheximide and confirmed that the half-life of GFP-RNF152 is about 1 hour in HEK293 cells and 2 hours in HeLa cells, respectively (Figure 2B). Besides Western blots, we also used Flow Cytometry analysis to confirm the degradation of GFP-RNF152 in these cell lines. As shown in Figure 2C, the GFP intensity in both HEK293 and Hela cell lines was significantly reduced after 2 hours of cycloheximide treatment. Lastly, to rule out the possibility that the degradation of GFP-RNF152 is due to the GFP fusion, which is larger than RNF152, we replaced GFP with a much smaller 3xFlag tag (23 amino acids). As shown in Figure 2D, 3xFlag-RNF152 was also quickly degraded in HEK293 cells.

Interestingly, we observed a $27 \mathrm{kDa}$ band on the GFP blot that is about the size of free GFP in the cycloheximide chase assay (Figure 2B). Because GFP is fused to the 
cytosolic side of RNF152 (Figure 2A), there are two possibilities to generate the $27 \mathrm{kDa}$ band. First, GFP-RNF152 may be internalized into the lysosome lumen for degradation, and the free GFP is the by-product in the lysosome lumen. Second, free GFP may be cleaved off RNF152 due to the instability of the fusion protein, in this case free GFP would be localized in the cytosol. To differentiate between these two possibilities, we adopted the Lyso-IP experiment developed by the Sabatini group (Abu-Remaileh et al., 2017). The Lyso-IP assay uses a 3xHA-tagged lysosome-specific membrane protein TMEM192 as the bait to pull down intact lysosomes. As expected, the full-length GFP-RNF152 and other lysosomal proteins such as LAMP2 and cathepsin D (CTSD) were enriched by Lyso-IP. In contrast, PDI (ER), Golgin160 (Golgi), EEA1 (endosomes), and GAPDH (cytosol) were not enriched (Figure 2D). Importantly, we found that the $27 \mathrm{kDa}$ GFP band was also enriched by Lyso-IP, which indicates that the free GFP is inside the lysosome lumen. These data suggest that RNF152 may be internalized and degraded in the lysosome.

Because a fraction of RNF152 localizes to the endosome (white arrows in Figure 1C, Xiong et al., 2020), it is possible that the observed degradation is due to the endosomal degradation of RNF152. To ensure that the lysosome population of RNF152 is fast-degrading, we performed the Lyso-IP experiment using cells collected before and after 2 hours of $\mathrm{CHX}$ treatment. Our result confirmed that the lysosome population of GFP-RNF152 is quickly turned over, while LAMP2 is very stable on the lysosome (Figure 2E). 


\section{RNF152 degradation is ubiquitination-dependent}

Protein ubiquitination is the prerequisite for degradation in eukaryotic cells. Given that RNF152 has a short half-life, we hypothesized that RNF152 might be ubiquitinated continuously in the cell. The full-length GFP-RNF152 appears as a $50 \mathrm{kDa}$ band on the Western blots. Interestingly, we also observed a faint $60 \mathrm{kDa}$ band that might be the mono-ubiquitinated form of GFP-RNF152 (Figure 3A, left panel). After longer exposure, a high-molecular-weight smear appeared on top of the full-length GFP-RNF152 (Figure $3 \mathrm{~A}$, right panel). Could this smear be the poly-ubiquitinated GFP-RNF152? To answer this, we transfected HA-tagged ubiquitin into cells that stably express either GFP-RNF152 or free GFP control, followed by immunoprecipitation using the GFP-TRAP nanobody. Indeed, HA-ubiquitin was incorporated into the high-molecular-weight smear of GFPRNF152, but not the GFP control (Figure 3B). This result confirmed that a significant portion of GFP-RNF152 is constantly poly-ubiquitinated.

To test if poly-ubiquitination of GFP-RNF152 is important for its degradation, we mutated all eight lysines in the cytosolic domain of RNF152 to arginine $(8 \mathrm{~K} \rightarrow \mathrm{R})$. As shown in Figure $3 \mathrm{C}-3 \mathrm{D}$, the $8 \mathrm{~K} \rightarrow \mathrm{R}$ mutation increased the steady-state level of GFP$R N F 1528 K \rightarrow R(2.7$ fold at time 0$)$. Additionally, the degradation kinetics of the mutant was also significantly slowed down (Figure 3E).

Because RNF152 is a RING domain-containing E3 ligase, we hypothesized that the degradation of GFP-RNF152 might be at least partially due to its auto-ubiquitination. To test this hypothesis, we mutated four cysteines in the RING finger motif to serines $(4 \mathrm{C} \rightarrow \mathrm{S}$ mutant) to disrupt its E3 ligase activity (Deng et al., 2015). Similar to the $8 \mathrm{~K} \rightarrow \mathrm{R}$ mutant, 
the protein level of GFP-RNF1524C $\rightarrow$ s at the steady-state was increased by 2.8 -fold $(\mathrm{t}=0 \mathrm{~h}$,

Figure 3C-3D), and the degradation kinetics was significantly slower (Figure 3E).

Taken all together, we concluded that the degradation of GFP-RNF152 is a ubiquitin-dependent process. The short half-life of GFP-RNF152 is likely due to its autoubiquitination.

\section{RNF152 is mainly degraded by the lysosome}

In eukaryotic cells, there are two primary mechanisms responsible for breaking down proteins: proteasome-dependent and lysosome-dependent proteolysis. The accumulation of free GFP inside the lysosome suggests that RNF152 is degraded by the lysosome. To test this hypothesis further, we treated the cells that stably express GFP. RNF152 with either lysosome V-ATPase inhibitor Bafilomycin A1 (BafA1) or proteasome inhibitor MG132. Inhibition of V-ATPase results in a rapid neutralization of lysosome $\mathrm{pH}$, leading to the Inhibition of luminal protease activities. After 6 hours of BafA1 treatment, the steady-state protein level of full-length GFP-RNF152 increased by two-fold (Figure 4A-B). In contrast, MG132 treatment did not lead to a significant change in the GFPRNF152 protein level, while the double treatment did not further increase the steady-state RNF152 level than BarfA1 alone.

After extended exposure, we also observed an accumulation of high-molecularweight smear in the BafA1-treated and the double treatment groups (Figure 4A and 4C). To verify that BafA1 treatment leads to the accumulation of poly-ubiquitinated GFP. RNF152, we co-expressed HA-tagged ubiquitin with GFP-RNF152 and performed immunoprecipitation. We found that the poly-ubiquitinated GFP-RNF152 indeed 
increased drastically after the BafA1 treatment and BafA1+MG132 double treatment, but not after the MG132 treatment (Figure 4D). These results suggest that the lysosome, but not the proteasome, is the primary organelle to degrade RNF152, which is consistent with the observation that free GFP accumulated inside the lysosome after degradation (Figure 2D).

We further confirmed our findings with Flow Cytometry analysis. As shown in Figure 4E, the GFP intensity only increased slightly after MG132 treatment. In contrast, BafA1 treatment led to a major increase in GFP intensity (7-8-fold increase). BafA1+MG132 double treatment did not lead to a further increase in GFP intensity. Although these Flow Cytometry results consistently suggest that RNF152 degradation is lysosome-dependent, we were surprised by the strong increase (7-8-fold) in GFP intensity after the BafA1 treatment.

To address this concern, we use confocal microscopy to image HEK293 cells that stably express GFP-RNF152 after either DMSO, MG132, or BafA1 treatment. Under the same imaging settings, we found that the GFP intensity after BafA1 treatment was much higher compared with DMSO or MG132 treatment groups. Most of the BafA1-stabilized GFP signals were colocalized with the lysosome marker LAMP2 (Figure 4F). Importantly, when we imaged the BafA1-treated cells with a Delta-Vision fluorescent microscope, which is incorporated with a powerful deconvolution software to enhance the resolution of images, we observed that much of the GFP signal was localized inside the lysosome lumen (line scan in Figure 4G). Similar results were also obtained with a Leica STED super-resolution microscope (data not shown). The luminal GFP signal inside the lysosome strongly supports a model that RNF152 is internalized into the lysosome and 
degraded by lumenal proteases. Once GFP gets into the lysosome lumen, the fluorescence will be quenched by the low $\mathrm{pH}$ (4.5-5). However, BafA1 treatment increases the lumenal $\mathrm{pH}$, and the GFP fluorescence is no longer quenched, which leads to a drastic increase of GFP intensity in the lysosome lumen.

Besides the steady-state protein levels, we also studied the effects of BafA1 and MG132 on the degradation kinetics of GFP-RNF152. As shown in Figure S2A-B, the degradation of GFP-RNF152 was blocked by BafA1 treatment, even when we extended the chase to 6 hours. On the other hand, the proteasome inhibitor MG132 only delays the degradation of GFP-RNF152. Interestingly, we observed an increase of free GFP intensity after both MG132 and BafA1 treatment. MG132 is known to partially inhibit some classes of lysosomal proteases such as Cathepsin A and Cathepsin B (Shirley et al., 2005). The delayed degradation of GFP-RNF152 and increased free GFP signals might be due to inefficient degradation by the lysosomal proteases.

Lastly, we examined the fate of the lysosome-specific population of GFP-RNF152 by lyso-IP. As shown in Figure S2C, the lysosome population of GFP-RNF152 is also stabilized by BafA1 treatment in the $\mathrm{CHX}$ chase assay.

Taken all results together, we concluded that RNF152 is mainly degraded through lysosome-dependent proteolysis. For the rest of our study, we will focus on identifying the machinery that can deliver RNF152 into the lysosomal lumen for degradation.

Macroautophagy machinery and CMA pathways are not involved in the degradation of GFP-RNF152 
In mammalian cells, there are four possible mechanisms to deliver intracellular materials into lysosomes for degradation: macroautophagy, microautophagy, ESCRTdependent formation of intraluminal vesicles at endosomes, and chaperone-mediated autophagy (Schuck, 2020; Schmidt and Teis, 2012; Bejarano and Cuervo, 2010). How is ubiquitinated RNF152 internalized into the lysosome lumen then? Although lysophagy (selective macroautophagy of lysosomes) can deliver an entire damaged lysosome to other healthy lysosomes for degradation (Anding and Baehrecke, 2017), it cannot selectively turnover a particular lysosome membrane protein while leaving others intact. Very recently, Overholzer and colleagues reported that glucose starvation or certain pharmacological drug treatments could trigger a microautophagy process to selectively turnover lysosomal membrane proteins. Although the corresponding microautophagy machinery remains to be identified, it was shown that the LC3 lipidation machinery, such as ATG5, is critical to initiate microautophagy (Lee et al., 2020). To test whether the LC3 lipidation-triggered microautophagy is involved in RNF152 degradation, we knocked out either ATG5 or ATG7 using the CRISPR-Cas9 method (Ran et al., 2013, An et al., 2019). In wildtype cells, Atg5 forms a stable 55 kDa conjugate with Atg12 in an Atg7-dependent manner (Figure 5A, left three lanes) (Mizushima et al., 1998). After knocking out Atg7, the conjugate can no longer form, and Atg5 appears as a $33 \mathrm{kDa}$ band (Figure 5A, last three lanes). However, neither ATG5 nor ATG7 knockout cell lines exhibited any defect in GFPRNF152 degradation (Figure 5A-B).

Autophagy and the ubiquitin-proteasome system (UPS) are the two major pathways for protein degradation in eukaryotic cells (Pohl and Dikic, 2019). There is mounting evidence that the two pathways can affect each other. It is possible that the UPS pathway 
is upregulated to compensate for the loss of the autophagy pathway (Wang et al., 2013;

Fan et al., 2018; Kocaturk and Gozuacik, 2018; Marshall and Vierstra, 2018). To rule out the possibility that GFP-RNF152 is re-directed to the proteasome for turnover in the ATG5 or ATG7KO cell lines, we treated the ATG7KO cells that stably express GFP-RNF152 with BafA1 and/or MG132. As shown in Figure 5C-D, the degradation of full-length GFP. RNF152 is still mainly dependent on the lysosome in the macroautophagy deficient cells. Thus, the macroautophagy machinery and likely the LC3 lipidation-triggered microautophagy are not involved in RNF152 degradation.

We also examined whether chaperone-mediated autophagy (CMA) is involved. In the CMA pathway, the chaperone Hsc70 recognizes a KFERQ-like motif of a cytosolic protein and delivers it to the lysosome for degradation (Cuervo and Wong, 2014). Using a web-based "KFERQ" motif finder, we identified one putative KFERQ-like motif in the cytosolic domain of RNF152: ${ }^{46} \mathrm{QKDVR}^{50}$ (Figure 5E) (Kirchner et al., 2019). Then, we mutated ${ }^{46} \mathrm{QK}^{47}$ to $\mathrm{AA}$ and examined its degradation kinetics. As shown in Figure $5 \mathrm{~F}-\mathrm{G}$, there was no significant difference in RNF152 degradation between the ${ }^{46} \mathrm{QK}^{47} \rightarrow \mathrm{AA}$ mutant and the WT, suggesting that the CMA pathway is not involved in the degradation of RNF152.

\section{The early-stage ESCRTs are less important for the degradation of GFP-RNF152}

Given that macroautophagy and CMA pathways are not involved, we then asked whether ESCRT machinery is responsible for internalizing ubiquitinated GFP-RNF152. The ESCRT machinery is composed of several sub-complexes, including ESCRT-0, I, II, III, and the AAA-ATPase VPS4, all of which are conserved from yeast to human (Hurley, 
2010; Henne et al., 2011). The ESCRT complex normally assembles on the surface of endosomes to sort ubiquitinated membrane proteins into the lumen as intralumenal vesicles (ILVs), creating the so-called multivesicular bodies (MVBs) (Vietri et al., 2020). Besides the ILV formation, mammalian ESCRTs play diverse roles at different membrane compartments. Recently, it was demonstrated that the ESCRT machinery could be assembled on the lysosome surface to repair damaged membranes (Radulovic et al., 2018; Skowyra et al., 2018). However, whether the ESCRT machinery can sort ubiquitinated lysosome membrane proteins such as RNF152 remains an open question. To answer this, we systematically knocked-down components of the ESCRT machinery and tested if the knockdown will affect RNF152 degradation.

We first knocked down TSG101 (ESCRT-I, Vps23 in yeast) and ALIX (accessory unit, Bro1 in yeast) using siRNA because it was shown that TSG101 and ALIX are required to recruit ESCRT-III onto the lysosome surface for membrane repair (Radulovic et al., 2018; Skowyra et al., 2018). Knocking down ALIX alone did not have an effect on RNF152 degradation. However, knocking down either TSG101 or both TSG101 and RNF152 only had a minor impact on the degradation kinetics of GFP-RNF152 (Figure S3A-B). There was also a slight increase of the ubiquitinated GFP-RNF152 (highmolecular-weight smear) in the TSG101 knockdown and TSG101+ALIX double knockdown groups (Figure S3A). This surprising result suggested that either TSG101 and ALIX might not be essential for the degradation, or a redundant component could be involved to recruit the ESCRT-III.

We also tested ESCRT-0 and ESCRT-II components by knocking down HRS (Vps27 in yeast) and VPS22, respectively. Similar to TSG101 and ALIX knockdown, HRS 
knockdown did not affect RNF152 degradation, but the VPS22 knockdown had a minor impact on the degradation of GFP-RNF152 (Figure S3D-F). In the case of VPS22 knockdown, we also observed a slight increase of the ubiquitinated GFP-RNF152 (Figure S3D).

To ensure the siRNA knockdown methods can truly disrupt the function of ESCRT machinery, we stained the cells with the FK2 antibody that specifically recognizes polyubiquitinated proteins (Firkowska et al., 2019). Since ESCRT machinery is responsible for internalizing ubiquitinated proteins from the endosome membrane, depleting ESCRT components will lead to the accumulation of poly-ubiquitinated proteins at the endosome surface. Indeed, after knocking-down either TSG101+ALIX or Vps22, we observed enlarged vacuole-like structures that stained positive with the FK2 antibody (Figure S3G). In the case of HRS knockdown, we did not observe the accumulation of poly-ubiquitinated signals on membrane structures (Figure S3G). It is unclear why this was the case. Nevertheless, the Western blot showed a pronounced reduction of the HRS protein level (Figure S3D). Besides, we noticed a severe growth defect in the HRS knockdown cells (data not shown).

Taken together, we concluded that early ESCRT components are either not essential (for ALIX and HRS) or less important (for TSG101 and VPS22) for the degradation of GFP-RNF152. Our results suggested that other redundant factors might be able to recruit the ESCRT-III to the lysosome membrane.

\section{The late-stage ESCRTs are important for the degradation of GFP-RNF152}

We then tested the late ESCRT-III components, which polymerize into spiral filaments to drive the internalization of ubiquitinated membrane cargoes as intraluminal 
vesicles. After knocking down both CHMP4A and CHMP4B (Snf7 in yeast), the degradation of full-length GFP-RNF152 is significantly delayed (Figure 6A-C). Besides, we observed a substantial accumulation of ubiquitinated GFP-RNF152 in the double knockdown sample (Figure 6A). Flow Cytometry analysis further supported that knocking down both CHMP4A and CHMP4B leads to the accumulation of GFP-RNF152, as indicated by the increase of GFP fluorescence (Figure 6D). After treating cells with BafA1 to stop the lumenal degradation, we noticed an accumulation of internalized GFP. RNF152 in the siRNA control. In contrast, GFP-RNF152 appeared to accumulate on the membrane of vacuole-like LAMP2 positive structures in $\sim 60 \%$ of cells after the double knockdown of CHMP4A and CHMP4B (Figure 6E-F).

We also validated the CHMP4A and CHMP4B knockdown by the FK2 antibody staining (Figure S4A). Double knockdown of CHMP4A and CHMP4B caused the accumulation of polyubiquitin on enlarged vacuolar structures. Together, our results suggested that the ESCRT-III components play essential roles in the degradation of GFPRNF152.

Besides ESCRT-III, we also investigated the role of AAA-ATPase VPS4. VPS4 is responsible for the disassembly of ESCRT-III filaments. Here, we used doxycycline to induce overexpression of HA-tagged wildtype Vps4A and its dominant-negative mutant E228Q, which disrupts the AAA-ATPase activity (Takahashi et al., 2018). Overexpression of the dominant-negative mutant (E228Q) significantly delayed the degradation of fulllength GFP-RNF152 (Figure 6G-I, red curve vs. black curve). Interestingly, after overexpression of wildtype HA-VPS4A, the turnover of RNF152 was also slightly delayed even though the effect was less severe than the E228Q mutant (Figure 6G-I). For both 
WT and E228Q mutant, we observed the accumulation of poly-ubiquitinated GFPRNF152 (Figure 6G). These results suggested that 1) VPS4 plays a critical role in GFP. RNF152 degradation, and 2) the overexpression of HA-tagged wildtype VPS4A may also disrupt ESCRT function.

To validate our conclusions, we stained the cells with the FK2 antibody. After overexpression, both WT and the E228Q mutant showed an accumulation of FK2 positive signals, and the E228Q mutant appeared to have a much stronger effect (Figure S4B). Specifically, after overexpressing HA-VPS4A, $\sim 50 \%$ of cells displayed FK2 positive signals, which are mainly localized to enlarged vacuolar structures. In contrast, after overexpressing the E228Q mutant, more than $90 \%$ of cells were stained positive with the FK2 antibody, and the signals were much stronger. These results indicated that overexpression of both wildtype HA-VPS4A and the dominant-negative mutant E228Q would disrupt the function of ESCRT machinery, likely due to the presence of the HA tag.

We further confirmed our finding that VPS4A plays an important role in the turnover of RNF152 using Flow Cytometry analysis. As shown in Figure 6J, overexpression of both wildtype HA-VPS4A and its dominant-negative mutant lead to an increase in the GFP intensity, indicating the stabilization of GFP-RNF152.

Taken together, our results strongly suggested that the late-stage ESCRT machinery, specifically ESCRT-III and Vps4, are important for the degradation of GFPRNF152.

\section{A conserved pathway to degrade RNF152}

Fundamental biological processes are generally conserved from yeast to humans. For example, the mTOR signaling complex can be found in both yeast and humans to 
regulate cell growth based on different nutrient levels. Here, our study uncovered a ubiquitin- and ESCRT- dependent pathway in humans to degrade lysosome membrane proteins. Is this pathway conserved in yeast? To directly answer the question, we expressed GFP-RNF152 in budding yeast. To our satisfaction, GFP-RNF152 was still correctly localized to the yeast vacuole membrane (Figure 7). Strikingly, when treated with cycloheximide, GFP-RNF152 was quickly internalized into the lumen and degraded (Figure 7A-B). Deletion of PEP4, the master vacuolar protease that is critical for activating other lumenal proteases, stopped the degradation of GFP-RNF152 (Figure 7A-B) (Ammerer et al., 1986; Woolford et al., 1986).

We then systematically deleted components of the ESCRT subcomplexes, including VPS27 (ESCRT-0), VPS23 (ESCRT-I), VPS22 (ESCRT-II), SNF7 (ESCRT-III), VPS4 (AAA-ATPase), and BRO1 (ALIX homolog). Because the $\mathrm{pH}(\sim 5.5-6.5)$ in yeast vacuole is not low enough to quench the GFP fluorescence, we can directly observe the accumulation of free GFP during protein degradation. As shown in figure 7C, deleting any ESCRT components stabilized GFP-RNF152 on the vacuole membrane. These results indicated that the ESCRT machinery is critical for the internalization and degradation of GFP-RNF152 in yeast. Unlike human cells, early-stage ESCRT components are just as crucial as the late-stage ESCRT components in yeast, suggesting that humans may have evolved an alternative mechanism to recruit late-stage ESCRTs onto the lysosome membrane.

In summary, our investigation indicated that the ubiquitin- and ESCRT-dependent turnover of lysosome membrane proteins is a fundamental process conserved from yeast to humans (Figure 7D). 


\section{DISCUSSION}

\section{Different ESCRT requirements between yeast and human lysosomes}

In this study, we uncovered a ubiquitin and ESCRT- dependent pathway to downregulate human lysosome membrane proteins such as RNF152. Strikingly, when expressed in budding yeast, RNF152 is also degraded by a similar mechanism (Figure 7). Previously, we and others have demonstrated that this ubiquitin and ESCRT dependent pathway is used by budding yeast to regulate many vacuole (functional equivalent to mammalian lysosomes) membrane proteins. For example, the Rsp5-Ssh4 E3 ligase complex ubiquitinates Ypq1 (a vacuolar lysine transporter) when lysine is depleted from the cytosol ( $\mathrm{Li}$ et al., 2015a). Similarly, a vacuolar $\mathrm{Zn}^{2+}$ influx transporter Cot1 is also regulated through ubiquitination by another E3 ligase complex, DSC, and degraded inside the vacuole (Li et al., 2015b,; Yang et al., 2018). Importantly, we and others also showed that ubiquitinated vacuole membrane proteins are internalized for degradation by the ESCRT machinery (Li et al., 2015a; Li et al., 2015b; Oku et al., 2017; Zhu et al., 2017; Morshed et al., 2020; Yang et al., 2020).

Although the ubiquitin- and ESCRT-dependent pathway is conserved from yeast to humans, we also noticed significant differences between the two systems. In budding yeast, knocking out every core component of the ESCRT machinery (ESCRT-0, I, II, III, Vps4, and Brol) stabilizes RNF152 on the vacuole membrane (Figure 7A-C). But in human cells, only ESCRT-III (CHMP4A and CHMP4B) and Vps4 AAA-ATPase activity are shown to be important to the degradation of RNF152 (Figure 6). In contrast, the 
early ESCRT components (ex: HRS[ESCRT-0], TSG101 [ESCRT-I], and Vps22 [ESCRT-II]) seems to be less critical (Figure S3). Our results are consistent with a previous study showing that the starvation-induced turnover of autophagy receptors by endosomal microautophagy depends on ESCRT-III and Vps4, but not the early ESCRTs (ESCRT-0, -I, and -II) (Mejlvang et al., 2018).

One possible explanation could be the functional redundancy among early components. Interestingly, many early ESCRT components share functional domains or binding features. For example, both HRS (ESCRT-0) and VPS28 (ESCRT-II) contains PI3P binding domains (Christ et al., 2017). Also, many ESCRT components, including HRS, STAM1\&2 (ESCRT-0), TSG101, MVB12A\&B (ESCRT-I), Vps36 (ESCRT-II), and ALIX, are all ubiquitin-binding proteins (Haglund and Dikic, 2012). Therefore, it is possible that some early ESCRT components are redundant in the degradation of LMPs.

Alternatively, it is also possible that humans may have evolved other mechanisms to recruit late-stage ESCRTs onto the lysosome membrane. During the formation of ILVs, ESCRT subcomplexes are sequentially assembled on the endosome membrane to sort and internalize ubiquitinated cargo proteins. After cargo internalization, Vps4 is recruited to disassemble and recycle the ESCRT-III sub-complex. Besides the ILV formation, ESCRTs have evolved a variety of functions on different membrane compartments in mammalian cells, such as membrane repair, budding of viral particles from the plasma membrane, midbody formation during cytokinesis, and closure of the autophagosomes. All these functions require ESCRT-III and VPS4, which are directly responsible for membrane deformation (Vietri et al., 2020). However, the corresponding proteins to 
recruit/assemble ESCRT-III at different membranes are quite different. For example, ESCRT-0, CEP55, and viral Gag proteins can recruit TSG101 or ALIX to distinct membrane surfaces (Vietri et al., 2020).

Many studies have suggested two parallel pathways of TSG101 (ESCRT-I) and ALIX (accessory unit of ESCRT) to independently recruit ESCRT-III to different membrane compartments. (Fujii et al., 2009; Jimenez et al., 2014; Christ et al., 2016; Tang et al., 2016; Larios et al., 2020). Here we observed that even knocking down both TSG101 and ALIX can only mildly affect the degradation of RNF152 (Figure S3A-C). These results suggested that additional factors might be involved in the degradation process. Identifying these recruitment factors will require further investigations.

\section{Multiple pathways may be involved in the selective turnover of LMPs}

Besides the ESCRT-dependent degradation pathway examined in this study, recent studies have suggested other mechanisms might also be involved in the degradation of LMPs. First, Overholzer and colleagues showed that LC3 lipidationtriggered microautophagy is responsible for the selective turnover of several LMPS, including TRPML1 and SNAT7 (SLC38A7) (Lee et al., 2020). However, there are still many unanswered questions about this pathway. For example, how does ATG5dependent microautophagy achieve its selectivity? It is unclear what machinery is responsible for selecting cargo proteins and how are selected LMPs sorted into the microautophagy. Moreover, how does the LC3 lipidation at the lysosome surface trigger microautophagy? Despite all these open questions, ATG5-dependent microautophagy provides an exciting model for the selective turnover of LMPs. Although our study did not find evidence that LC3 lipidation-dependent microautophagy is responsible for the 
degradation of RNF152, it is still possible that these two pathways may operate in parallel to regulate different subsets of LMPs.

In addition to the ESCRT-dependent pathway and LC3 lipidation-dependent microautophagy, mammalian lysosome may have evolved other mechanisms to turn over its membrane proteins, such as chaperone-mediated autophagy (CMA) and proteasomedependent degradation. The CMA pathway often targets cytosolic proteins that contain the KFERQ-like motif. However, many membrane proteins also have the KFERQ-like motif, which potentially can be recognized by chaperone Hsc70. Therefore, It is still possible that CMA is involved in regulating some LMPs even though RNF152 is not a CMA cargo. Besides, proteasome-dependent degradation is another well-characterized and conserved pathway to down-regulate membrane proteins. The best-known example is the ER-associated degradation (ERAD) pathway, in which misfolded proteins were ubiquitinated by the E3 ligases at the endoplasmic reticulum, extracted by an AAA ATPase P97 (CDC48 in yeast), and sent to the proteasome for degradation. Interestingly, several recent studies showed that p97 could be recruited to lysosomes to facilitate the lysophagy when lysosomes are severely damaged (Papadopoulos et al., 2017, Koerver et al., 2019). Although proteasome is not directly involved in the lysophagy, it is still possible that proteasome can degrade LMP substrates extracted by p97 (Papadopoulos and Meyer, 2017). As we are still at the early stage to understand the turnover mechanisms of lysosome membrane proteins, how ESCRT machinery, autophagy factors, and proteasome may coordinate to regulate LMPs remains an exciting question to addressed by the field. 


\section{References}

Abu-Remaileh M, Wyant GA, Kim C, et al. Lysosomal metabolomics reveals VATPase- and mTOR-dependent regulation of amino acid efflux from lysosomes. Science. 2017;358(6364):807-813. doi:10.1126/science.aan6298

Amick J, Ferguson SM. C9orf72: At the intersection of lysosome cell biology and neurodegenerative disease. Traffic. 2017;18(5):267-276. doi:10.1111/tra.12477

Ammerer G, Hunter CP, Rothman JH, Saari GC, Valls LA, Stevens TH. PEP4 gene of Saccharomyces cerevisiae encodes proteinase $A$, a vacuolar enzyme required for processing of vacuolar precursors. Mol Cell Biol. 1986;6(7):2490-2499. doi:10.1128/mcb.6.7.2490

An H, Ordureau A, Paulo JA, Shoemaker CJ, Denic V, Harper JW. TEX264 Is an Endoplasmic Reticulum-Resident ATG8-Interacting Protein Critical for ER Remodeling during Nutrient Stress. Mol Cell. 2019;74(5):891-908.e10. doi:10.1016/j.molcel.2019.03.034

Anding AL, Baehrecke EH. Cleaning House: Selective Autophagy of Organelles. Dev Cell. 2017;41(1):10-22. doi:10.1016/j.devcel.2017.02.016

Bejarano E, Cuervo AM. Chaperone-mediated autophagy. Proc Am Thorac Soc. 2010;7(1):29-39. doi:10.1513/pats.200909-102JS

Bissa B, Beedle AM, Govindarajan R. Lysosomal solute carrier transporters gain momentum in research. Clin Pharmacol Ther. 2016;100(5):431-436.

doi:10.1002/cpt.450

Carmona-Gutierrez D, Hughes AL, Madeo F, Ruckenstuhl C. The crucial impact of lysosomes in aging and longevity. Ageing Res Rev. 2016;32:2-12.

doi:10.1016/j.arr.2016.04.009

Chapel A, Kieffer-Jaquinod S, Sagné C, et al. An extended proteome map of the lysosomal membrane reveals novel potential transporters. Mol Cell Proteomics. 2013;12(6):1572-1588. doi:10.1074/mcp.M112.021980

Cheon SY, Kim H, Rubinsztein DC, Lee JE. Autophagy, Cellular Aging and Agerelated Human Diseases. Exp Neurobiol. 2019;28(6):643-657.

doi:10.5607/en.2019.28.6.643

Christ L, Raiborg C, Wenzel EM, Campsteijn C, Stenmark H. Cellular Functions and Molecular Mechanisms of the ESCRT Membrane-Scission Machinery. Trends Biochem Sci. 2017;42(1):42-56. doi:10.1016/j.tibs.2016.08.016

Christ L, Wenzel EM, LiestøI K, Raiborg C, Campsteijn C, Stenmark H. ALIX and ESCRT-I/II function as parallel ESCRT-III recruiters in cytokinetic abscission. J Cell Biol. 2016;212(5):499-513. doi:10.1083/jcb.201507009

Cook C, Stetler C, Petrucelli L. Disruption of protein quality control in Parkinson's disease. Cold Spring Harb Perspect Med. 2012;2(5):a009423.

doi:10.1101/cshperspect.a009423

Cuervo AM, Wong E. Chaperone-mediated autophagy: roles in disease and aging. Cell Res. 2014;24(1):92-104. doi:10.1038/cr.2013.153

Deng $L$, Jiang $C$, Chen $L$, et al. The ubiquitination of rag A GTPase by RNF152 negatively regulates mTORC1 activation. Mol Cell. 2015;58(5):804-818. doi:10.1016/j.molcel.2015.03.033 
Fan T, Huang Z, Wang W, et al. Proteasome inhibition promotes autophagy and protects from endoplasmic reticulum stress in rat alveolar macrophages exposed to hypoxia-reoxygenation injury. J Cell Physiol. 2018;233(10):6748-6758.

doi:10.1002/jcp.26516

Firkowska M, Macias M, Jaworski J. ESCRT Proteins Control the Dendritic Morphology of Developing and Mature Hippocampal Neurons. Mol Neurobiol. 2019;56(7):4866-4879. doi:10.1007/s12035-018-1418-9

Fujii K, Munshi UM, Ablan SD, et al. Functional role of Alix in HIV-1 replication. Virology. 2009;391(2):284-292. doi:10.1016/j.virol.2009.06.016

Haglund K, Dikic I. The role of ubiquitylation in receptor endocytosis and endosomal sorting. J Cell Sci. 2012;125(Pt 2):265-275. doi:10.1242/jcs.091280

Henne WM, Buchkovich NJ, Emr SD. The ESCRT pathway. Dev Cell. 2011;21(1):77-91. doi:10.1016/j.devcel.2011.05.015

Hung YH, Chen LM, Yang JY, Yang WY. Spatiotemporally controlled induction of autophagy-mediated lysosome turnover. Nat Commun. 2013;4:2111.

doi:10.1038/ncomms3111

Hurley JH. The ESCRT complexes. Crit Rev Biochem Mol Biol. 2010;45(6):463487. doi:10.3109/10409238.2010.502516

Jimenez AJ, Maiuri P, Lafaurie-Janvore J, Divoux S, Piel M, Perez F. ESCRT machinery is required for plasma membrane repair. Science. 2014;343(6174):1247136. doi:10.1126/science.1247136

Kao SH, Wang WL, Chen CY, et al. Analysis of Protein Stability by the Cycloheximide Chase Assay. Bio Protoc. 2015;5(1):e1374. doi:10.21769/BioProtoc.1374.

Kirchner P, Bourdenx M, Madrigal-Matute J, et al. Proteome-wide analysis of chaperone-mediated autophagy targeting motifs. PLoS Biol. 2019;17(5):e3000301. Published 2019 May 31. doi:10.1371/journal.pbio.3000301

Kocaturk NM, Gozuacik D. Crosstalk Between Mammalian Autophagy and the Ubiquitin-Proteasome System. Front Cell Dev Biol. 2018;6:128. Published 2018 Oct 2. doi:10.3389/fcell.2018.00128

Koerver L, Papadopoulos C, Liu B, et al. The ubiquitin-conjugating enzyme UBE2QL1 coordinates lysophagy in response to endolysosomal damage. EMBO Rep. 2019;20(10):e48014. doi:10.15252/embr.201948014

Larios J, Mercier V, Roux A, Gruenberg J. ALIX- and ESCRT-III-dependent sorting of tetraspanins to exosomes. J Cell Biol. 2020;219(3):e201904113. doi:10.1083/jcb.201904113

Lawrence RE, Zoncu R. The lysosome as a cellular centre for signalling, metabolism and quality control. Nat Cell Biol. 2019;21(2):133-142. doi:10.1038/s41556018-0244-7

Lee C, Lamech L, Johns E, Overholtzer M. Selective Lysosome Membrane Turnover Is Induced by Nutrient Starvation [published online ahead of print, 2020 Aug 31]. Dev Cell. 2020;S1534-5807(20)30666-3. doi:10.1016/j.devcel.2020.08.008

Li M, Koshi T, Emr SD. Membrane-anchored ubiquitin ligase complex is required for the turnover of lysosomal membrane proteins. J Cell Biol. 2015(b);211(3):639-652. doi:10.1083/jcb.201505062 
Li M, Rong Y, Chuang YS, Peng D, Emr SD. Ubiquitin-dependent lysosomal membrane protein sorting and degradation. Mol Cell. 2015(a);57(3):467-478. doi:10.1016/j.molcel.2014.12.012

Maejima I, Takahashi A, Omori H, et al. Autophagy sequesters damaged lysosomes to control lysosomal biogenesis and kidney injury. EMBO J. 2013;32(17):2336-2347. doi:10.1038/emboj.2013.171

Marshall RS, Vierstra RD. Proteasome storage granules protect proteasomes from autophagic degradation upon carbon starvation. Elife. 2018;7:e34532. Published 2018 Apr 6. doi:10.7554/eLife.34532

Mejlvang J, Olsvik H, Svenning S, et al. Starvation induces rapid degradation of selective autophagy receptors by endosomal microautophagy. J Cell Biol. 2018;217(10):3640-3655. doi:10.1083/jcb.201711002

Mittal E, Skowyra ML, Uwase G, et al. Mycobacterium tuberculosis Type VII Secretion System Effectors Differentially Impact the ESCRT Endomembrane Damage Response. mBio. 2018;9(6):e01765-18. Published 2018 Nov 27.

doi:10.1128/mBio.01765-18

Mizushima N, Noda T, Yoshimori T, et al. A protein conjugation system essential for autophagy. Nature. 1998;395(6700):395-398. doi:10.1038/26506

Morshed S, Sharmin T, Ushimaru T. TORC1 regulates ESCRT-0 complex formation on the vacuolar membrane and microautophagy induction in yeast. Biochem Biophys Res Commun. 2020;522(1):88-94. doi:10.1016/j.bbrc.2019.11.064

Nixon RA, Cataldo AM. Lysosomal system pathways: genes to neurodegeneration in Alzheimer's disease. J Alzheimers Dis. 2006;9(3 Suppl):277-289. doi:10.3233/jad2006-9s331

Oku M, Maeda Y, Kagohashi Y, et al. Evidence for ESCRT- and clathrindependent microautophagy. J Cell Biol. 2017;216(10):3263-3274.

doi:10.1083/jcb.201611029

Papadopoulos C, Kirchner P, Bug M, et al. VCP/p97 cooperates with YOD1, UBXD1 and PLAA to drive clearance of ruptured lysosomes by autophagy. EMBO J. 2017;36(2):135-150. doi:10.15252/embj.201695148

Papadopoulos C, Meyer H. Detection and Clearance of Damaged Lysosomes by the Endo-Lysosomal Damage Response and Lysophagy. Curr Biol. 2017;27(24):R1330-R1341. doi:10.1016/j.cub.2017.11.012

Pohl C, Dikic I. Cellular quality control by the ubiquitin-proteasome system and autophagy. Science. 2019;366(6467):818-822. doi:10.1126/science.aax3769

Radulovic M, Schink KO, Wenzel EM, et al. ESCRT-mediated lysosome repair precedes lysophagy and promotes cell survival. EMBO J. 2018;37(21):e99753. doi:10.15252/embj.201899753

Ran FA, Hsu PD, Wright J, Agarwala V, Scott DA, Zhang F. Genome engineering using the CRISPR-Cas9 system. Nat Protoc. 2013;8(11):2281-2308.

doi:10.1038/nprot.2013.143

Schmidt O, Teis D. The ESCRT machinery. Curr Biol. 2012;22(4):R116-R120. doi:10.1016/j.cub.2012.01.028

Schröder B, Wrocklage C, Pan C, et al. Integral and associated lysosomal membrane proteins. Traffic. 2007;8(12):1676-1686. doi:10.1111/j.1600-

0854.2007.00643.x 
Schuck S. Microautophagy - distinct molecular mechanisms handle cargoes of many sizes. J Cell Sci. 2020;133(17):jcs246322. Published 2020 Sep 9.

doi:10.1242/jcs.246322

Schwake M, Schröder B, Saftig P. Lysosomal membrane proteins and their central role in physiology. Traffic. 2013;14(7):739-748. doi:10.1111/tra.12056

Shirley RB, Kaddour-Djebbar I, Patel DM, Lakshmikanthan V, Lewis RW, Kumar MV. Combination of proteasomal inhibitors lactacystin and MG132 induced synergistic apoptosis in prostate cancer cells. Neoplasia. 2005;7(12):1104-1111.

doi:10.1593/neo.05520

Skowyra ML, Schlesinger PH, Naismith TV, Hanson PI. Triggered recruitment of ESCRT machinery promotes endolysosomal repair. Science.

2018;360(6384):eaar5078. doi:10.1126/science.aar5078

Sitaram A, Piccirillo R, Palmisano I, et al. Localization to mature melanosomes by virtue of cytoplasmic dileucine motifs is required for human OCA2 function. Mol Biol Cell. 2009;20(5):1464-1477. doi:10.1091/mbc.e08-07-0710

Takahashi $\mathrm{Y}, \mathrm{He} \mathrm{H}$, Tang Z, et al. An autophagy assay reveals the ESCRT-III component CHMP2A as a regulator of phagophore closure. Nat Commun. 2018;9(1):2855. Published 2018 Jul 20. doi:10.1038/s41467-018-05254-w

Tang S, Buchkovich NJ, Henne WM, Banjade S, Kim YJ, Emr SD. ESCRT-III activation by parallel action of ESCRT-I/II and ESCRT-0/Bro1 during MVB biogenesis. Elife. 2016;5:e15507. Published 2016 Apr 13. doi:10.7554/eLife. 15507

Vietri M, Radulovic M, Stenmark $\mathrm{H}$. The many functions of ESCRTs. Nat Rev Mol Cell Biol. 2020;21(1):25-42. doi:10.1038/s41580-019-0177-4

Wang XJ, Yu J, Wong SH, et al. A novel crosstalk between two major protein degradation systems: regulation of proteasomal activity by autophagy. Autophagy. 2013;9(10):1500-1508. doi:10.4161/auto.25573

Woolford CA, Daniels LB, Park FJ, Jones EW, Van Arsdell JN, Innis MA. The PEP4 gene encodes an aspartyl protease implicated in the posttranslational regulation of Saccharomyces cerevisiae vacuolar hydrolases. Mol Cell Biol. 1986;6(7):2500-2510. doi:10.1128/mcb.6.7.2500

Wyant GA, Abu-Remaileh M, Frenkel EM, et al. NUFIP1 is a ribosome receptor for starvation-induced ribophagy. Science. 2018;360(6390):751-758.

doi:10.1126/science.aar2663

Xiong MG, Xu ZS, Li YH, Wang SY, Wang YY, Ran Y. RNF152 positively regulates TLR/IL-1R signaling by enhancing MyD88 oligomerization. EMBO Rep. 2020;21(3):e48860. doi:10.15252/embr.201948860

Yambire KF, Rostosky C, Watanabe T, Pacheu-Grau D, Torres-Odio S, SanchezGuerrero A, Senderovich O, Meyron-Holtz EG, Milosevic I, Frahm J, West AP, Raimundo N. Impaired lysosomal acidification triggers iron deficiency and inflammation in vivo. Elife. 2019 Dec 3;8:e51031. doi: 10.7554/eLife.51031. PMID: 31793879; PMCID: PMC6917501.

Yang X, Arines FM, Zhang W, Li M. Sorting of a multi-subunit ubiquitin ligase complex in the endolysosome system. Elife. 2018;7:e33116. Published 2018 Jan 22. doi:10.7554/eLife.33116 
Yang $\mathrm{X}$, Zhang $\mathrm{W}$, Wen $\mathrm{X}$, et al. TORC1 regulates vacuole membrane composition through ubiquitin- and ESCRT-dependent microautophagy. J Cell Biol. 2020;219(3):e201902127. doi:10.1083/jcb.201902127

Zhu L, Jorgensen JR, Li M, Chuang YS, Emr SD. ESCRTs function directly on the lysosome membrane to downregulate ubiquitinated lysosomal membrane proteins. Elife. 2017;6:e26403. Published 2017 Jun 29. doi:10.7554/eLife.26403

\section{FIGURE LEGENDS}

Figure 1: Cycloheximide chase assay to screen for LMPs with short half-lives.

(A) Western blots showing the level of indicated LMPs in cells treated with cycloheximide $(\mathrm{CHX})$ for the indicated time periods. HEK293 cells were transfected with indicated plasmids. $\mathrm{CHX}$ chase assay was performed $20-24 \mathrm{~h}$ post-transfection and detected with either a GFP or mCherry antibody. (B) Quantification of the protein level in A, $n=3$. (C) Immunofluorescence showing the localization of LAPTM4A-mCherry, GFP-

RNF152, and GFP-OCA2 in HEK293 cells costained with a LAMP2 antibody.

LAPTM4A, RNF152, and OCA2 are pseudo-colored in green. LAMP2 is pseudo-colored in red. Scale bar $=10 \mu \mathrm{m}$. White arrows indicate GFP-RNF152 puncta that are not colocalized with LAMP2 signals.

\section{Figure 2: RNF152 has a short half-life.}

(A) Domain organization of RNF152. (B) Western blots showing the degradation of GFP-RNF152 in HeLa and HEK293 cells. GFP-RNF152 is stably expressed in these cell lines. (C) Flow Cytometry analysis showing GFP intensity in HeLa and HEK293 cells that stably express GFP-RNF152. Cells were incubated with indicated treatments for 2 hours before the Flow Cytometry analysis. Non-infected HeLa and HEK293 cells served as negative controls. (D) Western blots showing the degradation of 3XFLAGRNF152 in HEK293 cells. 3XFLAG-RNF152 is stably expressed. (E) Representative 
Western blots showing both full-length GFP-RNF152 (50kDa) and free GFP (27kDa) are enriched after Lyso-IP. LAMP2 (lysosomal membrane), CTSD (lysosomal lumen), PDI (ER), Golgi160 (Golgi), EEA1 (endosome), and GAPDH (cytosol) were also immunoblotted. Ctrl-Lyso: cells stably expressing TMEM192-2XFLAG; HA-Lyso: cells stable expressing TMEM192-3HA. Both cell lines also stably express GFP-RNF152. Asterisk: mouse heavy chain. (F) Representative Western blots showing the degradation of lysosome localized GFP-RNF152 (50kDa) after two-hour cycloheximide treatment. LAMP2 serves as an internal control.

\section{Figure 3: RNF152 degradation is ubiquitin-dependent.}

(A) Left panel: representative Western blots showing GFP-RNF152 degradation in HEK293 stable cell line. A faint band at 60kDa might be the mono-ubiquitinated form of GFP-RNF152. Right panel: long exposure of the left panel. A high-molecular-weight smear appears on top of the GFP-RNF152, which might be poly-ubiquitinated GFPRNF152. (B) Left panel: whole cell lysate (WCL) of HEK293 cells that stably express either GFP or GFP-RNF152 and transfected with HA-Ub. Right panel: GFP or GFPRNF152 were immunoprecipitated with GFP-TRAP nanobody and immunoblotted with an HA antibody. A representative Western blot shows that GFP-RNF152 but not free GFP is poly-ubiquitinated. The dotted box represents the size of full-length GFPRNF152 at 50kDa. (C) Representative Western blots showing degradation kinetics of wildtype (WT) GFP-RNF152, 8K $\rightarrow \mathrm{R}$ and 4C $\rightarrow \mathrm{S}$ mutants in HEK293 cells that stably express each construct. (D) Quantification of the protein level of WT GFP-RNF152 and its mutants at the steady-state ( $t=0 \mathrm{~h}$ in $\mathrm{C}), \mathrm{n}=3$. ${ }^{*} \mathrm{p}<0.05$. (E) Quantification of the 
protein level of WT GFP-RNF152 and its mutants in cycloheximide chase assay (all time points in $\mathrm{C}), \mathrm{n}=3$.

Figure 4: RNF152 is mainly degraded by the lysosome.

(A) Left panel: representative Western blots showing GFP-RNF152 protein level after MG132 (50 $\mu \mathrm{M})$, BafA1 (400 nM), and double treatment for 6 hours. Right panel: long exposure of the left panel. (B) Quantification of the full-length GFP-RNF152 protein level at $50 \mathrm{kDa}$ in $A, n=3$. n.s. not significant. ${ }^{* *} p<0.01,{ }^{* *} p<0.001$. (C) Quantification of the total GFP-RNF152 protein level, including full-length at 50kDa plus all highmolecular-weight smear in $A, n=3$. n.s. not significant. ${ }^{* *} p<0.01$. (D) GFP or GFPRNF152 were immunoprecipitated with GFP-TRAP nanobody and immunoblotted with antibodies against HA tag (Top panel) and GFP (Mid panel). Dotted boxes represent the size of full-length GFP-RNF152. Bottom panel: Western blots showing whole cell lysate (WCL). Cells stably expressing free GFP served as a negative control. All cell lines were transfected with HA-Ub plasmids. Cells were treated with MG132 (50 $\mu \mathrm{M})$, BafA1 (400 nM), or MG132+BafA1 for 6h. (E) Flow Cytometry analysis showing GFP intensity of HEK293 cells that stably express GFP-RNF152 after 6 hours of indicated treatment. (F) Immunofluorescence of LAMP2 with GFP-RNF152 in HEK293 cells that stably express GFP-RNF152 after indicated treatment. Scale bar=10 $\mu \mathrm{m} .(\mathrm{G})$ Immunofluorescence of LAMP2 with GFP-RNF152 in HEK293 cells that stably express GFP-RNF152 after 6 hours of BafA1 (400 nM) treatment. Line scanning analysis was performed on three lysosomal structures. Scale bar=10 $\mu \mathrm{m}$.

Figure 5: Macroautophagy and CMA pathways are not involved in the degradation of RNF152. 
(A) Representative Western blots showing the degradation of GFP-RNF152 in WT HEK293, ATG5KO, and ATG7KO cell lines after cycloheximide treatment. GFPRNF152 was stably expressed in all cell lines. (B) Quantification of GFP-RNF152 level in $A, n=3$. (C) Representative Western blots showing GFP-RNF152 protein level in ATG7KO cells after indicated treatment for 4 hours. WT HEK293 cells serve as the control for ATG7KO. GFP-RNF152 was stably expressed in both cell lines. (D) Quantification of GFP-RNF152 level in C, $n=3$. (E) Identifying the canonical CMA KFERQ-like motif in RNF152 starting at residue number 46 QKDVR. (F) Representative Western blots showing the degradation of WT 3XFLAG-RNF152 and QK $\rightarrow$ AA mutant in HEK293 cells that stably express each construct after cycloheximide treatment. QK $\rightarrow A A:{ }^{46} \mathrm{QK}^{47}$ were mutated to alanines. (G) Quantification of $F, n=3$.

Figure 6: ESCRT-III and VPS4 are important for the degradation of RNF152

(A) Representative Western blots showing the cycloheximide chase of GFP-RNF152 in control and CHMP4A + CHMP4B double knockdown cells. GFP-RNF152 was stably expressed in HEK293 cells. (B) Quantification of the protein level of full-length GFPRNF152 in A. $n=3$. (C) Quantification of the protein level of total GFP-RNF152 in A. n=3. (D) Flow Cytometry analysis showing GFP intensity in siRNA control and CHMP4A + CHMP4B double knockdown cells. GFP-RNF152 were stably expressed in HEK293 cells. (E) Immunofluorescence of LAMP2 with GFP-RNF152 in siRNA control and CHMP4A +CHMP4B double knockdown HEK293 cells that stably express GFPRNF152 after 6 hours of BafA1 (400nM) treatment. Images were taken using a Deltavision fluorescence microscopy and further deconvolved to improve the resolution. Scale bar=10 $\mu \mathrm{m}(\mathrm{F})$ Quantification of E showing the distribution of cells that contain 
either only puncta GFP signals or membrane GFP signals. (G) Representative Western blots showing the cycloheximide chase of GFP-RNF152 in cells overexpressing either WT HA-Vps4A or its dominant-negative mutant (E228Q). GFP-RNF152 were also stably expressed in these cells. To induce the expression of HA-VPS4A, cells were treated with $1 \mu \mathrm{g} / \mathrm{ml}$ of doxycycline for 24 hours. $(\mathrm{H})$ Quantification of the protein level of the fulllength GFP-RNF152 at 50kDa in $\mathrm{G}, \mathrm{n}=3$. (I) Quantification of the protein level of the total GFP-RNF152 in G, n=3. (J) Flow Cytometry analysis showing GFP intensity in no induction control, WT HA-VPS4A overexpressing and HA-VPS4A E228Q overexpressing cells. GFP-RNF152 was stably expressed in these HEK293 cells. Figure 7: The degradation of RNF152 is ESCRT-dependent in budding yeast. (A) Representative Western blots showing the degradation of GFP-RNF152 in WT and pep4 $\Delta$ yeast strains. (B) Quantification of the protein level in $A, n=3$. (C) Subcellular

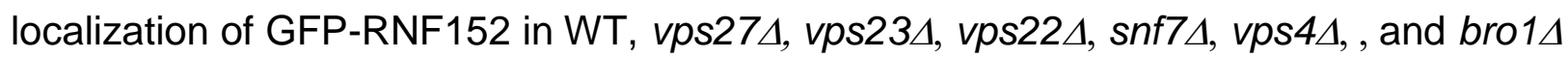
yeast strains before $(0 h)$ and after $(2 h)$ cycloheximide treatment. Scale bar=2 $\mu \mathrm{m}$. DIC: differential interference contrast. (D) A Model shows the conserved ubiquitin- and ESCRT-dependent mechanism to degrade LMPs in yeast and human cells.

\section{Figure S1: Cycloheximide chase assay for LMPs.}

Western blots showing examples of the $\mathrm{CHX}$ chase screen in HEK293 cells. LAMP1 and LAMP2 were detected at the endogenous protein level. For others, HEK293 cells were transfected with indicated overexpression plasmids. $\mathrm{CHX}$ chase assay was performed $20-24 \mathrm{~h}$ after transfection with either GFP or mCherry antibody. The majority of the tested LMPs are very stable. 
Figure S2: GFP-RNF152 is mainly degraded by the lysosome-dependent proteolysis.

(A) Representative Western blots showing the cycloheximide chase of GFP-RNF152

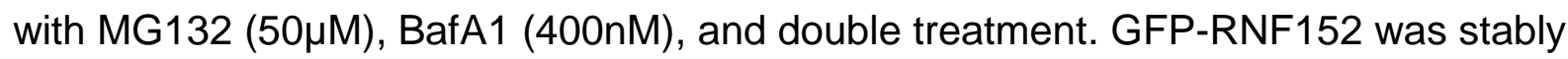
expressed in HEK293 cells. (B) Quantification of the protein level of the full-length GFPRNF152, $n=3$. (C) Representative Western blots showing that the degradation of lysosome localized GFP-RNF152 $(50 \mathrm{kDa})$ is blocked by BafA1 $(400 \mathrm{nM})$ treatment after Lyso-IP. LAMP2 serves as an internal control. Ctrl-Lyso: cells stably express TMEM192-2XFLAG. HA-Lyso: cells stable express TMEM192-3HA. Both cell lines also stably express GFP-RNF152.

Figure S3: Early ESCRT components are less important for the degradation of RNF152.

(A) Representative Western blots showing the cycloheximide chase of GFP-RNF152 in siRNA control, TSG101 knockdown, ALIX knockdown, and double knockdown cells. GFP-RNF152 was stably expressed in HEK293 cells. (B) Quantification of the protein level of full-length GFP-RNF152 in A, $n=3$. (C) Quantification of the protein level of the total GFP-RNF152 (signal at and above 50kDa) in A, n=3. (D) Representative Western blot showing the cycloheximide chase of GFP-RNF152 in siRNA control, HRS knockdown, and Vps22 knockdown cells. GFP-RNF152 was stably expressed in HEK293 cells. (E) Quantification of the full-length GFP-RNF152 in D, n=3. (F) Quantification of the protein level of the total GFP-RNF152 in D, n=3. (G) Immunostaining of poly-ubiquitinated proteins using the FK2 antibody in siRNA control 
HEK293 cells, HRS knockdown, TSG101+ALIX knockdown, and Vps22 knockdown cells. Nuclei were stained with Hoechst. Scale bar $=10 \mu \mathrm{m}$.

Figure S4: ESCRT-III knockdown and overexpression of VPS4A disrupt ESCRT

\section{function.}

(A) Immunostaining of poly-ubiquitinated proteins using the FK2 antibody in control HEK293 cells and CHMP4A+CHMP4B double knockdown cells. Nuclei were stained with Hoechst. Scale bar=10 $\mu \mathrm{m}$. (B) Immunostaining of poly-ubiquitinated proteins using FK2 antibody in no doxycycline induction control HEK293 cells, WT HA-Vps4A overexpressing, and HA-Vps4A E228Q overexpressing cells. The expression of HAVps4A was induced by $1 \mu \mathrm{g} / \mathrm{ml}$ of doxycycline treatment for 24 hours. Scale bar $=10 \mu \mathrm{m}$

\section{MATERIALS AND METHODS}

\section{Mammalian cell culture}

All mammalian cell lines used in this study are listed in Table S1. The following cell lines were obtained from ATCC: HEK293 (CRL-1573), HEK293T (CRL-3216) and, HeLa (CCL-2). Cells were cultured in DMEM (Invitrogen) containing 10\% Super Calf Serum (Gemini), $1 \%$ penicillin and streptomycin (Invitrogen) and $1 \mu \mathrm{g} / \mathrm{ml}$ plasmocin (Invivogen) at $37^{\circ} \mathrm{C}, 5 \% \mathrm{CO}_{2}$. All cells were tested negative for mycoplasma contamination using Mycoalert ${ }^{\mathrm{TM}}$ mycoplasma detection kit (Lonza).

\section{Plasmids}

All mammalian plasmids used in this study are listed in Table S2. Most of the lysosomal membrane protein overexpression plasmids were purchased from GeneCopoeia. The CDS of RNF152 was purchased from Horizon Discovery. The 
$4 C \rightarrow S$ and $Q K \rightarrow A A$ mutants of RNF152 were generated by PCR-based site-directed mutagenesis. The $8 \mathrm{~K} \rightarrow \mathrm{R}$ mutant of RNF152 was synthesized as a gBlock ${ }^{\mathrm{TM}}$ gene fragment by Integrated DNA Technologies.

To generate transfer plasmids for GFP-RNF152 stable cell lines, EGFP was fused to the N-terminal of RNF152 (WT or mutants) using PCR-based overlapping extension, with 2X Gly-Gly-Gly-Ser linker in between. Then, EGFP-RNF152 was cloned into the pHAGE2-IRES-puro vector using restriction enzymes Notl and BamHI. To generate mCherry selection transfer plasmids, mCherry was amplified from the pmCherry-N1 (Clontech) vector and cloned into a pHAGE2 vector to replace the puromycin-resistant gene using restriction enzymes Ndel and Clal. To generate transfer plasmids for 3XFLAG-RNF152 stable cell lines, RNF152 (WT or mutants) was cloned into the pBICEP-CMV2-3XFLAG (Millipore-Sigma) vector using restriction enzymes Sall and BamHI. Then, 3XFLAG-RNF152 was cloned into pHAGE2-IRES-Puro vector using restriction enzyme $\mathrm{Ncol}$ and BamHI.

The CDS of Vps4A E228Q was purchased from Addgene (80351). Vps4A E228Q was cloned into the pCMV-HA (Clontech) vector using restriction enzymes EcoRI and Notl. The WT HA-Vps4A was obtained by using PCR-based site-directed mutagenesis. Then the WT HA-Vps4A and HA-Vps4A E228Q were cloned into pCW57.1 (Addgene 41393) using restriction enzymes Nhel and Agel.

\section{Transfection and cycloheximide chase screen}

HEK293 cells were cultured in DMEM containing 10\% serum only media for at least 4 days before transfection. Cells were transfected with individual overexpression plasmids (2.4 $\mu \mathrm{g}$ DNA for a 3.5cm dish) using Lipofectamine 2000 (Invitrogen) 
according to the manufacturer's instruction. After 20-24 hours of transfection, cells were treated with $100 \mu \mathrm{g} / \mathrm{ml}$ cycloheximide (Millipore-Sigma). At indicated chase time, cell samples were collected in ice-cold 1XPBS, pelleted at $800 x \mathrm{x}$ for 1 minute, and stored at $-80^{\circ} \mathrm{C}$ before subsequent Western blot analysis.

\section{siRNA knockdown}

HEK293 cells were cultured in DMEM containing $10 \%$ serum only media for at least 4 days before siRNA knockdown. Cells were transfected with siRNAs using Lipofectamine RNAimax (Invitrogen) according to the manufacturer's instruction. After 24 hours, cells were transfected with the same amount of siRNA again. 72 hours after the first round of transfection, cells were subjected to subsequent Western blotting, immunostaining, or Flow Cytometry analysis.

The following siRNA sequences were used in this study at indicated concentration:

TSG101 (50nM): 5'-CCUCCAGUCUUAUCUCGUC-dTdT-3' (Skowyra et al., 2018)

ALIX (50nM): 5'-CCUGGAUAAUGAUGAAGGATT-dTdT-3' (Skowyra et al., 2018)

VPS22 (50nM): 5'-CUUGCAGAGGCCAAGUAUA-dTdT-3' (Christ et al., 2016)

HRS (50nM): 5'-CGACAAGAACCCACACGU-dTdT-3' (Bache et al., 2003)

CHMP4A (100nM): 5'-GGCACAAACUGACGGGACA-dTdT-3' (Mamińska et al., 2016)

CHMP4B (100nM): 5'-CGAUAAAGUUGAUGAGUUA-dTdT-3' (Mejlvang et al., 2018)

ON-TARGETplus Non-targeting Pool (50nM, Dharmacon ${ }^{\mathrm{TM}}$ ): 5'-

UGGUUUACAUGUCGACUAA-3', 5'-UGGUUUACAUGUUGUGUGA-3', 5'-

UGGUUUACAUGUUUUUCUGA-3', 5'-UGGUUUACAUGUUUUCCUA-3'.

\section{Generation of Lentiviral stable cell lines}


Stable cell lines were generated as described in Abu-Remaileh et al. 2017 with some modifications (Abu-Remaileh et al., 2017). HEK293T cells were transfected with transfer plasmid, psPAX2 (Addgene 12260), and pMD2.G (Addgene 12259) at 3.5:3.5:1 ratio using Lipofectamine 2000 according to manufacturer's instruction. Three days after transfection, the virus-containing supernatant was collected using a $5 \mathrm{ml}$ syringe and applied through a $0.45 \mu \mathrm{m}$ filter. To generate stable cell lines, HEK293 or HeLa cells were seeded in $3.5 \mathrm{~cm}$ dishes and infected with the infectious media (DMEM containing $10 \%$ super calf serum, $10 \mu \mathrm{g} / \mathrm{ml}$ polybrene, $\mathrm{MOI}$ between 0.3 to 0.4 ). For puromycin selection, the media was refreshed with DMEM containing $10 \%$ super calf serum and 1 $\mu \mathrm{g} / \mathrm{ml}$ puromycin. The selection lasted for at least 7 days before subsequent analysis. For mCherry selection cells (pHAGE2-GFP-RNF152-IRES-mCherry), the media was refreshed with DMEM containing $10 \%$ super calf serum. Three days after infection, cells with proportional GFP vs. mCherry expression were enriched by FACS. Sorting was repeated 7 days after the first round of FACS.

\section{Generation of CRISPR-Cas9 KO cell lines}

ATG5 and ATG7 knockout HEK293 cells were generated as described (Ran et al., 2013). The sgRNA guides for ATG5 and ATG7 CRISPR-Cas9 knockout were described in An et al., 2019: 5'-GATCACAAGCAACTCTGGAT-3' for ATG5, and 5'ATCCAAGGCACTACTAAAAG-3' for ATG7 (An et al., 2019). In brief, sgRNA guides were ligated into pspCas9(BB)-2A-Puro (Addgene, 48139) plasmid. HEK293 cells were transfected with CRISPR-Cas9 knockout plasmids using Lipofectamine 2000 according to the manufacturer's instruction. After 24 hours of transfection, cells were treated with $1 \mu \mathrm{g} / \mathrm{ml}$ puromycin (Invitrogen) for 72 hours. Single cells were isolated into 96-well plates 
using limited dilution to a final concentration of 0.5 cell per well. The knockout colonies were screened by Western blot analysis using antibodies against ATG5 and/or ATG7. The $\mathrm{KO}$ cell lines were further verified by sequencing analysis to confirm the indels at target sites.

\section{Yeast strains, plasmids, media, and growth conditions}

All yeast strains and plasmids used in this study are listed in Table S3. Difco Yeast Nitrogen Base (YNB) w/o amino acids were purchased from Millipore-Sigma. Yeast strains were grown in YNB at $26^{\circ} \mathrm{C}$ before further analysis.

\section{Mammalian sample preparation and Western blotting}

Cells were collected in ice-cold 1XPBS, pelleted at 800xg for 1 minute, and lysed in lysis buffer (20mM Tris $\mathrm{pH}=8.0,150 \mathrm{mM} \mathrm{NaCl}, 1 \%$ Triton) containing 1 Xprotease inhibitor cocktail (Biotool) at $4^{\circ} \mathrm{C}$ for 20 minutes. Cell lysates were centrifuged at 18,000 $\mathrm{g}$ for 15 minutes at $4^{\circ} \mathrm{C}$. The protein concentration of the supernatant was measured by Bradford assay (Bio-rad) and normalized. After adding 2X urea sample buffer (150mM Tris $\mathrm{pH}$ 6.8, 6M Urea, 6\% SDS, 40\% glycerol, 100mM DTT, 0.1\% Bromophenol blue), samples were heated at $65^{\circ} \mathrm{C}$ for 8 minutes. $20 \mu \mathrm{g}$ of each lysate was loaded and separated on $11 \%$ SDS-PAGE gel. Protein samples were transferred to nitrocellulose membrane for Western blot analysis. After incubated with primary and secondary antibodies, membranes were scanned using the Odyssey ${ }^{\circledR} \mathrm{CLx}$ imaging system (LICOR).

The following primary antibodies were used for Western blotting in this study: rabbit anti-GFP (1:3000, TP401, Torrey Pines Biolabs), mouse anti-actin (1:5000, Proteintech), mouse anti-LAMP1 (1:1000, H4A3, DHSB), mouse anti-LAMP2 (1:1000, 
H4B4, DHSB), rabbit anti-CTSD (1:1000, Cell Signaling Technology), mouse anti-PDI (1:2000, BD Biosciences), rabbit anti-Golgin160 (1:1000, Proteintech), mouse-anti-EEA (1:500, G-4, Santa Cruz Biotechnology), rabbit-GAPDH (1:2000, Proteintech), rabbit anti-ATG5 (1:2000, D5FF5U, Cell Signaling Technology), rabbit anti-ATG7 (1:2000, D12B11, Cell Signaling Technology), rabbit anti-FLAG (1:2000, Millipore-Sigma), mouse anti-TSG101 (1:200, C-2, Santa Cruz Biotechnology), mouse anti-ALIX (1:500, 1A12, Santa Cruz Biotechnology), mouse anti-Vps22 (1:500, C-11, Santa Cruz Biotechnology), mouse anti-HRS (1:500, C-7, Santa Cruz Biotechnology), mouse antiHA (1:1000, 16B12, BioLegend), rabbit anti-CHMP4B (1:2000, Proteintech).

The following secondary antibodies were used in this study: goat anti-mouse IRDye ${ }^{\circledR} 680 \mathrm{LT}$, goat anti-mouse IRDye ${ }^{\circledR} 800 \mathrm{CW}$, goat anti-rabbit IRDye ${ }^{\circledR} 680 \mathrm{LT}$, goat anti-rabbit IRDye ${ }^{\circledR} 800 \mathrm{CW}$. All secondary antibodies were purchased from LI-COR Biosciences and used at 1:10,000 dilution.

\section{Yeast sample preparation and Western blotting}

Typically, $7 \mathrm{OD}_{600}$ unit yeast cells were collected for sample preparation at each timepoint. The cells were first resuspended with 10\% ice-cold TCA and incubated on ice for at least $1 \mathrm{hr}$. After washing with $0.1 \%$ TCA, the cell pellets were then resuspended in $70 \mu \mathrm{l} 2 \times$ boiling buffer (150 mM Tris, pH 6.8; 6 M urea; 6\% SDS; $10 \%$ glycerol; 100 mM DTT), lysed by bead beating for 5 minutes, and heat-treated at $65^{\circ} \mathrm{C}$ for another 5 minutes. After the addition of $70 \mu \mathrm{l} 2 \times$ urea sample buffer (50 mM Tris, $\mathrm{pH} 7.5 ; 6 \mathrm{M}$ urea; 10 mM EDTA; 2\% SDS; 100 mM DTT, and 0.1\% bromophenol blue), samples were treated for another round of bead beating and $65^{\circ} \mathrm{C}$ heating for 5 minutes, respectively. After spinning at $13,000 \mathrm{~g}$ for 5 minutes, the supernatant was collected, 
subjected to SDS-PAGE, and transferred to nitrocellulose membranes for Western blotting analysis. One $\mathrm{OD}_{600}$ unit $(20 \mu \mathrm{l})$ of yeast cells was loaded in each lane.

The following primary antibodies were used in this study: mouse anti-Pgk1 (1:5,000, 22C5D8; Invitrogen) and rabbit anti-GFP (1:3000, TP401, Torrey Pines Biolabs).

\section{Immunostaining for mammalian samples}

All incubation processes were performed in dark. Cells grown on 1.5 circular glass coverslips were washed with ice-cold 1XPBS and fixed in cold $100 \%$ methanol for 8 minutes at $-20^{\circ} \mathrm{C}$. The fixed samples were blocked in $3 \%$ BSA (in 1XPBS) for 30 minutes at room temperature followed by incubating with primary and secondary antibodies. The Cell Nucleus was stained using Hoechst (1:8000, Invitrogen).

Coverslips were mounted in Fluoromount- $\mathrm{G}^{\circledR}$ (SouthernBiotech) and cured for at least 24 hours before imaging.

Samples were imaged with either a DeltaVision fluorescence microscope (GE Healthcare Life Science) or a Leica SP8 confocal microscopy. For images taken with the DeltaVision fluorescence microscope, deconvolution was performed with the softWoRx program. Images were further cropped and adjusted using ImageJ (National Institutes of Health).

The following primary antibodies were used for immunostaining in this study: mouse anti-LAMP2 (1:100, H4B4, DHSB), mouse anti-ubiquitin (1:100, FK2, MilliporeSigma). 
The following secondary antibodies were used in this study: FITC goat antimouse (1:100, Jackson ImmunoReseach) and TRITC goat anti-mouse (1:100, Jackson ImmunoResearch).

\section{Yeast Microscopy and image processing}

Yeast cells were collected and washed with MilliQ water once before imaging. The microscopy and imaging processing were performed with a DeltaVision system (GE Healthcare Life Sciences) as described in Yang et al., 2018, and the FITC (excitation, 475/28; emission, 525/48) filter set was used for GFP channel. Image acquisition and deconvolution were performed with the softWoRx program. The images were further cropped or adjusted using ImageJ (National Institutes of Health).

\section{Ubiquitin immunoprecipitation with GFP-Trap ${ }^{\circledR}$ A nanobody}

The HA-Ubiquitin plasmid was transfected into HEK293 cells that either stably express free GFP or GFP-RNF152. Immunoprecipitation was performed 48 hours posttransfection according to the manufacturer's instruction with some modifications. In brief, cells (one $10 \mathrm{~cm}$ dish of near-confluent cells per IP group) were collected in icecold 1 XPBS, pelleted at $1000 \mathrm{~g}$ for 1 minute, and lysed in $300 \mu$ l of lysis buffer $(20 \mathrm{mM}$ Tris $\mathrm{pH}=8.0,150 \mathrm{mM} \mathrm{NaCl}, 1 \%$ Triton) containing $100 \mu \mathrm{M}$ of $\mathrm{N}$-Ethylmaleimide (Millipore-Sigma) and 1 Xprotease inhibitor cocktail (Biotool) at $4^{\circ} \mathrm{C}$ for 20 minutes. Cell lysates were centrifuged at $18,000 \mathrm{~g}$ for 15 minutes at $4^{\circ} \mathrm{C}$. The concentration of the supernatant was measured by Bradford assay (Bio-rad) and normalized. $15 \mu$ l of GFPTrap ${ }^{\circledR} \mathrm{A}$ (pre-equilibrated with lysis buffer, Chromotek) was added to $285 \mu$ l of normalized cell lysate and incubated at $4^{\circ} \mathrm{C}$ for 2 hours with gentle rocking. The resin was then washed once with lysis buffer, three times with stringent washing buffer (8M Urea, 
$1 \%$ SDS in 1XPBS), and once with 1\%SDS in 1XPBS. To elute bound proteins, the resin was incubated with 2X Urea sample buffer (150mM Tris pH 6.8, 6M Urea, 6\% SDS, $40 \%$ glycerol, $100 \mathrm{mM} \mathrm{DTT}, 0.1 \%$ Bromophenol blue) at $65^{\circ} \mathrm{C}$ for 10 minutes. The resulting eluates were analyzed by Western blotting.

\section{Lyso-IP}

LysolP was conducted as described before (Abu-Remaileh et al., 2017) with some modifications. About $2 \times 10^{7}$ cells in a $15 \mathrm{~cm}$ dish were used for each LysolP experiment. Cells were rinsed twice with cold PBS, scraped, and collected with $1 \mathrm{ml}$ KPBS (136 mM KCl, $\left.10 \mathrm{mM} \mathrm{KH}_{2} \mathrm{PO}_{4}, \mathrm{pH}=7.25\right)$. Cells were centrifuged at $1000 \mathrm{~g}$ for 2 minutes at $4^{\circ} \mathrm{C}$. Pelleted cells were resuspended in $1 \mathrm{ml}$ of KPBS with protease inhibitor and homogenized. The homogenate was then centrifuged at $1000 \mathrm{~g}$ for 2 minutes at $4^{\circ} \mathrm{C}$. For input, $40 \mu \mathrm{l}$ of supernatant was taken (about $5 \%$ to the total amount) and mixed with 2X Urea sample buffer (150mM Tris pH 6.8, 6M Urea, 6\% SDS, 40\% glycerol, $100 \mathrm{mM}$ DTT, $0.1 \%$ Bromophenol blue). For IP, $800 \mu \mathrm{l}$ supernatant was incubated with $20 \mu \mathrm{l}$ anti-HA beads (Millipore-Sigma) and rotated for 20 minutes. The beads were washed with KPBS 6 times. To eluate bound lysosomes, the beads were resuspended in $40 \mu \mathrm{l} \mathrm{KPBS}$ and $2 \mathrm{X}$ Urea sample buffer (150mM Tris pH 6.8, 6M Urea, 6\% SDS, 40\% glycerol, $100 \mathrm{mM}$ DTT, $0.1 \%$ Bromophenol blue). Samples were heated at $65^{\circ} \mathrm{C}$ for 10 minutes, followed by Western blot analysis.

\section{Flow Cytometry analysis and FACS}

Cells were washed with 1XPBS and trypsinized until all cells are dissociated from the dishes. Dissociated cells were neutralized with DMEM containing $10 \%$ serum media and pelleted at $300 \mathrm{xg}$ for 3 minutes. Cells were resuspended in ice-cold 1 XPBS and 
analyzed using either an LSR Fortessa (BD Biosciences) or a Ze5 (Bio-rad) flow cytometer. For FACS, cells were sorted using FACSAria III cell sorter (BD Biosciences). Flow cytometry analysis and FACS were performed by technicians from the Flow Cytometry Core at the University of Michigan. The data were analyzed using FlowJo software.

\section{Quantification and statistical analysis}

The band intensity for Western blot was quantified using Image Studio software (LI-COR). Graphs were generated using Prism (GraphPad). Statistical analysis was performed with the Student t-test. Error bars represent the standard deviation.

\begin{tabular}{|l|l|l|}
\hline \multicolumn{2}{|l|}{ Supplemental Table 1: Mammalian cell lines used in this study } \\
\hline Cell lines & Description & reference/source \\
\hline Human HEK293 & CRL-1573 & ATCC \\
\hline Human HEK293T & CRL-3216 & ATCC \\
\hline Human HeLa & CCL-2 & ATCC \\
\hline Human HEK293, GFP- & pHAGE2-EF1 $\alpha$-EGFP- & This study \\
RNF152 & RNF152-IRES-Puro & \\
\hline Human HEK293, GFP- & pHAGE2-EF1 $\alpha$-EGFP- & This study \\
RNF152 $(4 C \rightarrow$ S) & RNF152 $(4 C \rightarrow$ S)-IRES- & \\
& Puro & \\
\hline
\end{tabular}




\begin{tabular}{|c|c|c|}
\hline $\begin{array}{l}\text { Human HEK293, GFP- } \\
\text { RNF152 }(8 K \rightarrow R)\end{array}$ & $\begin{array}{l}\text { pHAGE2-EF1 } \alpha \text {-EGFP- } \\
\text { RNF152 }(8 K \rightarrow R) \text {-IRES- } \\
\text { Puro }\end{array}$ & This study \\
\hline $\begin{array}{l}\text { Human HEK293, ATG5KO, } \\
\text { GFP-RNF152 }\end{array}$ & $\begin{array}{l}\text { ATG5 CRISPR-Cas9 } \\
\text { knockout, pHAGE2-EF1 } \alpha- \\
\text { EGFP-RNF152-IRES-Puro }\end{array}$ & This study \\
\hline $\begin{array}{l}\text { Human HEK293, ATG7KO, } \\
\text { GFP-RNF152 }\end{array}$ & $\begin{array}{l}\text { ATG7 CRISPR-Cas9 } \\
\text { knockout, pHAGE2-EF1 } \alpha- \\
\text { EGFP-RNF152-IRES-Puro }\end{array}$ & This study \\
\hline $\begin{array}{l}\text { Human HEK293, GFP- } \\
\text { RNF152, Ctrl-Lyso }\end{array}$ & $\begin{array}{l}\text { pHAGE2-EF1 } \alpha \text {-EGFP- } \\
\text { RNF152-IRES-mCherry, } \\
\text { pLJC5-TMEM192-2XFLAG- } \\
\text { Puro (Addgene 102929) }\end{array}$ & $\begin{array}{l}\text { This study (Abu- } \\
\text { Remaileh et al. } \\
\text { 2017) }\end{array}$ \\
\hline $\begin{array}{l}\text { Human HEK293, GFP- } \\
\text { RNF152, HA-Lyso }\end{array}$ & $\begin{array}{l}\text { pHAGE2-EF1 } \alpha \text {-EGFP- } \\
\text { RNF152-IRES-mCherry, } \\
\text { pLJC5-TMEM192-3XHA- } \\
\text { Puro (Addgene 102930) }\end{array}$ & $\begin{array}{l}\text { This study (Abu- } \\
\text { Remaileh et al. } \\
\text { 2017) }\end{array}$ \\
\hline $\begin{array}{l}\text { Human HEK293, GFP- } \\
\text { RNF152, HA-Vps4A }\end{array}$ & $\begin{array}{l}\text { pHAGE2-EF1 } \alpha \text {-EGFP- } \\
\text { RNF152-IRES-mCherry, } \\
\text { pCW57.1-HA-Vps4A-Puro }\end{array}$ & This study \\
\hline $\begin{array}{l}\text { Human HEK293, GFP- } \\
\text { RNF152, HA-Vps4A E228Q }\end{array}$ & $\begin{array}{l}\text { pHAGE2-EF1 } \alpha \text {-EGFP- } \\
\text { RNF152-IRES-mCherry, }\end{array}$ & This study \\
\hline
\end{tabular}




\begin{tabular}{|l|l|l|}
\hline & $\begin{array}{l}\text { pCW57.1-HA-Vps4A } \\
\text { (E228Q)-Puro }\end{array}$ & \\
\hline RNFman HEK293, 3XFLAG- & pHAGE2-EF1 $\alpha$-3XFLAG- & This study \\
RNF152-IRES-Puro & \\
RNF152 (QK $\rightarrow$ AA) & pHAGE2-EF1 $\alpha$-3XFLAG- & This study \\
RNF152 (QK $\rightarrow$ AA)-IRES- & \\
\hline Human HeLa, GFP-RNF152 & pHAGE2-EF1 $\alpha$-EGFP- & This study \\
& RNF152-IRES-Puro & \\
\hline
\end{tabular}

\begin{tabular}{|c|c|c|c|}
\hline \multicolumn{4}{|c|}{ Supplemental Table 2: Mammalian plasmids used in this study } \\
\hline Vector & Insert & description & reference/source \\
\hline pEGFP-C1 & RNF152 & $\begin{array}{l}\text { CMV promoter, N- } \\
\text { terminal GFP }\end{array}$ & This study \\
\hline $\begin{array}{l}\text { pBICEP-CMV2- } \\
\text { 3XFLAG }\end{array}$ & RNF152 & $\begin{array}{l}\text { CMV promoter, N- } \\
\text { terminal 3XFLAG }\end{array}$ & This study \\
\hline $\begin{array}{l}\text { pHAGE2-IRES- } \\
\text { Puro }\end{array}$ & EGFP & $\begin{array}{l}\text { EF1 } \alpha \text { promoter, } \\
\text { puromycin selection }\end{array}$ & This study \\
\hline $\begin{array}{l}\text { pHAGE2-IRES- } \\
\text { Puro }\end{array}$ & $\begin{array}{l}\text { EGFP- } \\
\text { RNF152 }\end{array}$ & $\begin{array}{l}\text { EF1 } \alpha \text { promoter, } \\
\text { puromycin selection }\end{array}$ & This study \\
\hline
\end{tabular}




\begin{tabular}{|c|c|c|c|}
\hline $\begin{array}{l}\text { pHAGE2-IRES- } \\
\text { Puro }\end{array}$ & $\begin{array}{l}\text { EGFP- } \\
\text { RNF152 } \\
(4 \mathrm{C} \rightarrow \mathrm{S})\end{array}$ & $\begin{array}{l}\text { EF1 } \alpha \text { promoter, } \\
\text { puromycin selection }\end{array}$ & This study \\
\hline $\begin{array}{l}\text { pHAGE2-IRES- } \\
\text { Puro }\end{array}$ & $\begin{array}{l}\text { EGFP- } \\
\text { RNF152 } \\
(8 \mathrm{~K} \rightarrow \mathrm{R})\end{array}$ & $\begin{array}{l}\text { EF1 } \alpha \text { promoter, } \\
\text { puromycin selection }\end{array}$ & This study \\
\hline $\begin{array}{l}\text { pHAGE2-IRES- } \\
\text { Puro }\end{array}$ & $\begin{array}{l}\text { 3XFLAG- } \\
\text { RNF152 }\end{array}$ & $\begin{array}{l}\text { EF1 } \alpha \text { promoter, } \\
\text { puromycin selection }\end{array}$ & This study \\
\hline $\begin{array}{l}\text { pHAGE2-IRES- } \\
\text { Puro }\end{array}$ & $\begin{array}{l}\text { 3XFLAG- } \\
\text { RNF152 } \\
(\mathrm{QK} \rightarrow \mathrm{AA})\end{array}$ & $\begin{array}{l}\text { EF1 } \alpha \text { promoter, } \\
\text { puromycin selection }\end{array}$ & This study \\
\hline $\begin{array}{l}\text { pHAGE2-IRES- } \\
\text { mCherry }\end{array}$ & $\begin{array}{l}\text { EGFP- } \\
\text { RNF152 }\end{array}$ & $\begin{array}{l}\text { EF1 } \alpha \text { promoter, } \\
\text { mCherry selection }\end{array}$ & This study \\
\hline pEGFP-C1 & Vps4 E228Q & $\begin{array}{l}\text { CMV promoter, N- } \\
\text { terminal GFP }\end{array}$ & $\begin{array}{l}\text { Votteler et al. } \\
2016 \\
\text { Addgene } 80351\end{array}$ \\
\hline pCMV-HA & $\begin{array}{l}\text { HA-Vps4A } \\
\text { E228Q }\end{array}$ & $\begin{array}{l}\text { CMV promoter, N- } \\
\text { terminal HA }\end{array}$ & This study \\
\hline pCW57.1 & $\begin{array}{l}\text { HA-Vps4A } \\
\text { WT }\end{array}$ & Tet-on promoter & This study \\
\hline pCW57.1 & $\begin{array}{l}\text { HA-Vps4A } \\
\text { E228Q }\end{array}$ & Tet-on promoter & This study \\
\hline
\end{tabular}




\begin{tabular}{|c|c|c|c|}
\hline pCMV-HA-Ub & & $\begin{array}{l}\text { CMV promoter, three } \\
\text { repeats of } \mathrm{HA}-\mathrm{Ub}\end{array}$ & This study \\
\hline pLJC5 & $\begin{array}{l}\text { TMEM192- } \\
\text { 2XFLAG }\end{array}$ & UbC promoter & $\begin{array}{l}\text { Abu-Remaileh et } \\
\text { al. } 2017 \\
\text { Addgene } 102929\end{array}$ \\
\hline pLJC5 & $\begin{array}{l}\text { TMEM192- } \\
\text { 3ХHA }\end{array}$ & UbC promoter & $\begin{array}{l}\text { Abu-Remaileh et } \\
\text { al. } 2017 \\
\text { Addgene } 102930\end{array}$ \\
\hline $\begin{array}{l}\text { pSpCas9(BB)-2A- } \\
\text { Puro (PX459) }\end{array}$ & & $\begin{array}{l}\text { CRISPR-Cas9 } \\
\text { knockout }\end{array}$ & $\begin{array}{l}\text { Ran et al. } 2013 \\
\text { Addgene, } 48139\end{array}$ \\
\hline psPAX2 & & $\begin{array}{l}\text { Lentiviral packaging } \\
\text { plasmid }\end{array}$ & Addgene 12260 \\
\hline pMD2.G & & VSV-G envelope & Addgene 12259 \\
\hline \multicolumn{4}{|c|}{ Overexpression plasmids used in the cycloheximide chase screen } \\
\hline pcDNA3-EGFP & CLCN7 & $\begin{array}{l}\text { CMV promoter, C- } \\
\text { terminal GFP }\end{array}$ & $\begin{array}{l}\text { This study. CDS } \\
\text { was purchased } \\
\text { from Origene. }\end{array}$ \\
\hline pCMV6-AC-GFP & OSTM1 & $\begin{array}{l}\text { CMV promoter, C- } \\
\text { terminal turboGFP }\end{array}$ & $\begin{array}{l}\text { This study, } \\
\text { Origene }\end{array}$ \\
\hline pCMV-SPORT6 & p40-EGFP & $\begin{array}{l}\text { CMV promoter, C- } \\
\text { terminal GFP }\end{array}$ & $\begin{array}{l}\text { Gift from Dr. M } \\
\text { Boonen. (Boonen } \\
\text { et al. 2006) }\end{array}$ \\
\hline
\end{tabular}




\begin{tabular}{|c|c|c|c|}
\hline pEGFP-C1 & $\begin{array}{l}\text { hPAT1 } \\
\text { (SLC36A1) }\end{array}$ & $\begin{array}{l}\text { CMV promoter, N- } \\
\text { terminal GFP }\end{array}$ & $\begin{array}{l}\text { This study, CDS } \\
\text { purchased from } \\
\text { Origene } \\
\text { Technologies }\end{array}$ \\
\hline pEGFP-C1 & TMEM192 & $\begin{array}{l}\text { CMV promoter, N- } \\
\text { terminal GFP }\end{array}$ & $\begin{array}{l}\text { Gift from B. } \\
\text { Schröder. } \\
\text { (Schröder et al. } \\
2010 \text { ) }\end{array}$ \\
\hline pEGFP-C2 & TRPML1 & $\begin{array}{l}\text { CMV promoter, N- } \\
\text { terminal GFP }\end{array}$ & Dong et al. 2008. \\
\hline pEGFP-N1 & CTNS & $\begin{array}{l}\text { CMV promoter, C- } \\
\text { terminal GFP }\end{array}$ & $\begin{array}{l}\text { This study, CDS } \\
\text { purchased from } \\
\text { DNASU. }\end{array}$ \\
\hline pEGFP-N1 & hSpinster1 & $\begin{array}{l}\text { CMV promoter, C- } \\
\text { terminal GFP }\end{array}$ & $\begin{array}{l}\text { This study. (Rong } \\
\text { et al. 2011) }\end{array}$ \\
\hline pEGFP-N1 & SCARB2 & $\begin{array}{l}\text { CMV promoter, C- } \\
\text { terminal GFP }\end{array}$ & $\begin{array}{l}\text { This study, CDS } \\
\text { purchased from } \\
\text { DNASU. }\end{array}$ \\
\hline $\begin{array}{l}\text { pReceiver-M03- } \\
\text { EGFP }\end{array}$ & PQLC2 & $\begin{array}{l}\text { CMV promoter, C- } \\
\text { terminal GFP }\end{array}$ & $\begin{array}{l}\text { This study } \\
\text { GeneCopoeia }\end{array}$ \\
\hline $\begin{array}{l}\text { pReceiver-M03- } \\
\text { EGFP }\end{array}$ & TTYH2 & $\begin{array}{l}\text { CMV promoter, C- } \\
\text { terminal GFP }\end{array}$ & $\begin{array}{l}\text { This study } \\
\text { GeneCopoeia }\end{array}$ \\
\hline
\end{tabular}




\begin{tabular}{|c|c|c|c|}
\hline $\begin{array}{l}\text { pReceiver-M03- } \\
\text { EGFP }\end{array}$ & TTYH3 & $\begin{array}{l}\text { CMV promoter, C- } \\
\text { terminal GFP }\end{array}$ & $\begin{array}{l}\text { This study } \\
\text { GeneCopoeia }\end{array}$ \\
\hline $\begin{array}{l}\text { pReceiver-M29- } \\
\text { EGFP }\end{array}$ & C9orf91 & $\begin{array}{l}\text { CMV promoter, N- } \\
\text { terminal GFP }\end{array}$ & $\begin{array}{l}\text { This study } \\
\text { GeneCopoeia }\end{array}$ \\
\hline $\begin{array}{l}\text { pReceiver-M29- } \\
\text { EGFP }\end{array}$ & ITM2C & $\begin{array}{l}\text { CMV promoter, N- } \\
\text { terminal GFP }\end{array}$ & $\begin{array}{l}\text { This study } \\
\text { GeneCopoeia }\end{array}$ \\
\hline $\begin{array}{l}\text { pReceiver-M29- } \\
\text { EGFP }\end{array}$ & MFSD8 & $\begin{array}{l}\text { CMV promoter, N- } \\
\text { terminal GFP }\end{array}$ & $\begin{array}{l}\text { This study } \\
\text { GeneCopoeia }\end{array}$ \\
\hline $\begin{array}{l}\text { pReceiver-M29- } \\
\text { EGFP }\end{array}$ & OCA2 & $\begin{array}{l}\text { CMV promoter, N- } \\
\text { terminal GFP }\end{array}$ & $\begin{array}{l}\text { This study } \\
\text { GeneCopoeia }\end{array}$ \\
\hline $\begin{array}{l}\text { pReceiver-M29- } \\
\text { EGFP }\end{array}$ & SLC38A7 & $\begin{array}{l}\text { CMV promoter, N- } \\
\text { terminal GFP }\end{array}$ & $\begin{array}{l}\text { This study } \\
\text { GeneCopoeia }\end{array}$ \\
\hline $\begin{array}{l}\text { pReceiver-M29- } \\
\text { EGFP }\end{array}$ & STARD3 & $\begin{array}{l}\text { CMV promoter, N- } \\
\text { terminal GFP }\end{array}$ & $\begin{array}{l}\text { This study } \\
\text { GeneCopoeia }\end{array}$ \\
\hline $\begin{array}{l}\text { pReceiver-M29- } \\
\text { EGFP }\end{array}$ & TMEM106B & $\begin{array}{l}\text { CMV promoter, N- } \\
\text { terminal GFP }\end{array}$ & $\begin{array}{l}\text { This study } \\
\text { GeneCopoeia }\end{array}$ \\
\hline $\begin{array}{l}\text { pReceiver-M29- } \\
\text { EGFP }\end{array}$ & TMEM127 & $\begin{array}{l}\text { CMV promoter, N- } \\
\text { terminal GFP }\end{array}$ & $\begin{array}{l}\text { This study } \\
\text { GeneCopoeia }\end{array}$ \\
\hline $\begin{array}{l}\text { pReceiver-M29- } \\
\text { EGFP }\end{array}$ & TMEM175 & $\begin{array}{l}\text { CMV promoter, N- } \\
\text { terminal GFP }\end{array}$ & $\begin{array}{l}\text { This study } \\
\text { GeneCopoeia }\end{array}$ \\
\hline $\begin{array}{l}\text { pReceiver-M55- } \\
\text { mCherry }\end{array}$ & LAPTM5 & $\begin{array}{l}\text { CMV promoter, N- } \\
\text { terminal mCherry }\end{array}$ & $\begin{array}{l}\text { This study } \\
\text { GeneCopoeia }\end{array}$ \\
\hline
\end{tabular}




\begin{tabular}{|l|l|l|l|}
\hline pReceiver-M55- & TMEM55B & CMV promoter, N- & This study \\
mCherry & terminal mCherry & GeneCopoeia \\
mCheceiver-M56- & LAPTM4A & CMV promoter, C- & This study \\
pReceiver-M56- & SLC7A14 & CMV promoter, C- & This study \\
mCherry & & terminal mCherry & GeneCopoeia \\
\hline
\end{tabular}

\section{Supplemental Table 3: Yeast strains and Plasmids used in this study}

S. cerevisiae strains

\begin{tabular}{|c|c|c|c|}
\hline strain & name & genotype & reference/source \\
\hline SEY6210 & wild type & $\begin{array}{l}\text { Mata, leu1-3, } 112 \text { ura3-52 } \\
\text { his3-200, trp1-901 lys2-801 } \\
\text { suc2-D9 }\end{array}$ & $\begin{array}{l}\text { Robinson et al., } \\
1988\end{array}$ \\
\hline SEY6210.1 & wild type & $\begin{array}{l}\text { Mata, leu1-3, } 112 \text { ura3-52 } \\
\text { his3-200, trp1-901 lys2-801 } \\
\text { suc2-D9 }\end{array}$ & $\begin{array}{l}\text { Robinson et al., } \\
1988\end{array}$ \\
\hline YXY813 & pep4s & 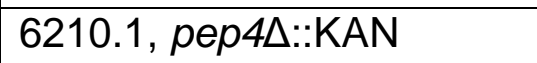 & This study \\
\hline YML377 & vps27A & 6210, vps27A::HIS3 & Li et al., 2015 \\
\hline YML068 & vps4 $\Delta$ & 6210.1, vps4A::TRP1 & Li et al., 2015 \\
\hline YXY624 & vps23 & 6210.1, vps23A::TRP1 & This study \\
\hline YXY1031 & vps22 & 6210, vps22 $::$ KAN & This study \\
\hline YXY625 & snf7 & 6210.1, snf7A::TRP1 & This study \\
\hline YXY1030 & bro1s & 6210, bro1 ::KAN & This study \\
\hline
\end{tabular}




\begin{tabular}{|l|l|l|l|}
\hline \multicolumn{2}{|l|}{ S. cerevisiae expression plasmids } & reference/source \\
\hline vector & Insert & description & \\
\hline pRS415 & GFP-RNF152 & ADH1 promoter, N-terminal & This study \\
& & GFP & \\
\hline
\end{tabular}

Reference:

Abu-Remaileh M, Wyant GA, Kim C, et al. Lysosomal metabolomics reveals VATPase- and mTOR-dependent regulation of amino acid efflux from lysosomes. Science. 2017;358(6364):807-813. doi:10.1126/science.aan6298

An H, Ordureau A, Paulo JA, Shoemaker CJ, Denic V, Harper JW. TEX264 Is an Endoplasmic Reticulum-Resident ATG8-Interacting Protein Critical for ER Remodeling during Nutrient Stress. Mol Cell. 2019;74(5):891-908.e10.

doi:10.1016/j.molcel.2019.03.034

Bache KG, Brech A, Mehlum A, Stenmark H. Hrs regulates multivesicular body formation via ESCRT recruitment to endosomes. J Cell Biol. 2003;162(3):435-442. doi:10.1083/jcb.200302131

Boonen M, Hamer I, Boussac M, et al. Intracellular localization of p40, a protein identified in a preparation of lysosomal membranes. Biochem J. 2006;395(1):39-47. doi:10.1042/BJ20051647

Christ L, Wenzel EM, LiestøI K, Raiborg C, Campsteijn C, Stenmark H. ALIX and ESCRT-I/II function as parallel ESCRT-III recruiters in cytokinetic abscission. J Cell Biol. 2016;212(5):499-513. doi:10.1083/jcb.201507009

Li M, Rong Y, Chuang YS, Peng D, Emr SD. Ubiquitin-dependent lysosomal membrane protein sorting and degradation. Mol Cell. 2015(a);57(3):467-478. doi:10.1016/j.molcel.2014.12.012

Mamińska A, Bartosik A, Banach-Orłowska M, et al. ESCRT proteins restrict constitutive NF-kB signaling by trafficking cytokine receptors. Sci Signal. 2016;9(411):ra8. Published 2016 Jan 19. doi:10.1126/scisignal.aad0848

Mejlvang J, Olsvik H, Svenning S, et al. Starvation induces rapid degradation of selective autophagy receptors by endosomal microautophagy. J Cell Biol. 2018;217(10):3640-3655. doi:10.1083/jcb.201711002

Ran FA, Hsu PD, Wright J, Agarwala V, Scott DA, Zhang F. Genome engineering using the CRISPR-Cas9 system. Nat Protoc. 2013;8(11):2281-2308.

doi:10.1038/nprot.2013.143

Robinson JS, Klionsky DJ, Banta LM, Emr SD. Protein sorting in Saccharomyces cerevisiae: isolation of mutants defective in the delivery and processing of multiple vacuolar hydrolases. Mol Cell Biol. 1988;8(11):4936-4948. doi:10.1128/mcb.8.11.4936

Rong Y, McPhee CK, Deng S, et al. Spinster is required for autophagic lysosome reformation and $\mathrm{mTOR}$ reactivation following starvation [published correction appears in Proc Natl Acad Sci U S A. 2011 Jul 5;108(27):11297. McPhee, Christina [corrected to McPhee, Christina K]; Baehreck, Eric H [corrected to Baehrecke, Eric H]]. Proc Natl Acad Sci U S A. 2011;108(19):7826-7831. doi:10.1073/pnas.1013800108 
Schröder B, Wrocklage C, Hasilik A, Saftig P. Molecular characterisation of 'transmembrane protein 192' (TMEM192), a novel protein of the lysosomal membrane. Biol Chem. 2010;391(6):695-704. doi:10.1515/BC.2010.062

Skowyra ML, Schlesinger PH, Naismith TV, Hanson PI. Triggered recruitment of ESCRT machinery promotes endolysosomal repair. Science.

2018;360(6384):eaar5078. doi:10.1126/science.aar5078

Votteler J, Ogohara C, Yi S, et al. Designed proteins induce the formation of nanocage-containing extracellular vesicles. Nature. 2016;540(7632):292-295.

doi:10.1038/nature20607 
Figure 1

A

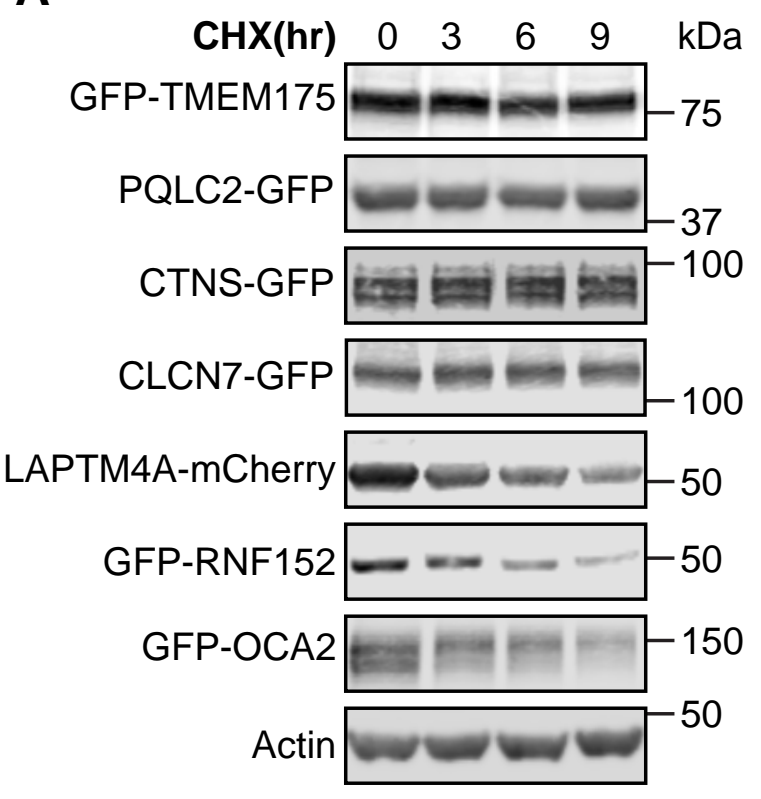

B

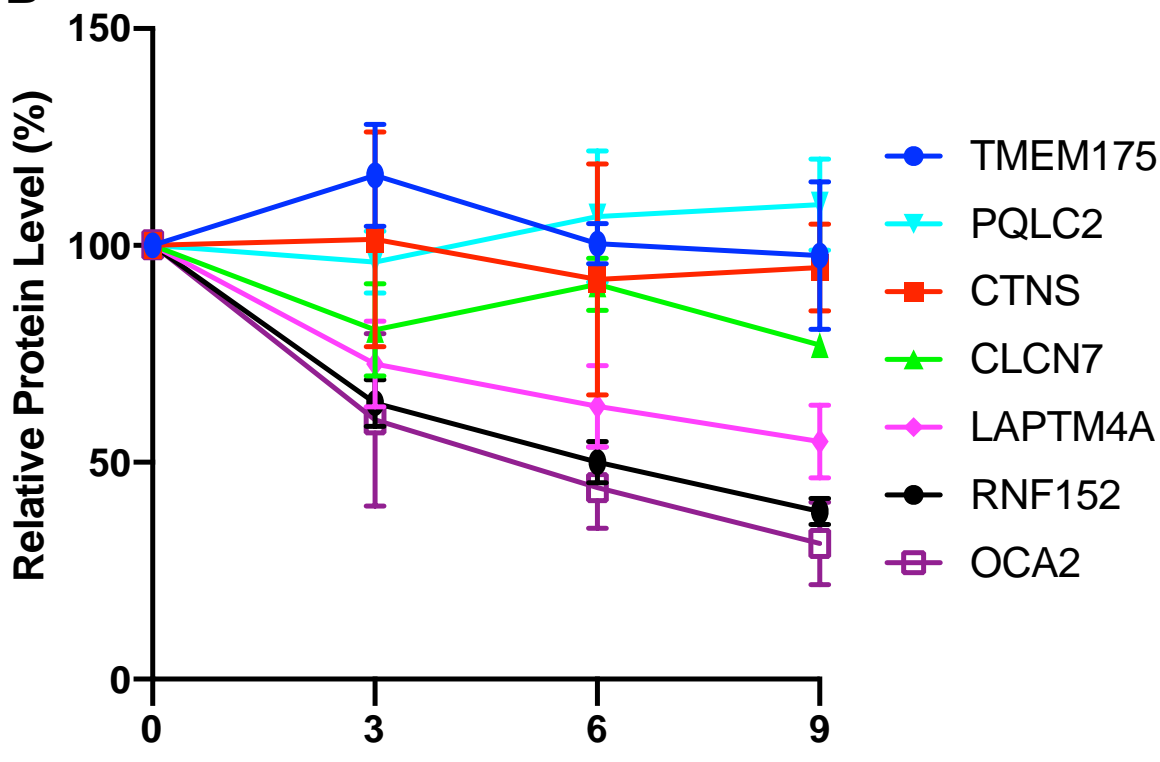

CHX Treatment (hr)

C

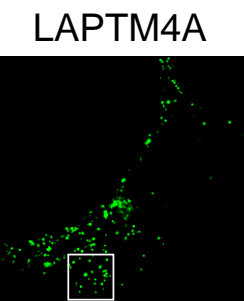

LAMP2

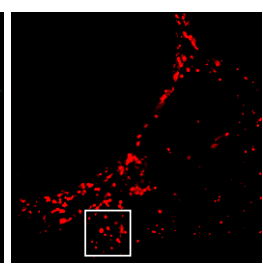

Merge
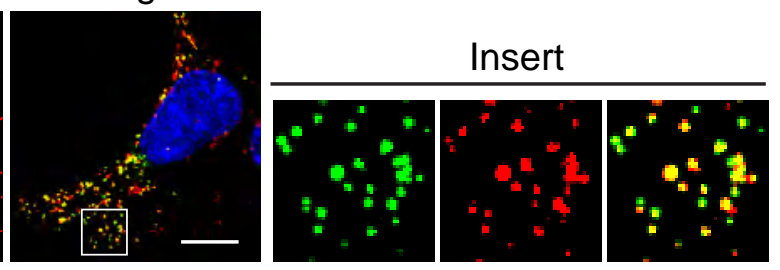

RNF152

LAMP2
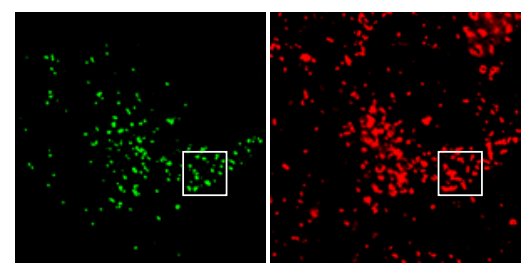

Merge
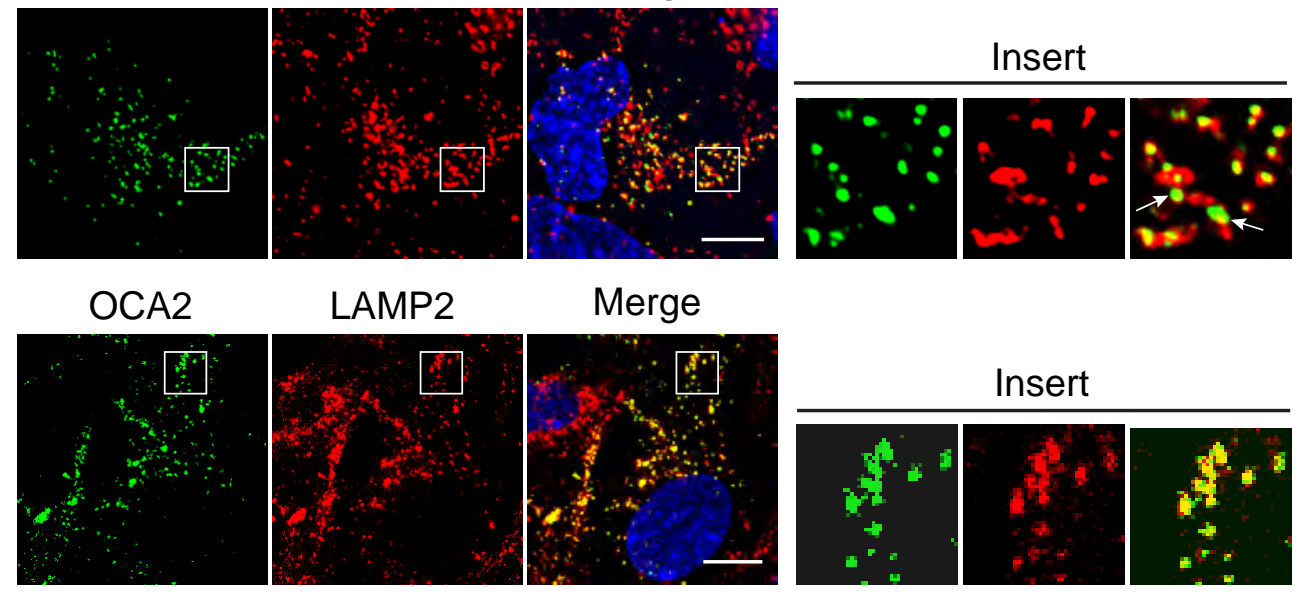

LAMP2

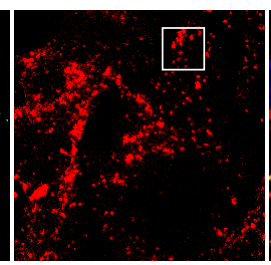

\begin{abstract}
Merge
\end{abstract}
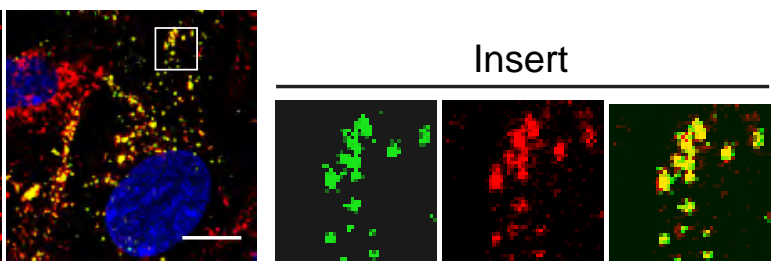
bioRxiv preprint doi: https://doi.org/10.1101/2020.11.18.389296; this version posted November 20, 2020. The copyright holder for this preprint

(which was not certified by peer review) is the author/funder, who has granted bioRxiv a license to display the preprint in perpetuity. It is made

A availabeytosor CC $^{-B Y}$-NC-ND 4.0 International license-minal

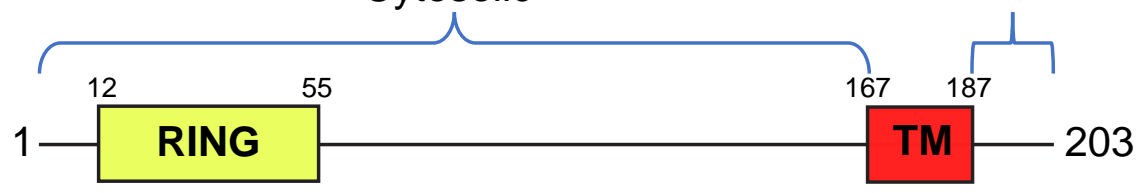

B

HeLa, GFP-RNF152

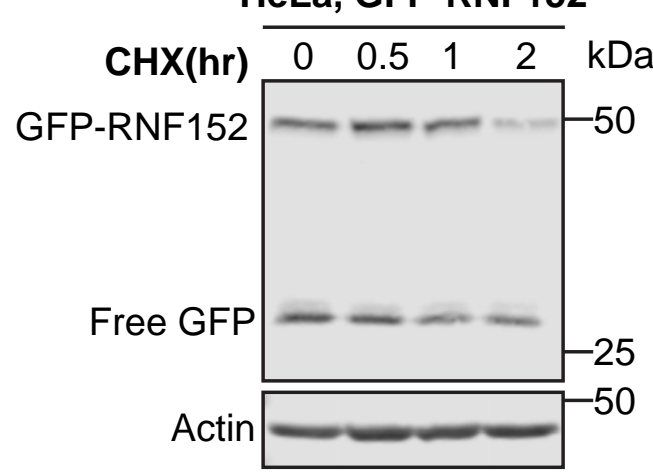

C

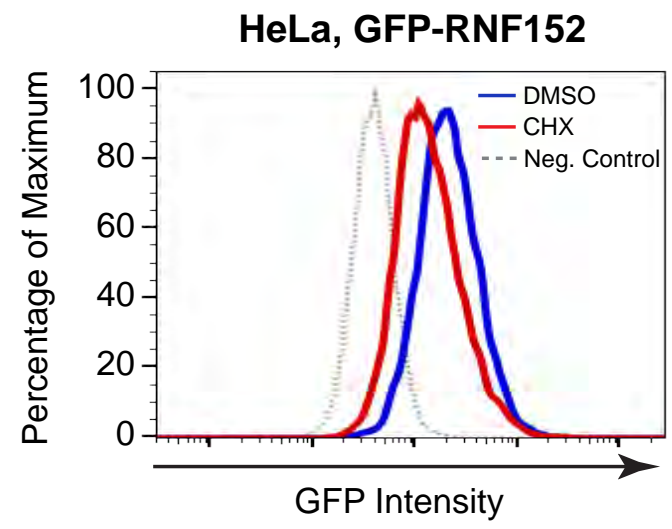

E

HEK293, GFP-RNF152

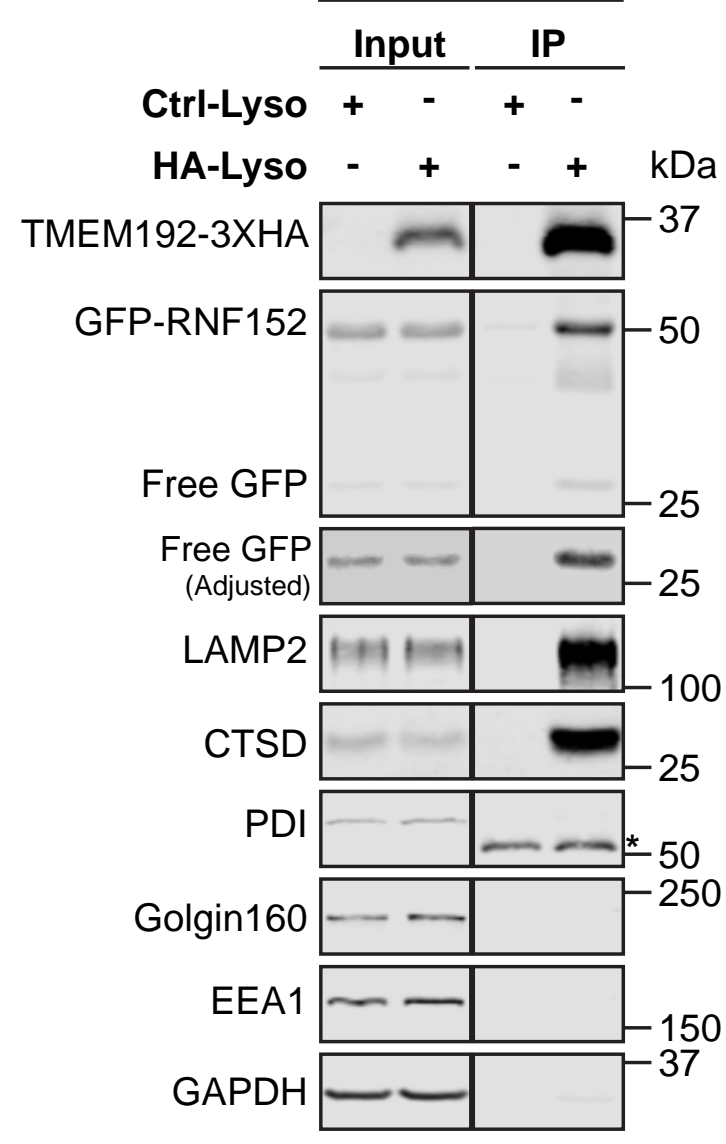

Figure 2

D

HEK293, 3XFLAG-RNF152

$\begin{array}{llllll}\mathbf{C H X}(\mathrm{hr}) & 0 & 0.5 & 1 & 2 & \mathrm{kDa}\end{array}$

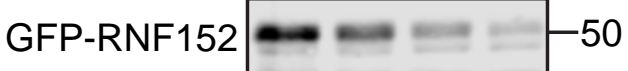

3XFLAG-RNF152 $\begin{array}{lllll}\mathrm{CHX}(\mathrm{hr}) & 0 & 1 & 2 & \mathrm{kDa}\end{array}$

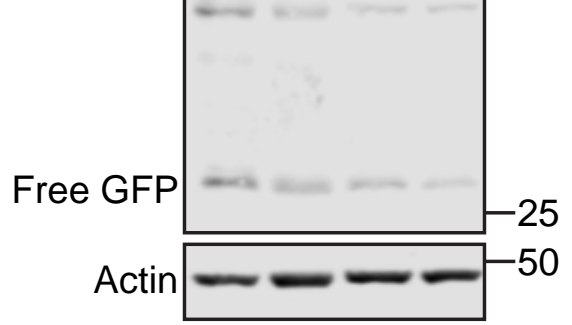

Actin

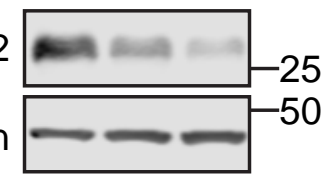

F

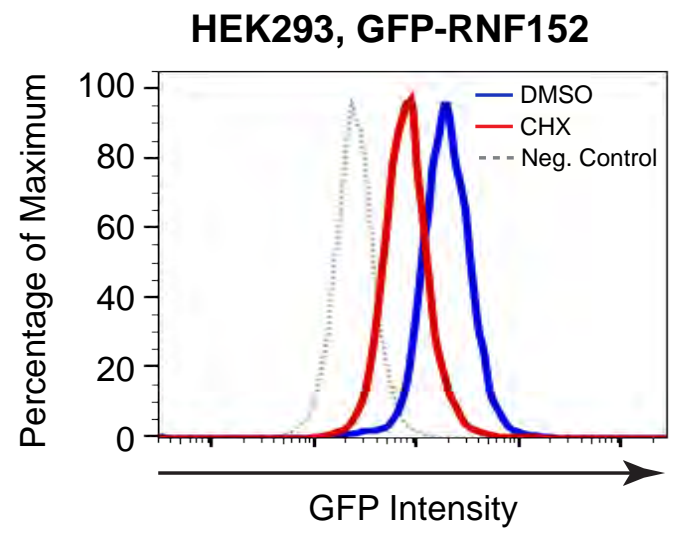

HEK293, GFP-RNF152
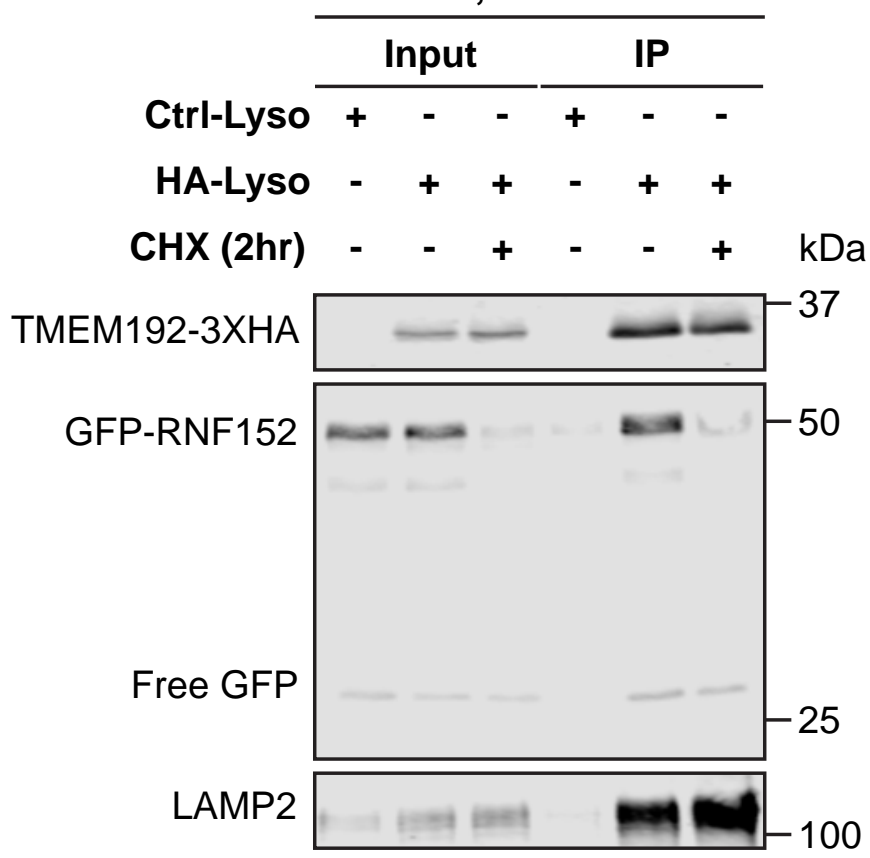
Figure 3

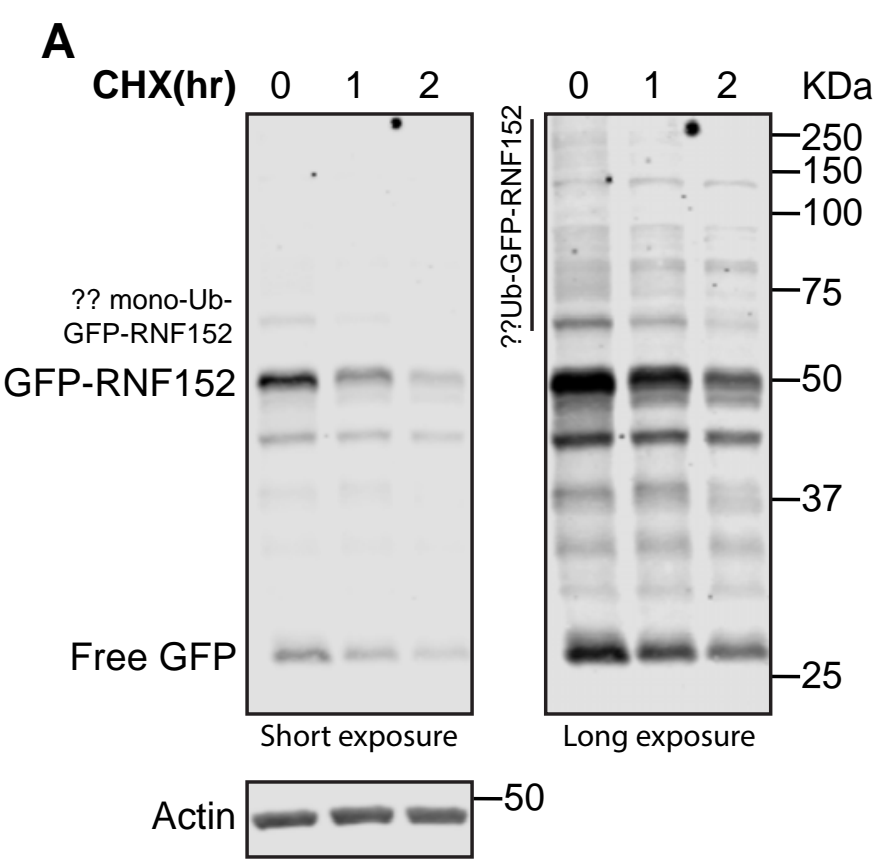

B

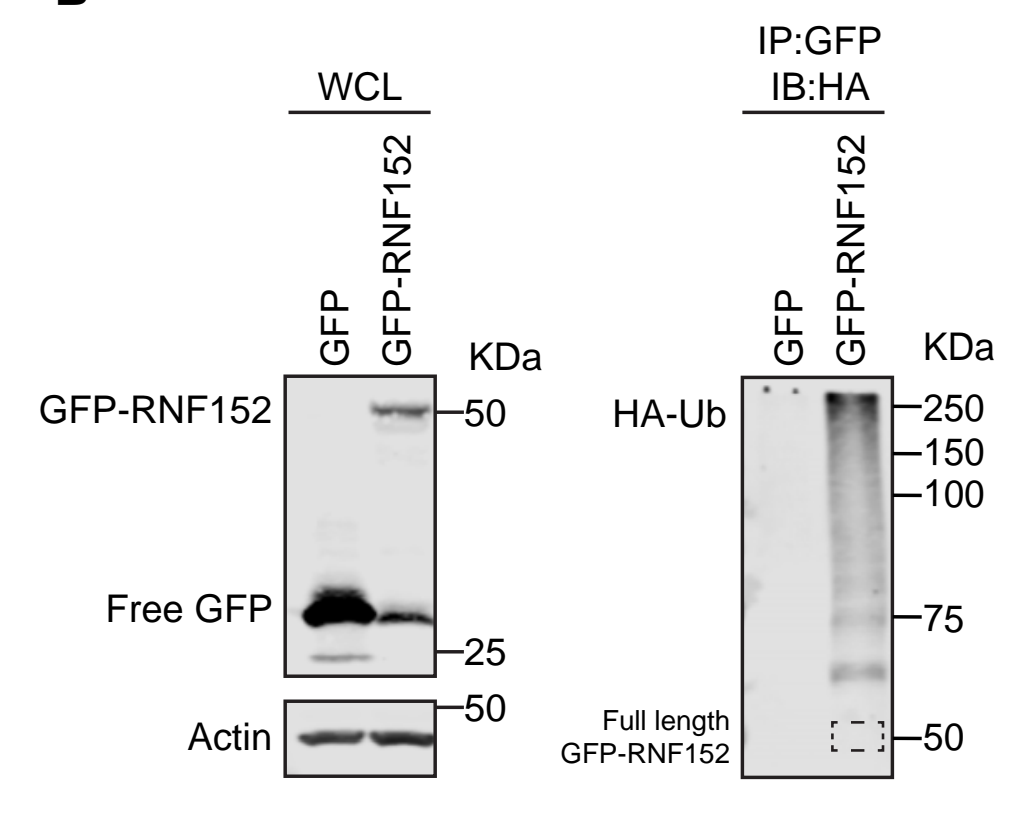

C

D
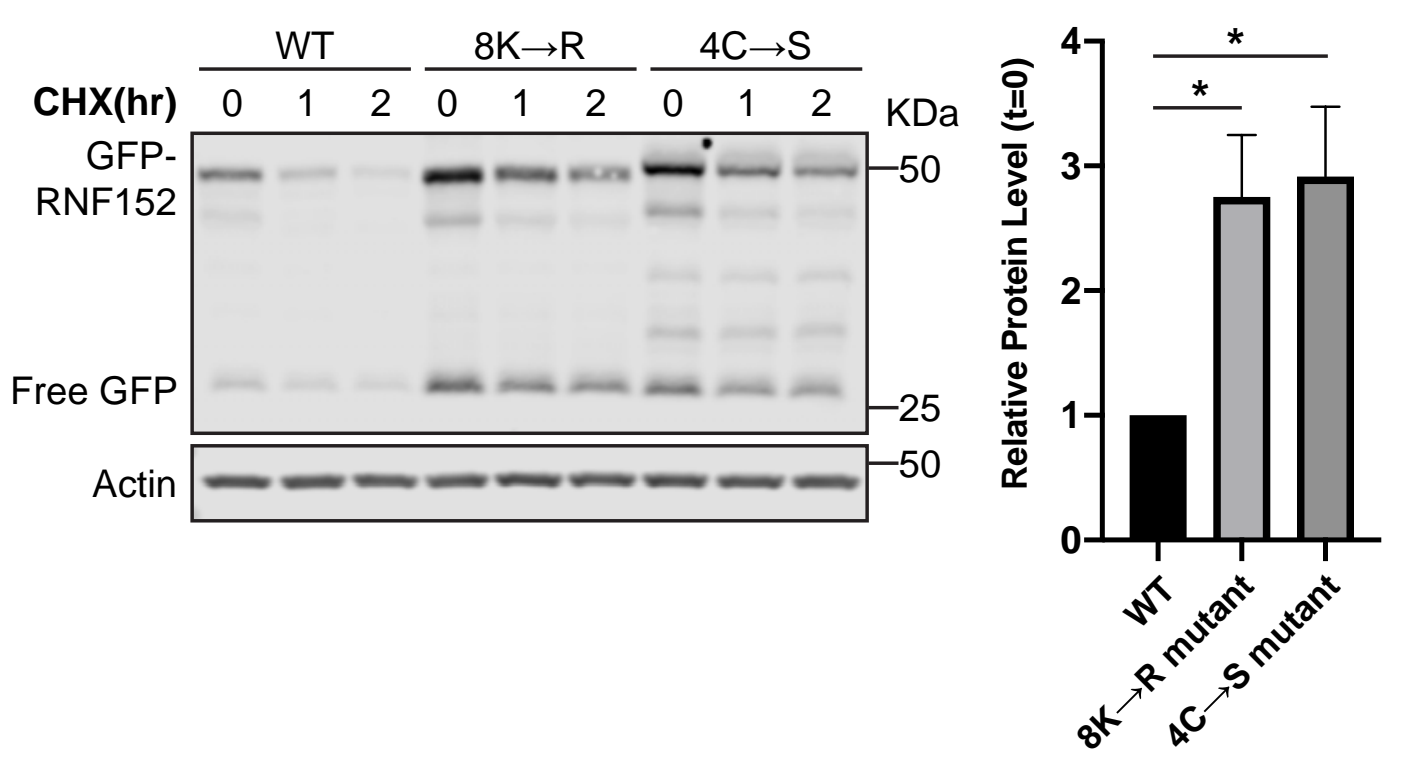

E

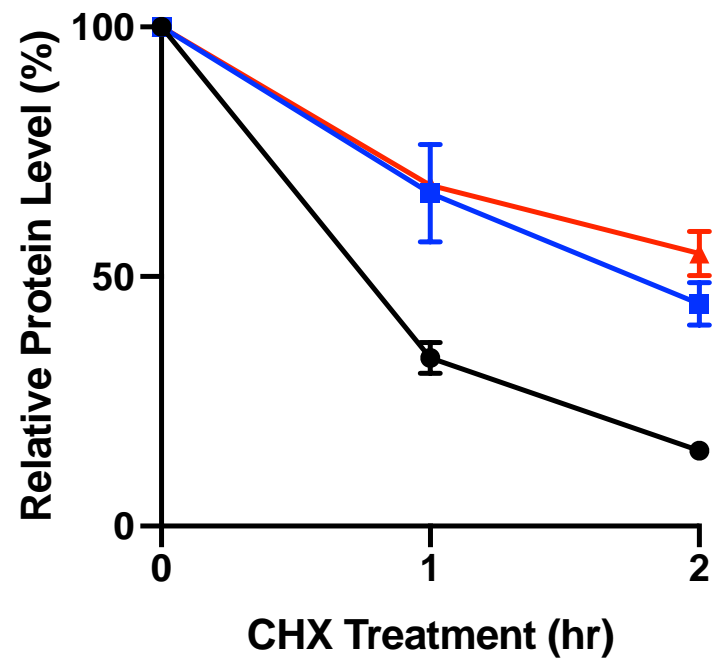

$\rightarrow$ WT $\rightarrow$ 8K->R mutant $\leftarrow$ 4C->S mutant 
bioRxiv preprint doi: https://doi.org/10.1101/2020.11.18.389296; this version posted November 20, 2020. The copyright holder for this preprint

(which was not certified by peer review) is the author/funder, who has granted bioRxiv a license to display the preprint in perpetuity. It is made

A available under aCC-BY-NC-ND 4.0 International license.
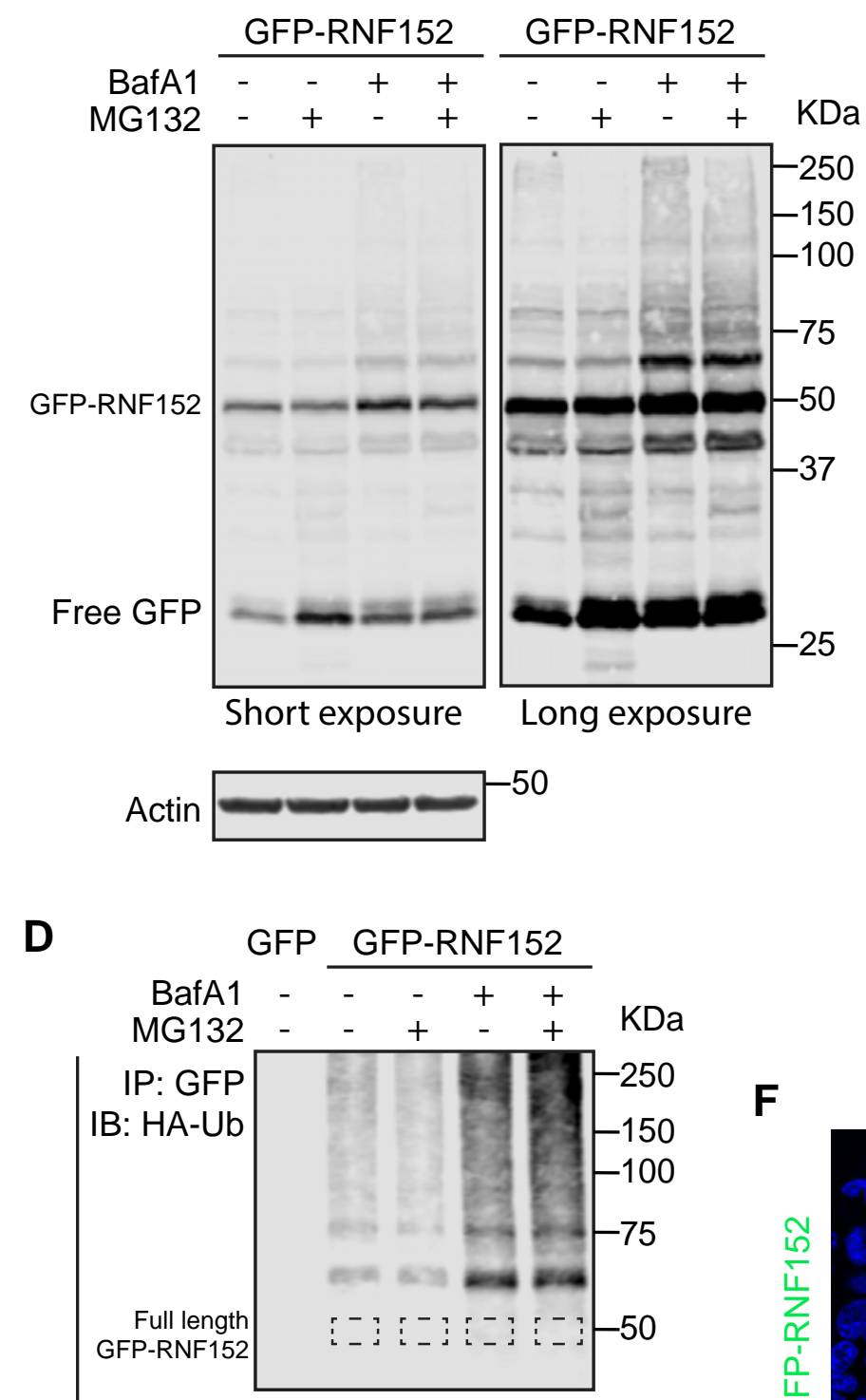

IP

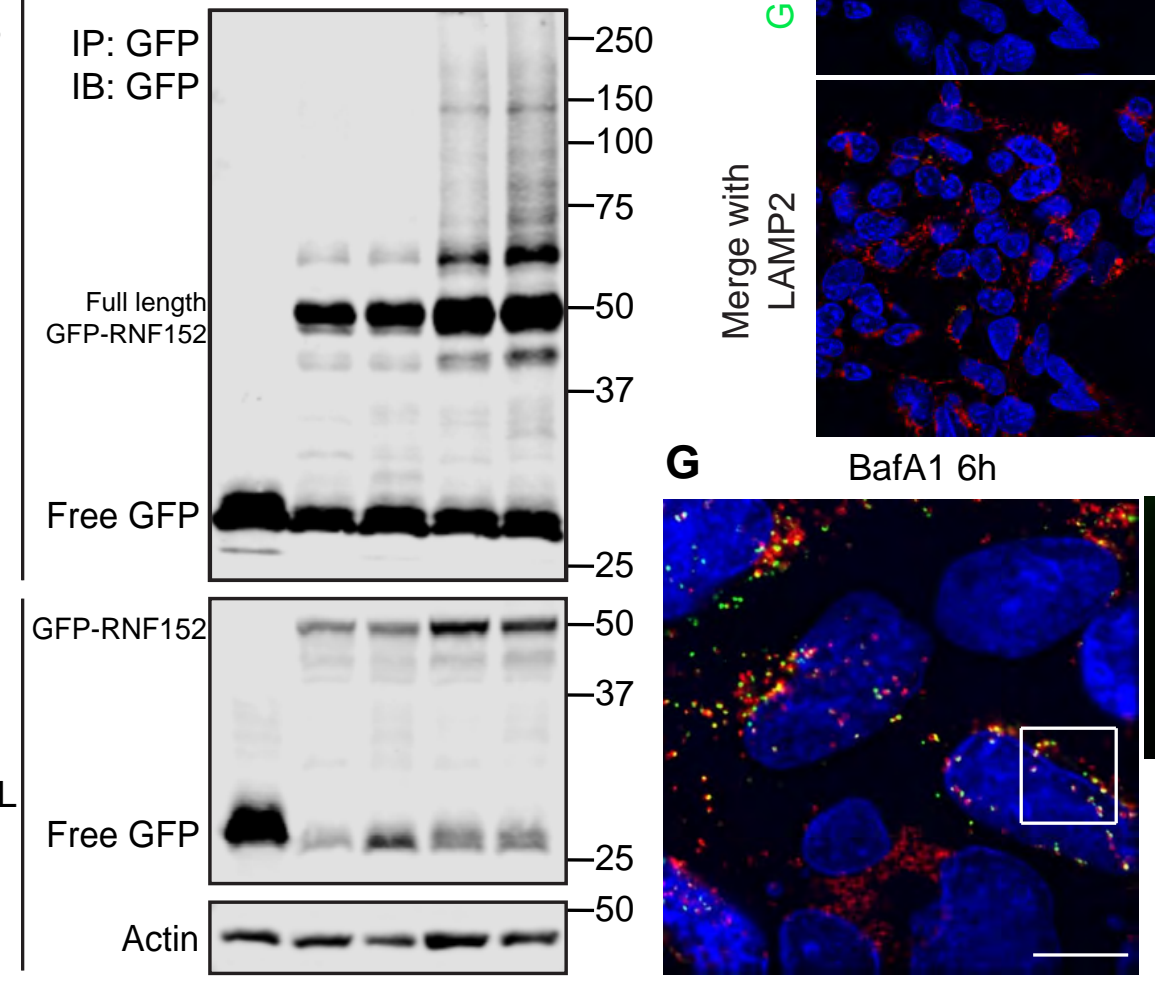

C
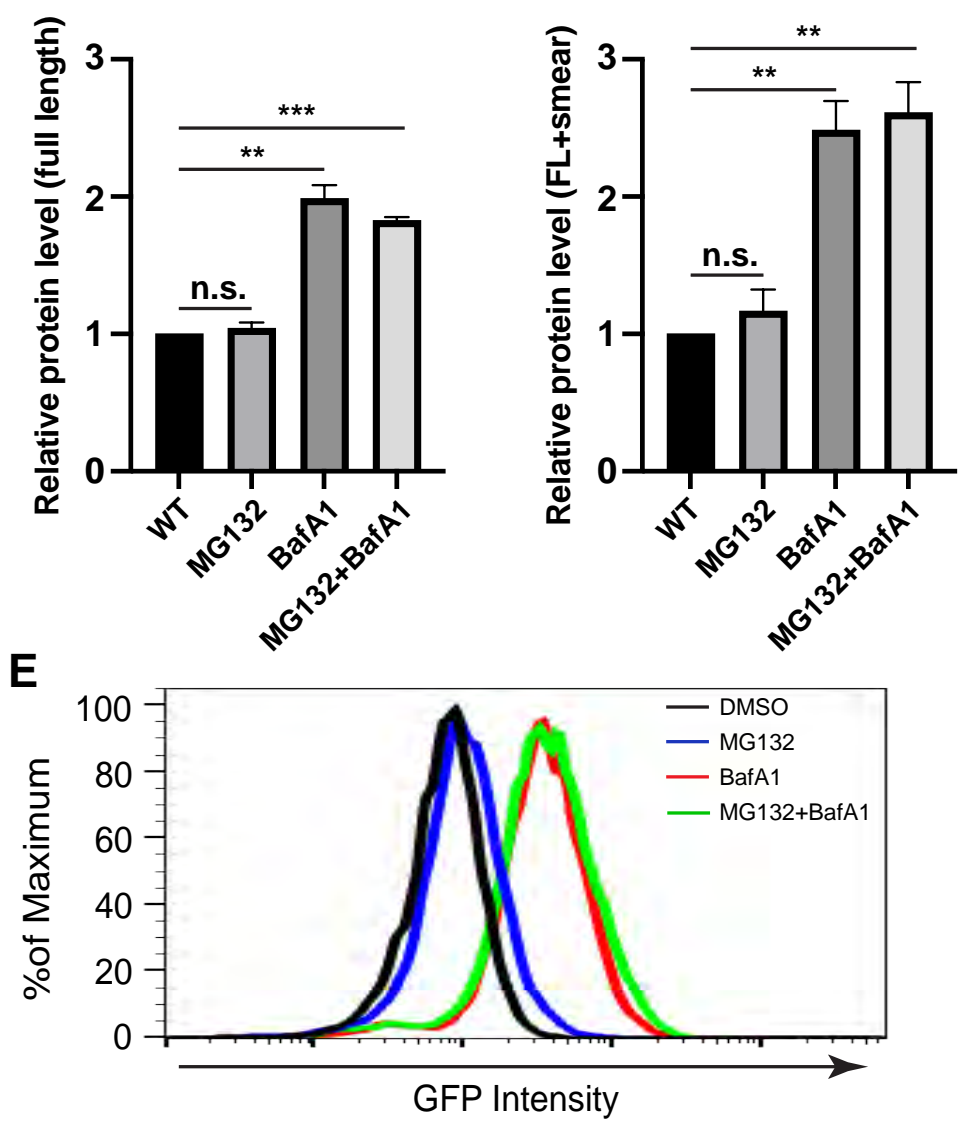

F $\quad$ DMSO $6 \mathrm{~h}$

MG132 6h

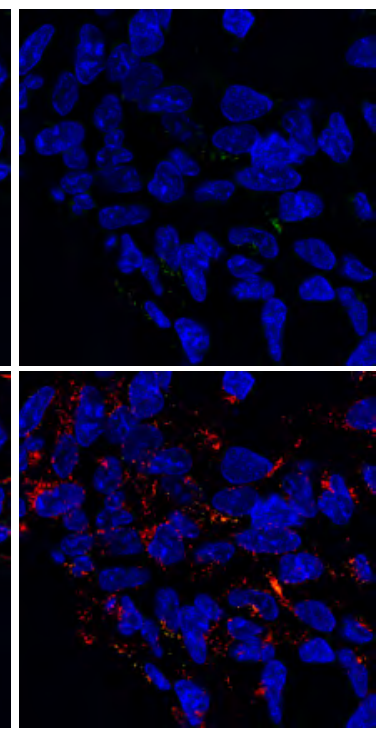

BafA1 6h

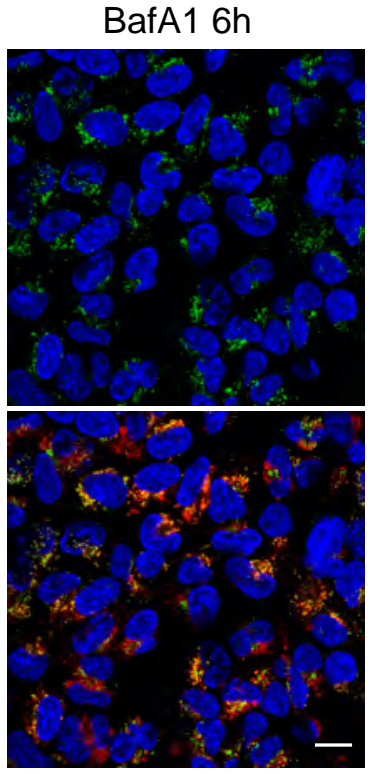

GFP-RNF152
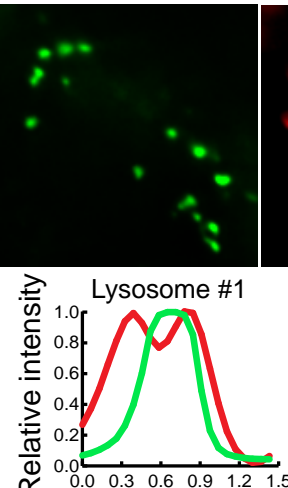

LAMP2

Merge
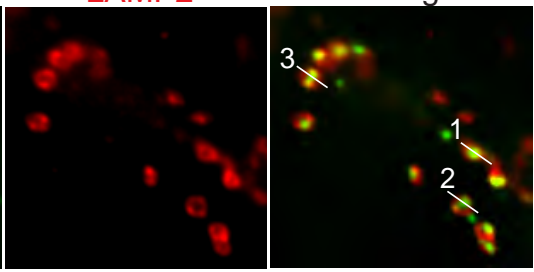

Lysosome \#2

Lysosome \#3
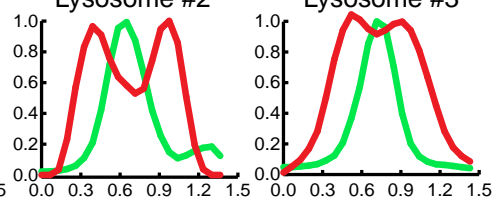

Distance $(\mu \mathrm{m})$ 
bioRxiv preprint doi: https://doi.org/10.1101/2020.11.18.389296; this version posted November 20, 2020. The copyright holder for this preprint (which was not certified by peer review) is the author/funder, who has granted bioRxiv a license to display the preprint in perpetuity. It is made available under aCC-BY-NC-ND 4.0 International license.

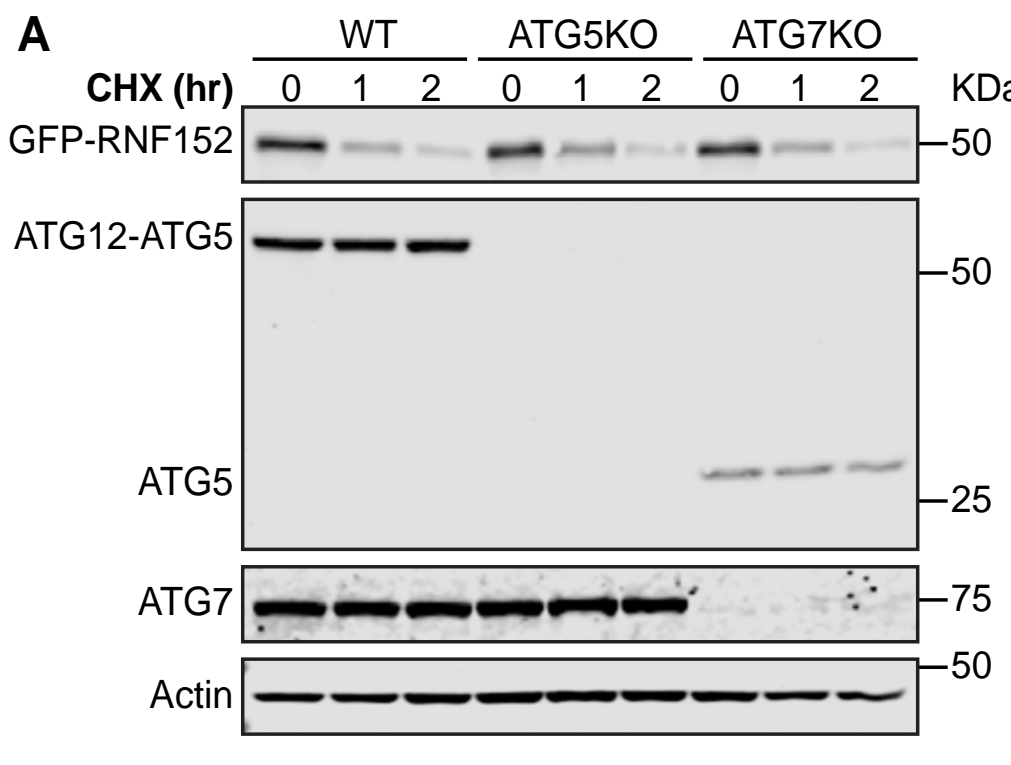
B

Figure 5

C

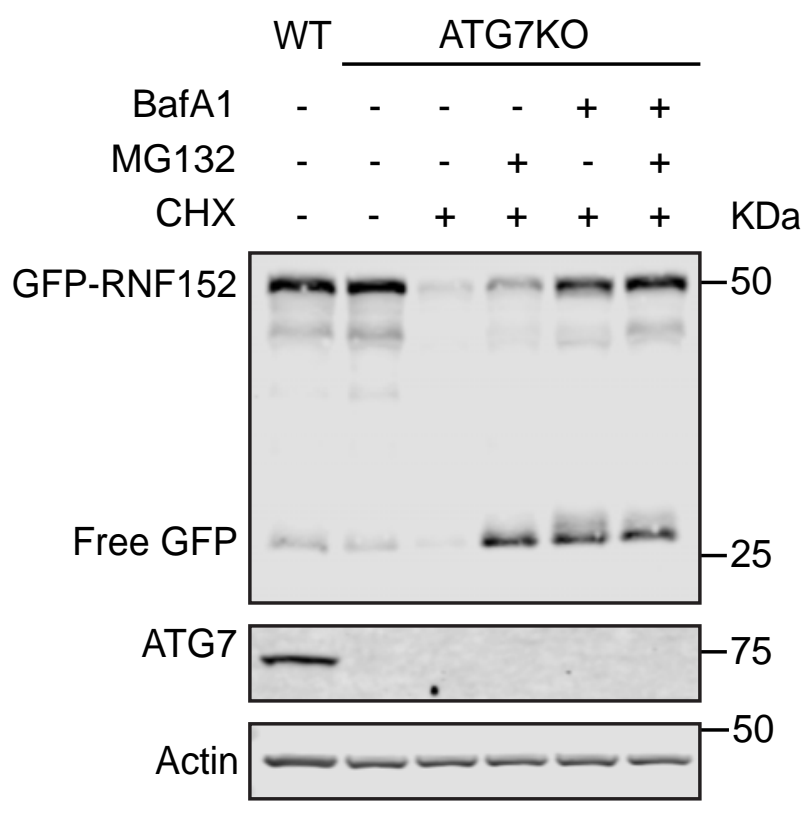

$\mathbf{E}$

Canonical CMA motif: KFERQ

RNF152: ${ }^{40}$ QMRTSQKDVR CPWCRGVTKL ${ }^{70}$

$\mathbf{F}$

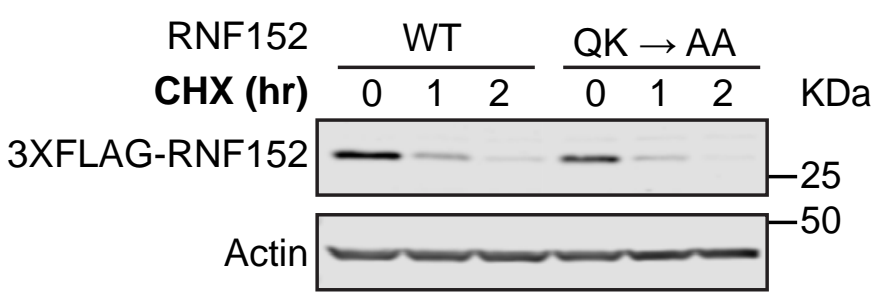

G

D
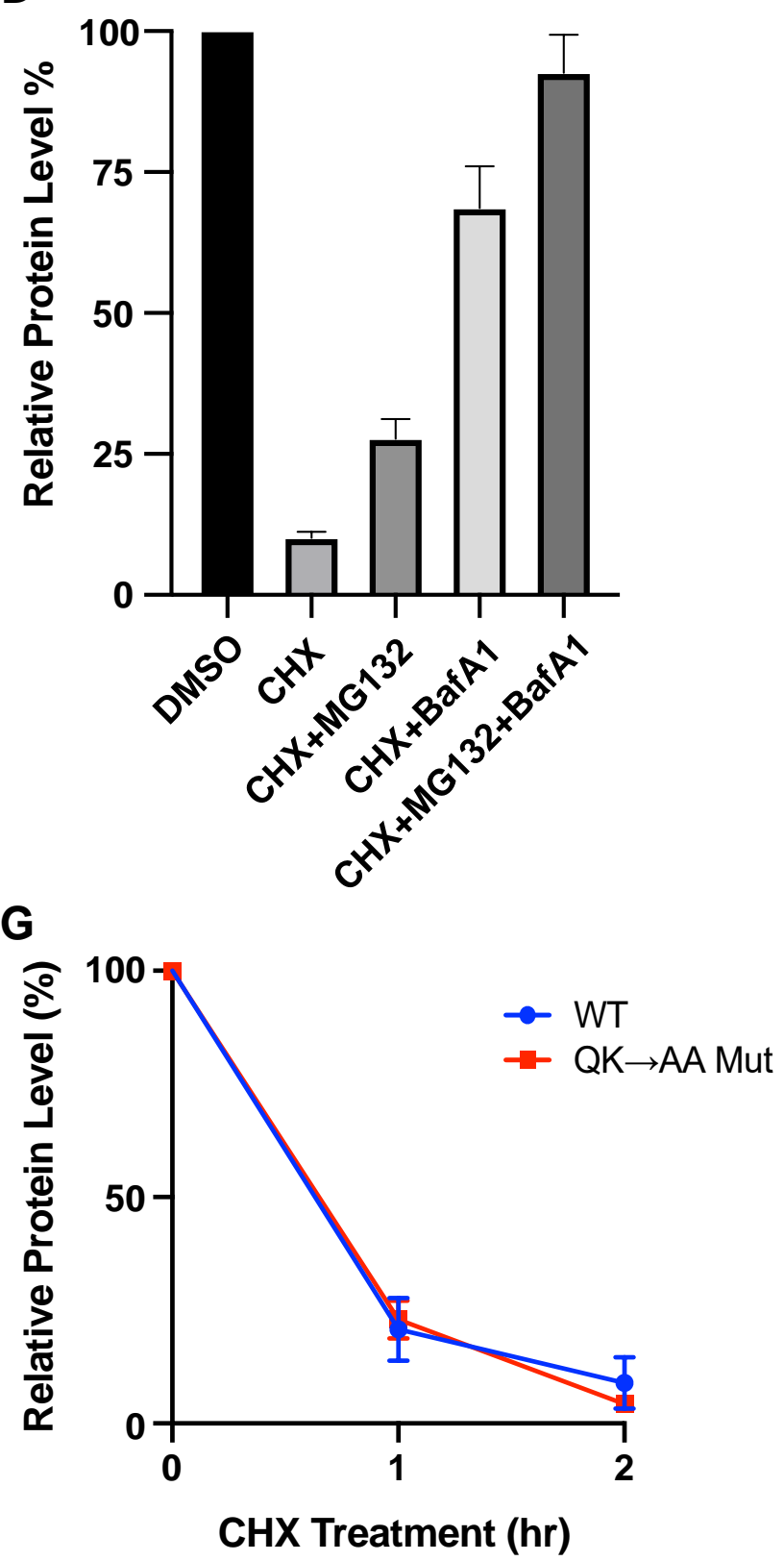
bioRxiv preprint doi: https://doi.org/10.1101/2020.11.18.389296; this version posted November 20, 2020. The copyright holder for this preprint

A (which was not certified by peer review) is the author/funder, who has granted bioRxiv a license to display the preprint in perpetuity. It is mate $\mathbf{g}$ ure 6

CHX (hr) $\begin{array}{lllllllll} & 0 & 1 & 2 & 0 & 1 & 2 & \mathrm{kDa}\end{array}$
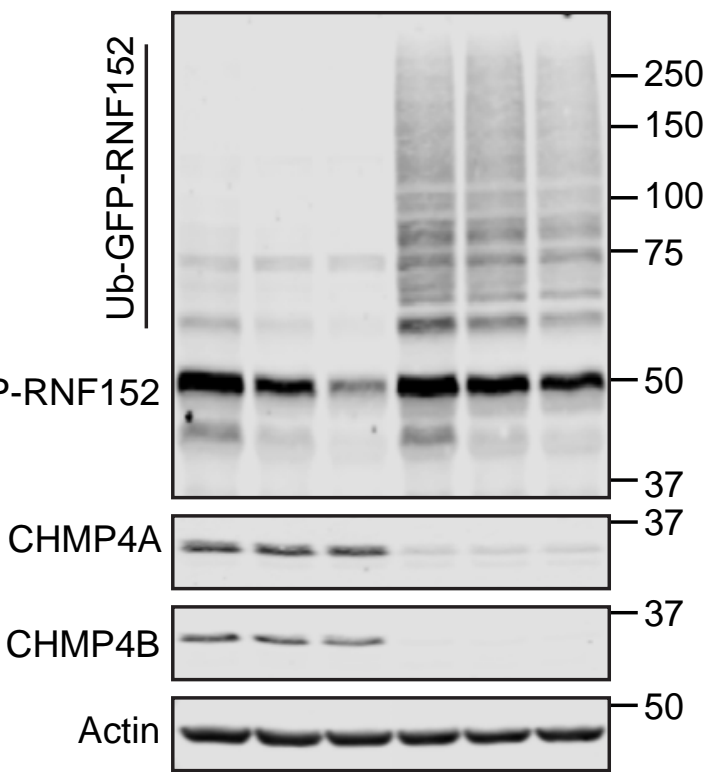

B
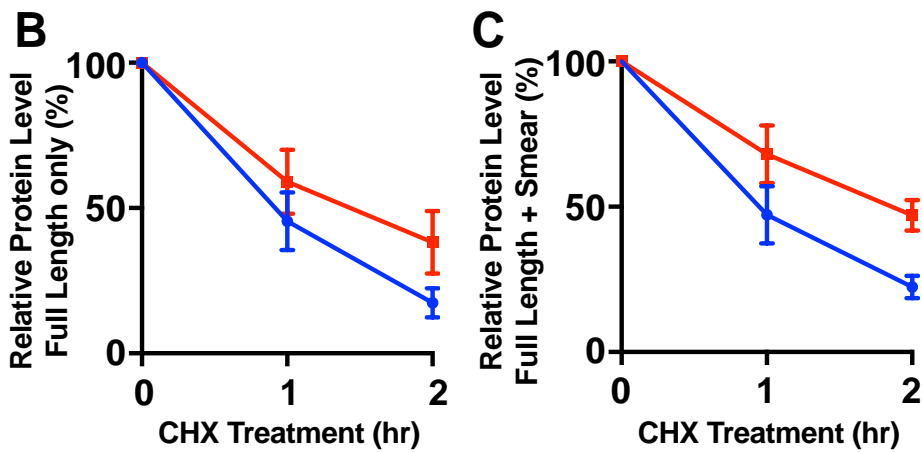

- si Control $\rightarrow$ si CHMP4A+4B

$\rightarrow$ si Control $\rightarrow$ si CHMP4A+4B

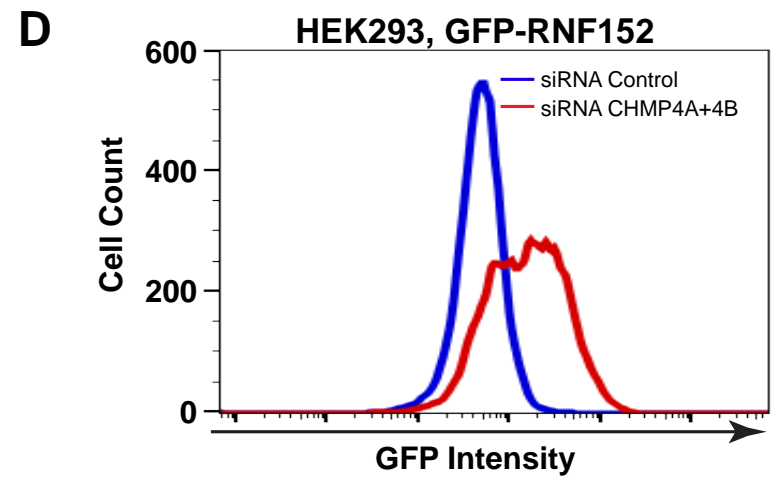

E

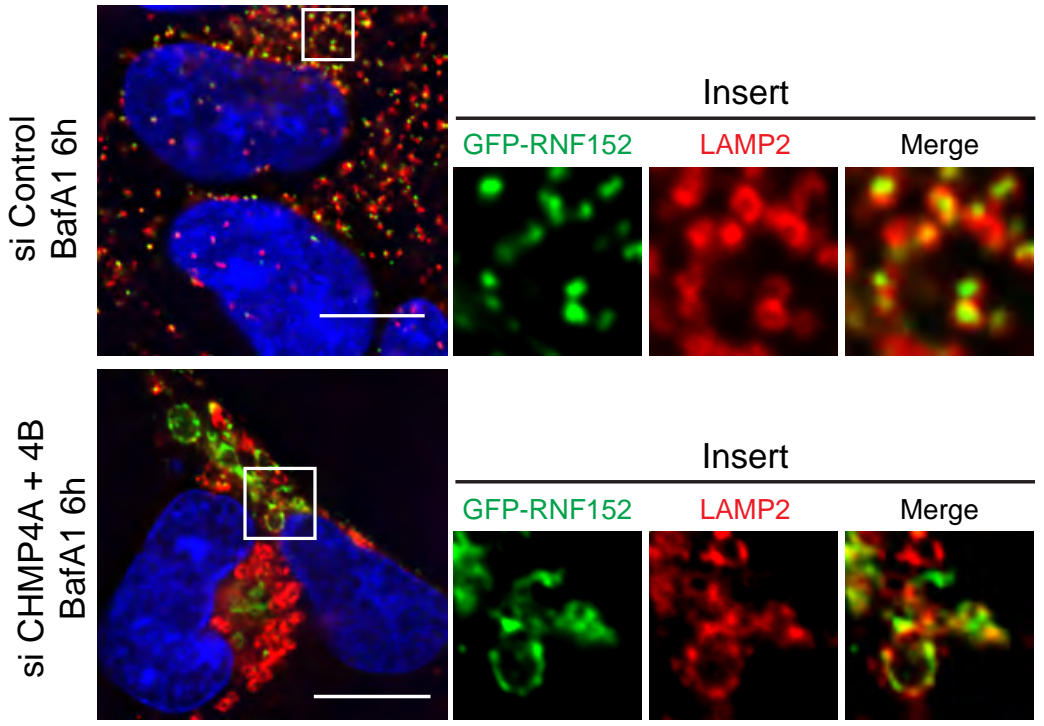

Dox

$\begin{array}{lllllllllll}\mathbf{C H X}(\mathrm{hr}) & 0 & 1 & 2 & 0 & 1 & 2 & 0 & 1 & 2 & \mathrm{kDa}\end{array}$

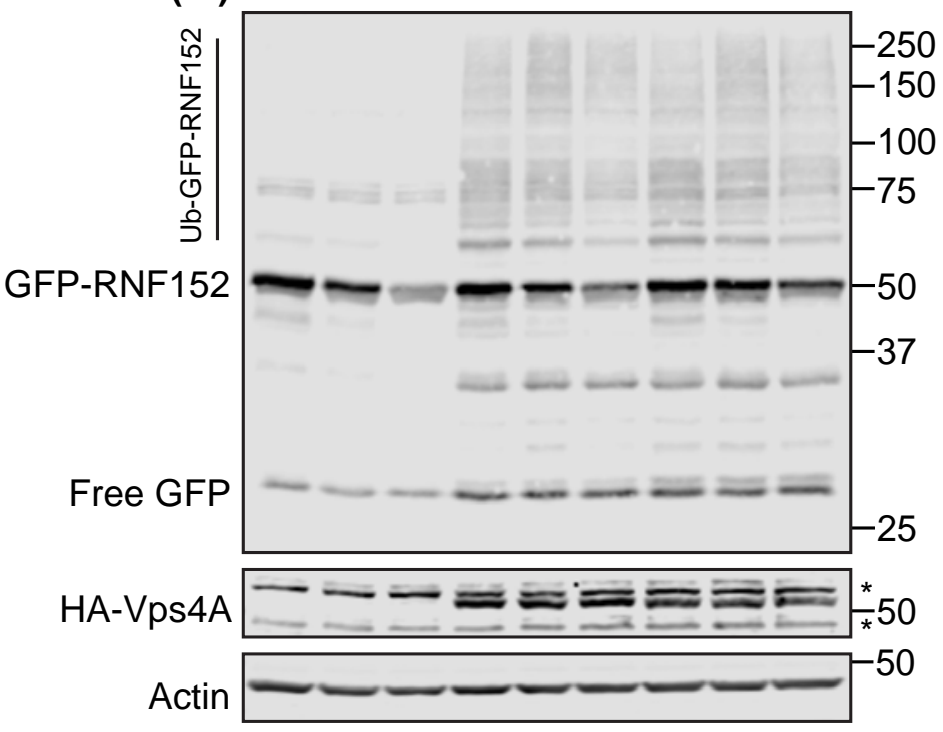

$\mathrm{H}$

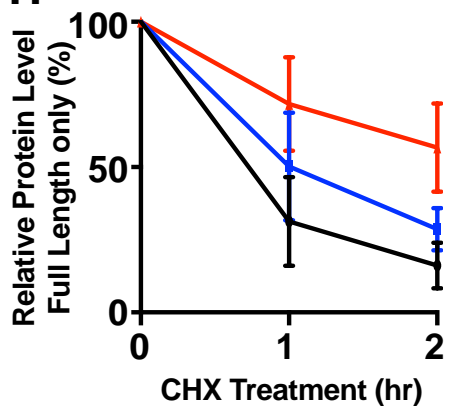

No induction $\rightarrow$ VPS4A WT $\rightarrow$ VPS4AEQ

J

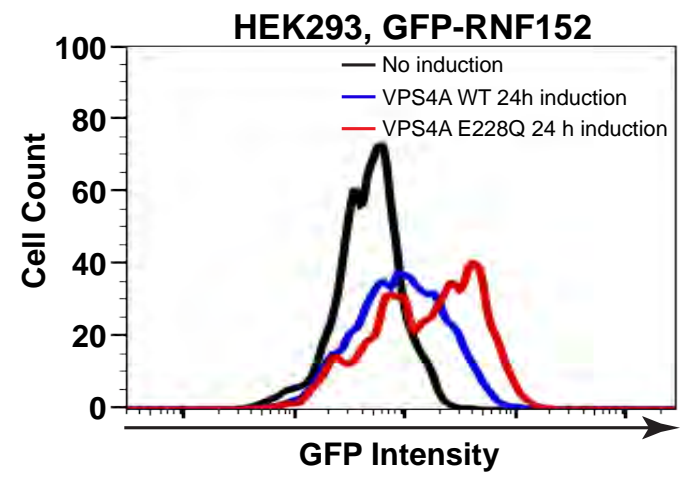

$\mathbf{F}$

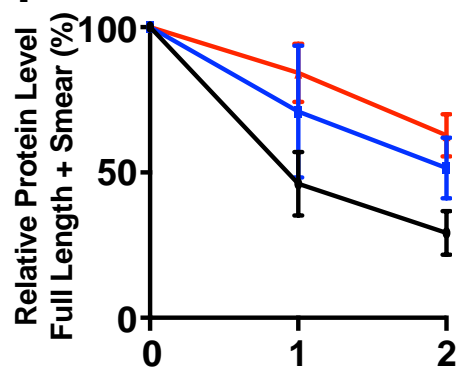

CHX Treatment (hr)

$\rightarrow$ No induction $\rightarrow$ VPS4A WT $\leftarrow$ VPS4AEQ

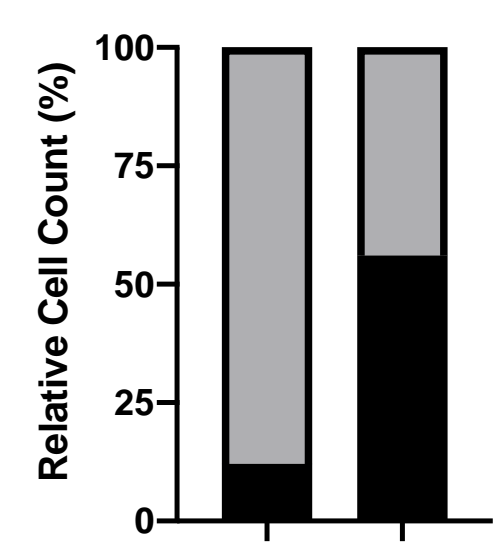

siRNA: Control CHMP4A+4B

$\square$ Cells contain only puncta GFP signals Cells contain membrane GFP signals 
bioRxiv preprint doi: https://doi.org/10.1101/2020.11.18.389296; this version posted November 20, 2020. The copyright holder for this preprint

(which was not certified by peer review) is the author/funder, who has granted bioRxiv a license to display the preprint in perpetuity. It is made available under aCC-BY-NC-ND 4.0 International license.

Figure 7

A

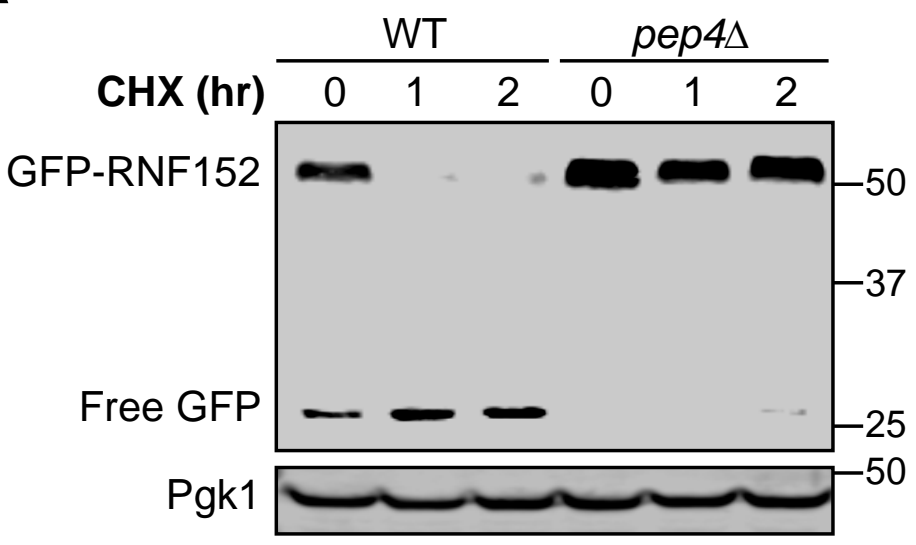

B

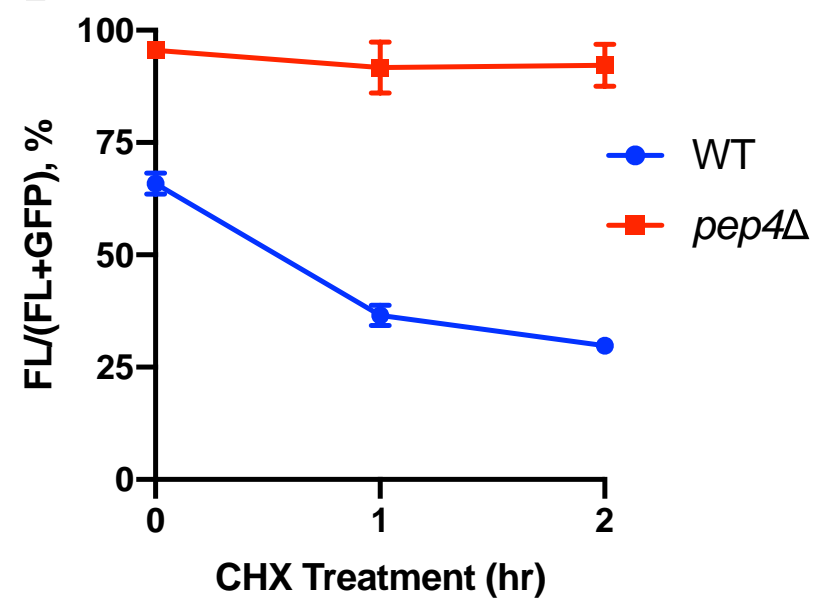

C

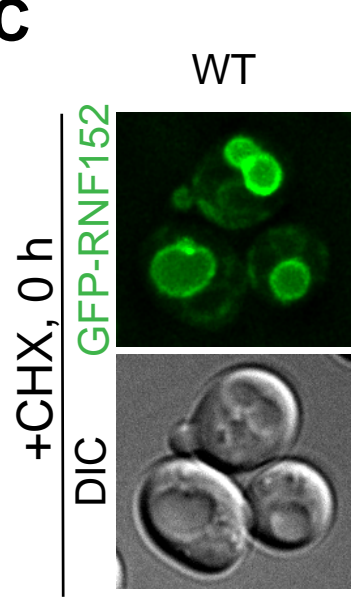

vps27 (ESCRT-0) vps230
$($ ESCRT-I) vps22A
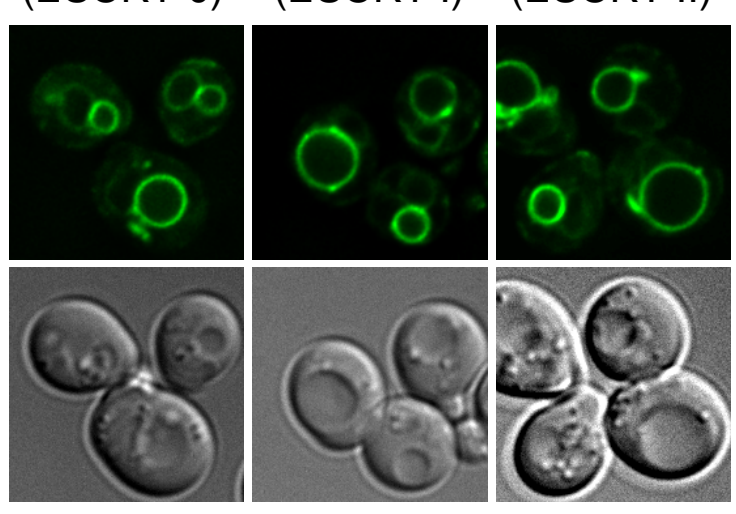

snf7

vps $4 \Delta$
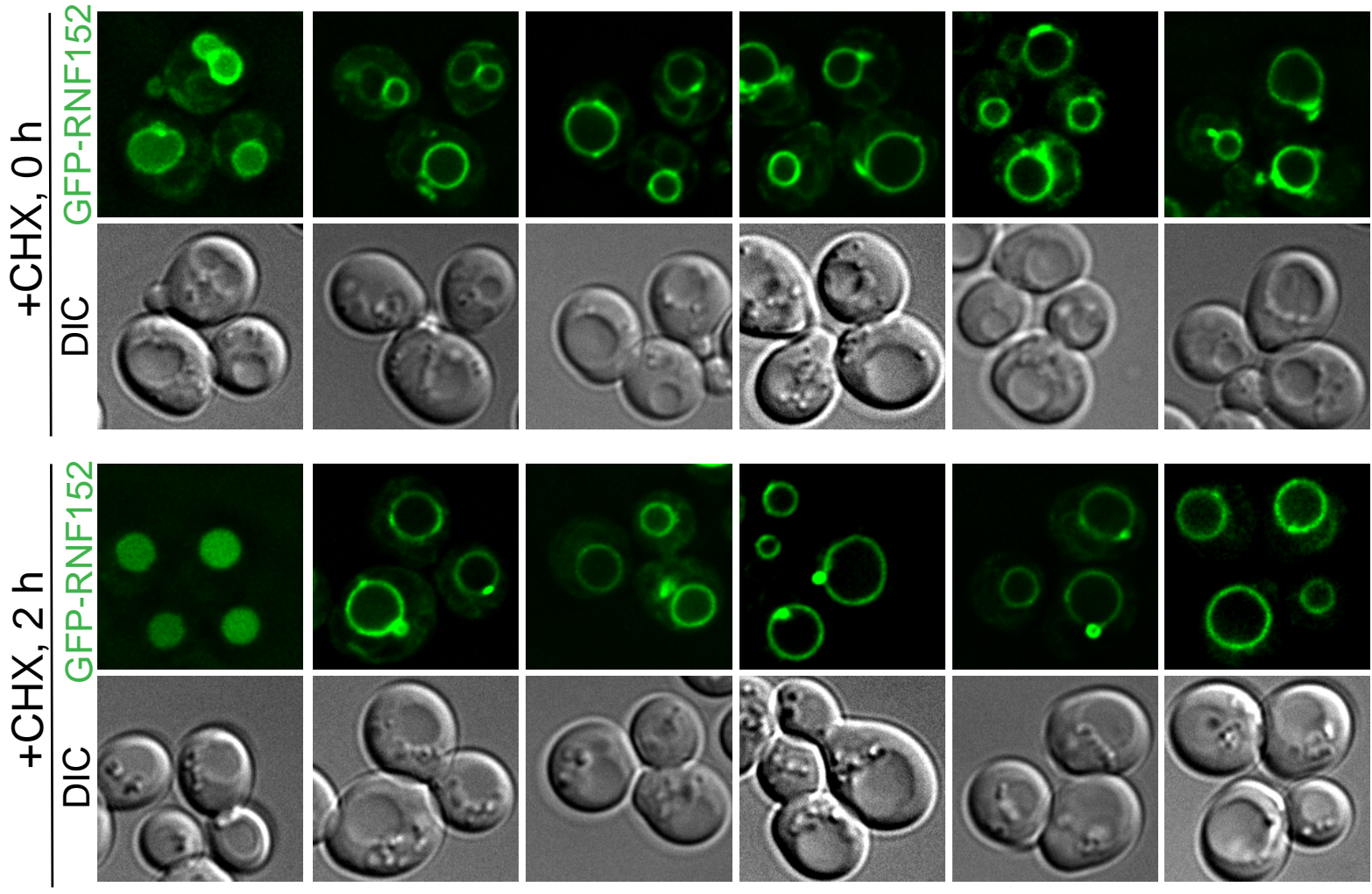

e) bro1 $\Delta$

D
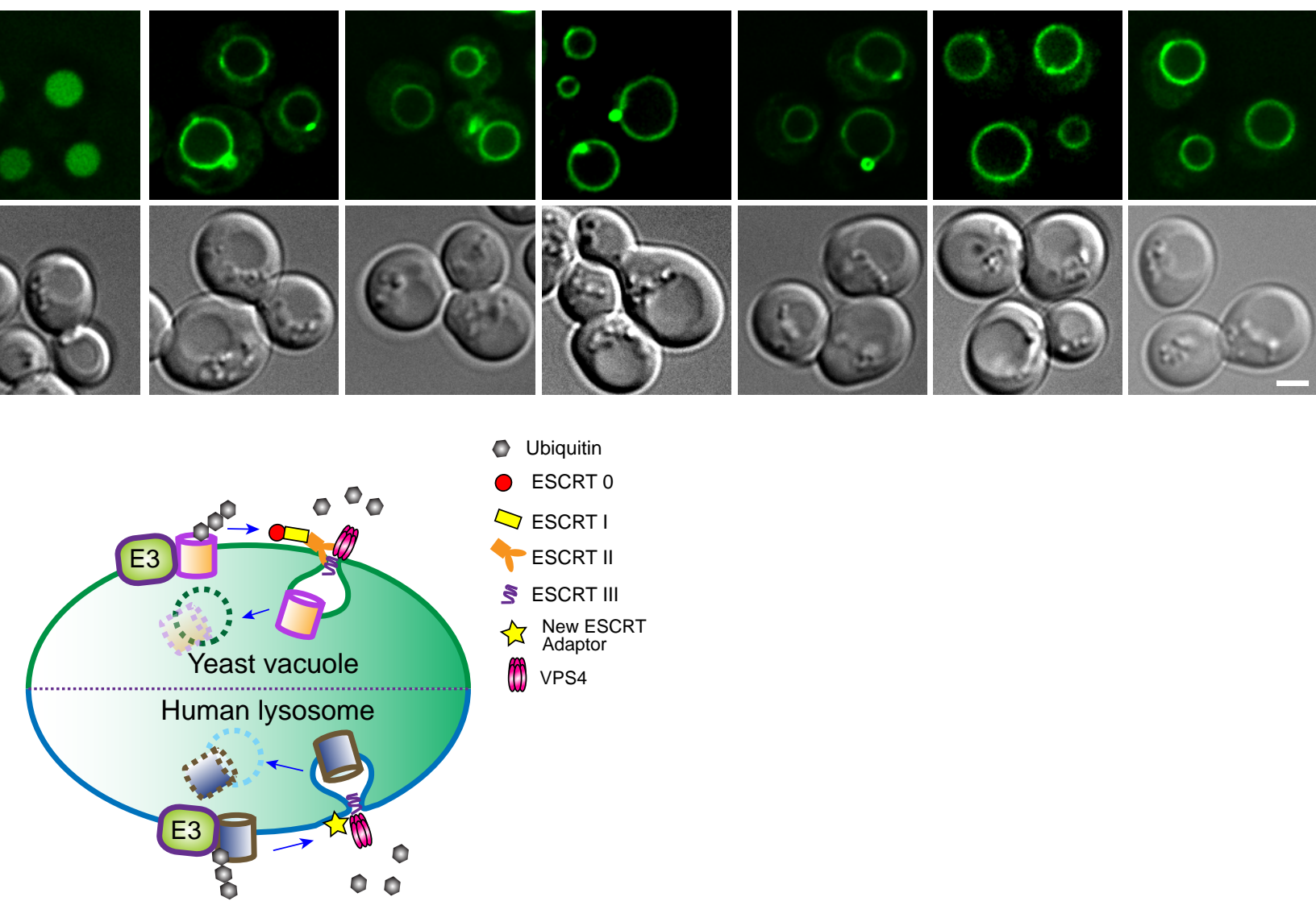

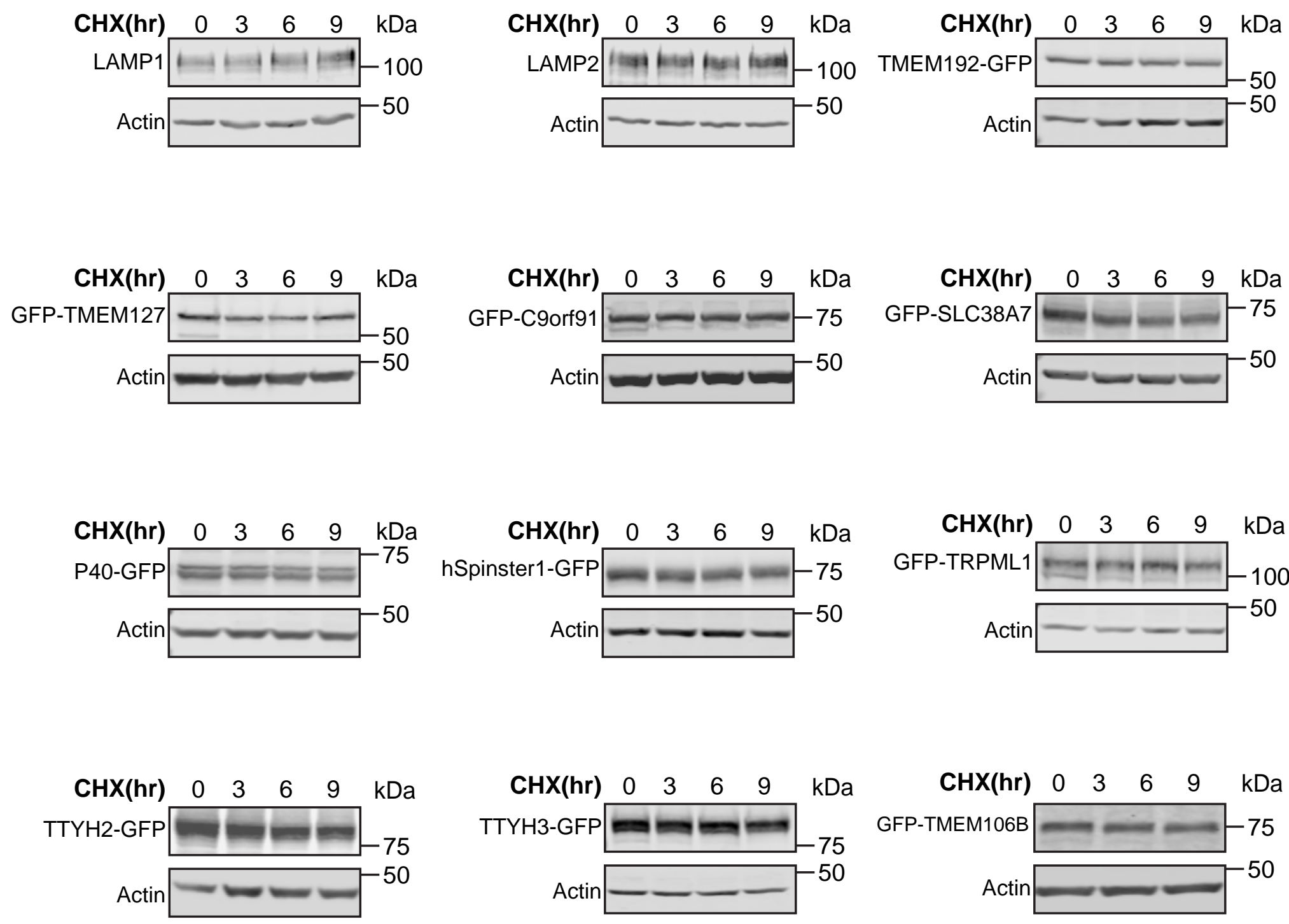
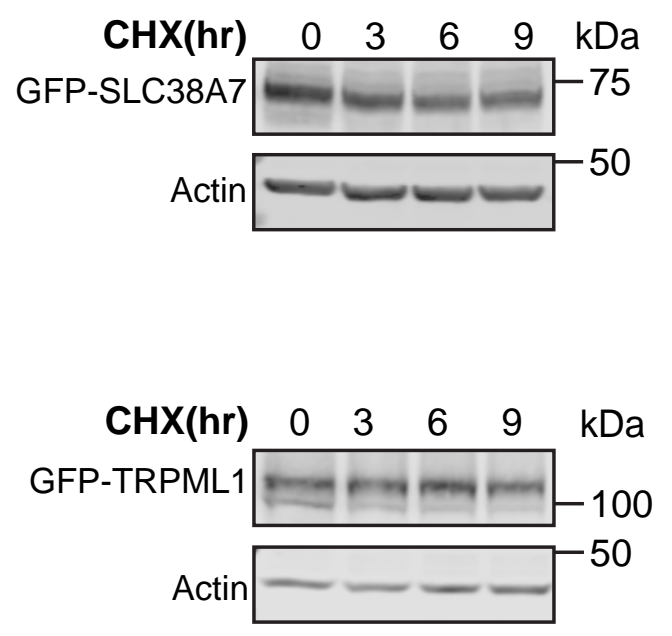

CHX(hr) $\quad 0 \quad 3 \quad 6 \quad 9 \quad \mathrm{kDa}$ GFP-TMEM106B $=-\cdots$

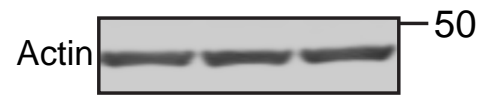

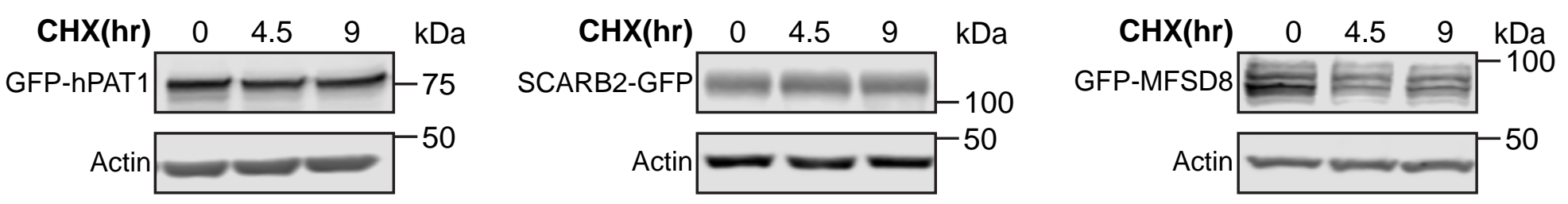

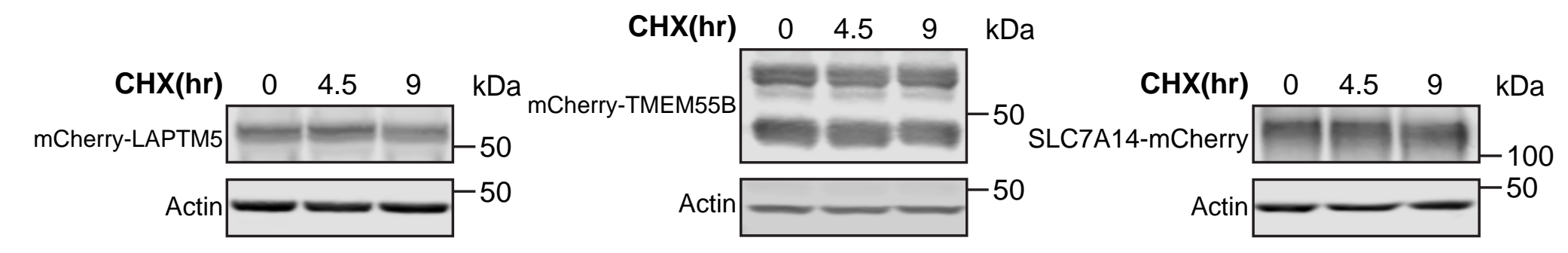


bioRxiv preprint doi: https://doi.org/10.1101/2020.11.18.389296; this version posted November 20,2020 . The copyright holder for this preprint (which was not certified by peer review) is the author/funder, who has granted bioRxiv a license to display the preprint in perpetuity. It is made available under aCC-BY-NC-ND 4.0 International license.
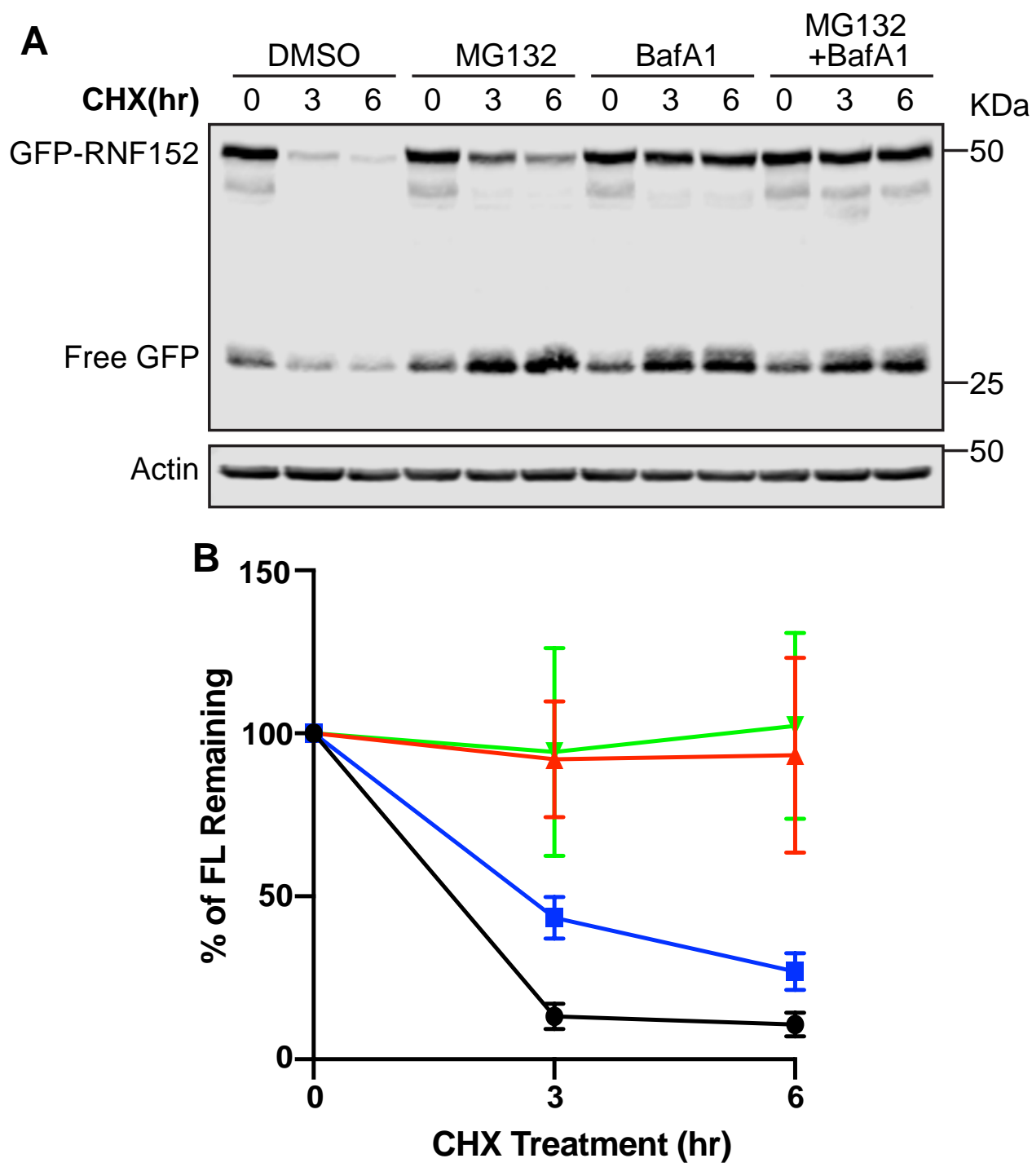

$\rightarrow \mathrm{CHX}+\mathrm{DMSO} \rightarrow \mathrm{CHX}+\mathrm{MG} 132$

$\rightarrow \mathrm{CHX}+\mathrm{BafA} 1 \rightarrow \mathrm{CHX}+\mathrm{MG} 132+\mathrm{BafA} 1$

C

HEK293, GFP-RNF152

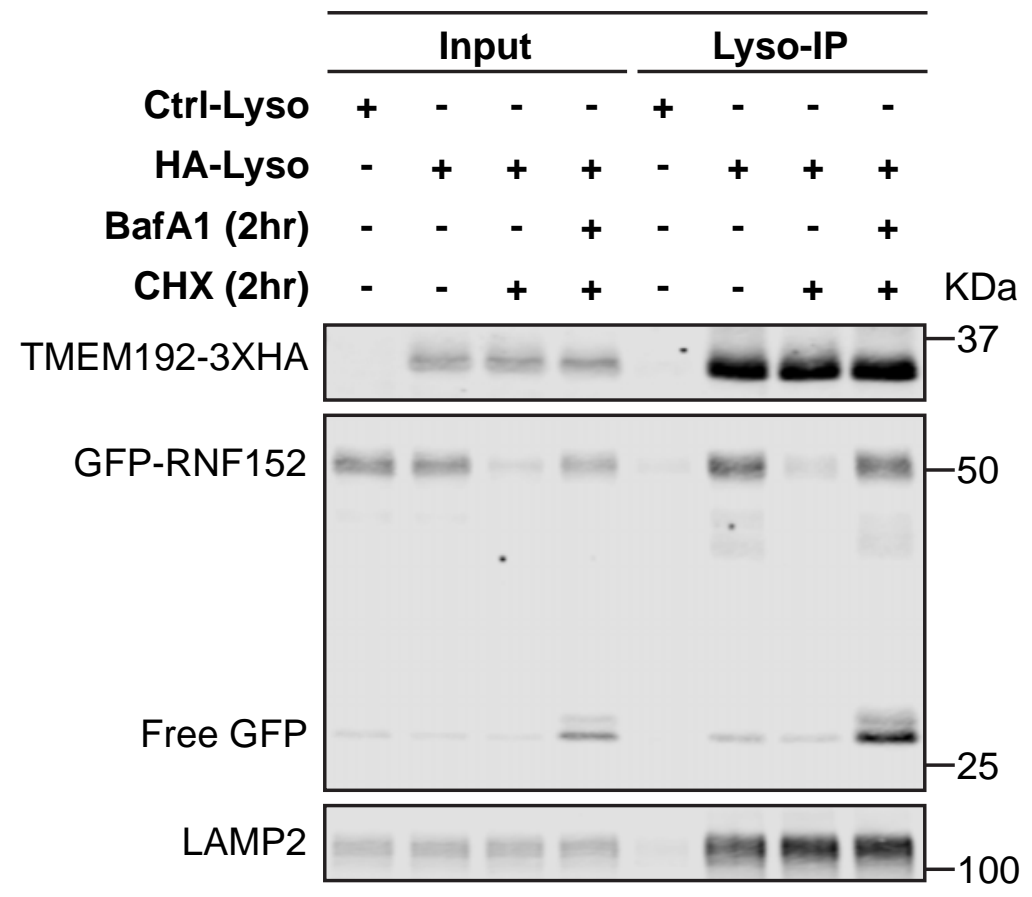


A

ALIX+

siRNA Control TSG101 ALIX TSG101

$\begin{array}{lllllllllllllllll}\mathrm{CHX}(\mathrm{hr}) & 0 & 1 & 2 & 0 & 1 & 2 & 0 & 1 & 2 & 0 & 1 & 2 & \mathrm{KDa}\end{array}$
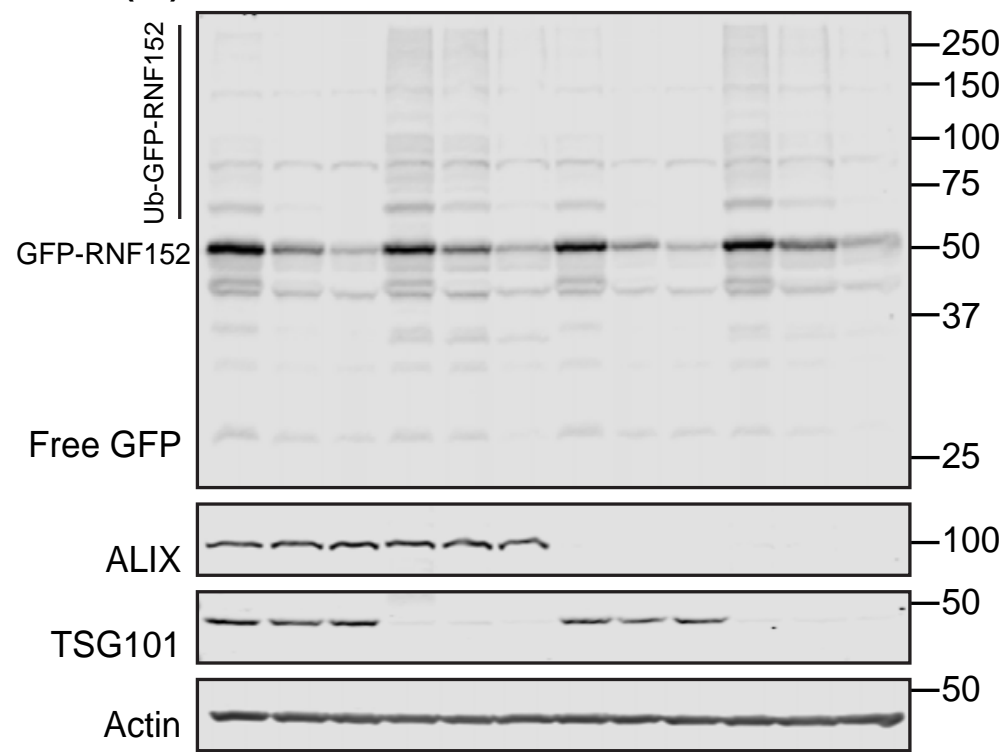

B

C

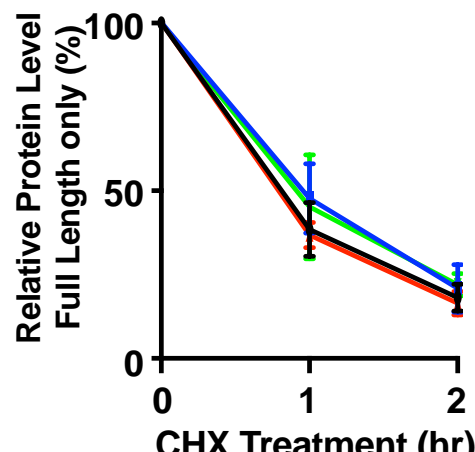

CHX Treatment (hr)

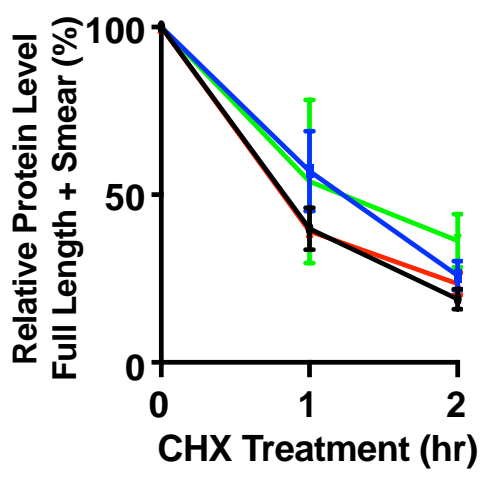

$\rightarrow$ si Control $\rightarrow$ si TSG101

$\multimap$ si Control $\neg$ si TSG101

$\leftarrow$ si ALIX $\rightarrow$ si TSG101+ ALIX

E

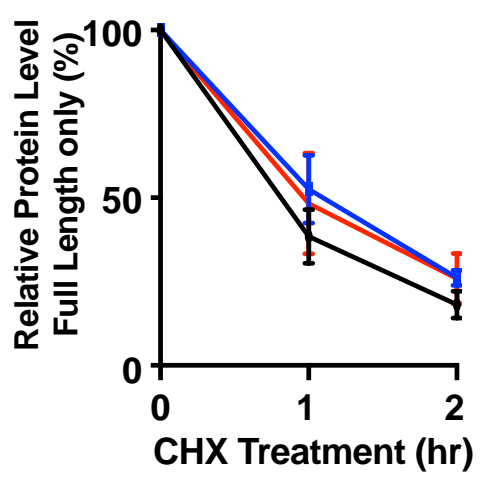

$\multimap$ si Control $\rightarrow$ si HRS

$\leftarrow$ si VPS22

$\mathbf{F}$

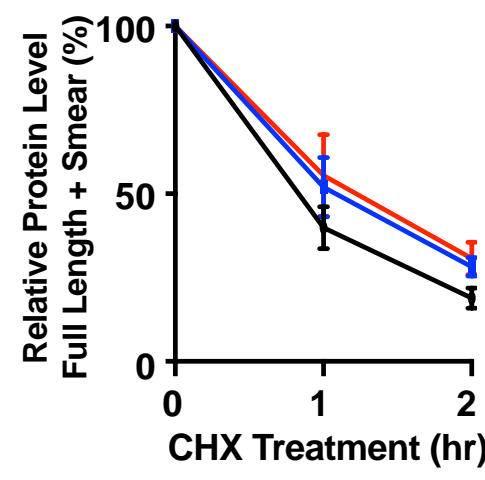

$\rightarrow$ si Control $\rightarrow$ si HRS $\leftarrow$ si VPS22

si Vps22
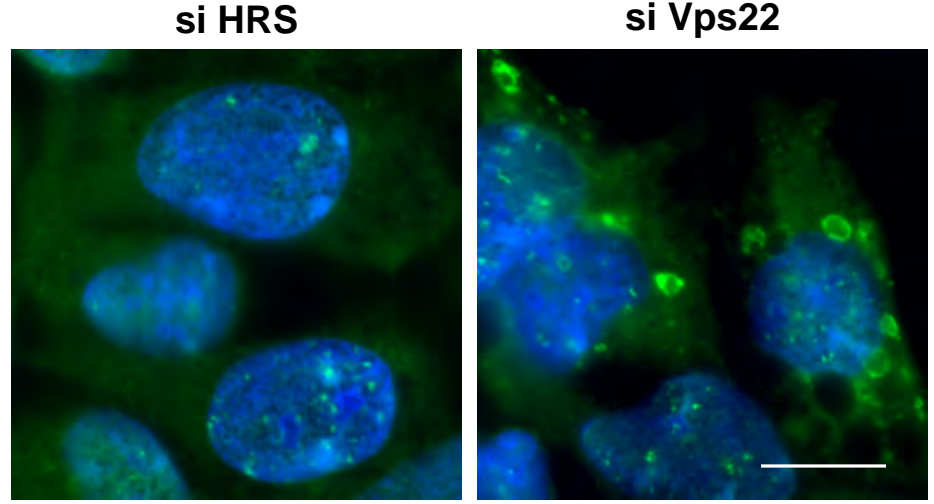
Figure S4

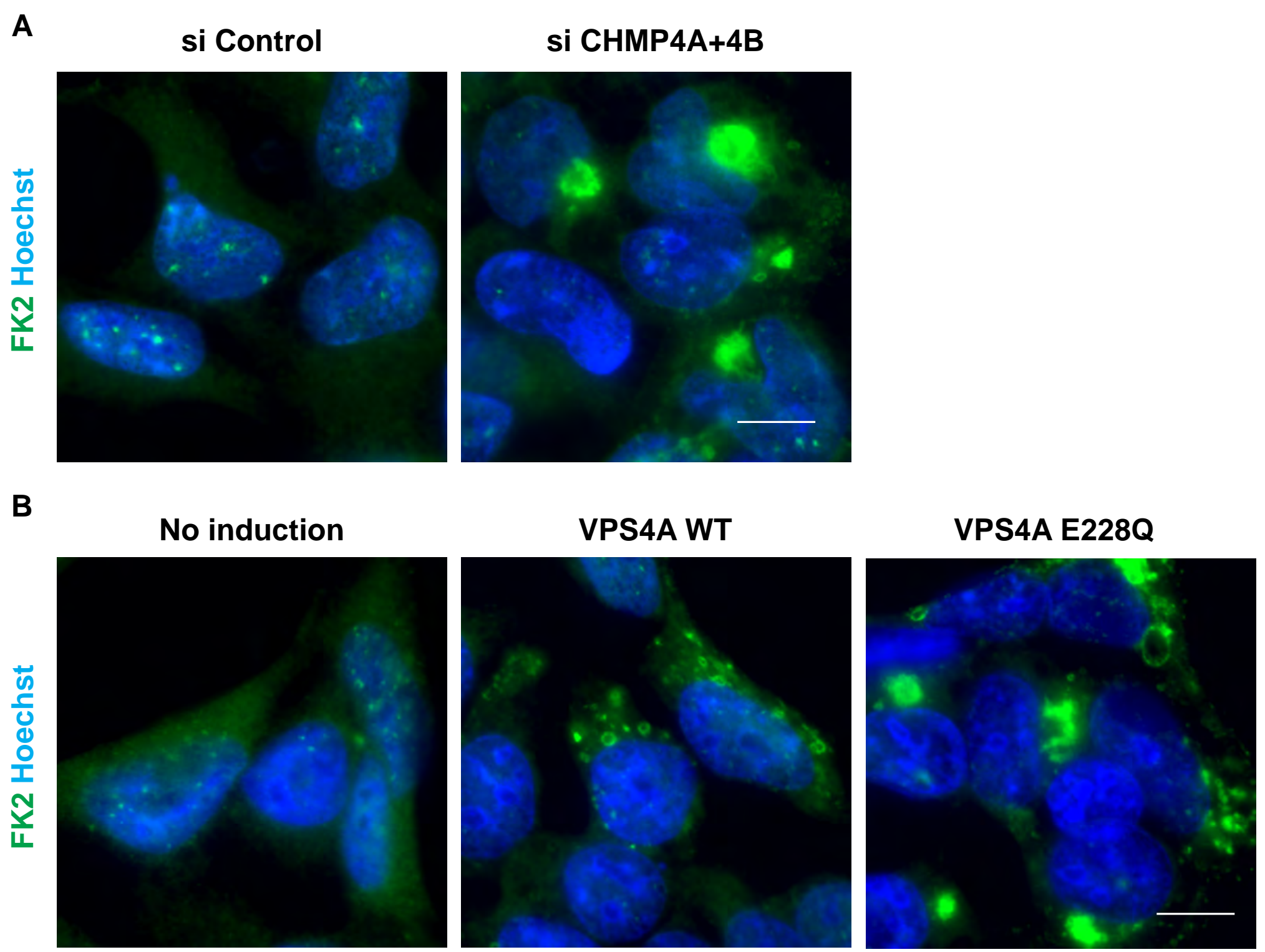

